Portland State University

PDXScholar

Fall 12-3-2019

\title{
Student Voice in a Participatory Design Process Focused on Developing Equity-Based STEM Teaching Practices
}

Frank Heimerdinger

Portland State University

Follow this and additional works at: https://pdxscholar.library.pdx.edu/open_access_etds

Part of the Curriculum and Instruction Commons, and the Educational Leadership Commons Let us know how access to this document benefits you.

\section{Recommended Citation}

Heimerdinger, Frank, "Student Voice in a Participatory Design Process Focused on Developing EquityBased STEM Teaching Practices" (2019). Dissertations and Theses. Paper 5343.

https://doi.org/10.15760/etd.7216

This Dissertation is brought to you for free and open access. It has been accepted for inclusion in Dissertations and Theses by an authorized administrator of PDXScholar. Please contact us if we can make this document more accessible: pdxscholar@pdx.edu. 
Student Voice in a Participatory Design Process Focused on Developing Equity-Based

STEM Teaching Practices

by

Frank Heimerdinger

A dissertation submitted in partial fulfillment of the requirements for the degree of

\author{
Doctor of Education \\ in \\ Educational Leadership: Curriculum and Instruction
}

Dissertation Committee:

Swapna Mukhopadhyay, Chair

Anita Bright

Micki M. Caskey

Gwen Shusterman

Portland State University

Fall 2019 


\begin{abstract}
The purpose of this study with second grades students in a mid-sized city in the Northwest was to examine an equity-based STEM teaching practice and design process that builds on student's voice in the context of an elementary school. Teaching practice innovations were designed using a participatory process drawing on student voice and experience, culturally responsive pedagogy, STEM content, and teaching practices. The students collaborated with the teacher to design and enact equity-based STEM teaching practice innovations and gave necessary and appropriate feedback regarding its efficacy in creating equitable and empowering learning experiences from their own perspective. A specific goal of these equity-based teaching practices was to develop and enact STEM learning experiences that are meaningful and relevant to students' everyday academic, cultural, and social lives. This research also sheds light on the institutional and policy barriers that exist in STEM classrooms and ways that historically marginalized students' voices could be a powerful force in designing STEM curriculum to be more equitable and empowering from the students' perspective.
\end{abstract}




\section{Dedication}

I dedicate this work to my mom and dad, Uli and Grete Heimerdinger. Without their love and support I would have never been able become the person I am know. I dedicate this work to my daughter, Delainey Tanner. Being her dad during my formative years helped me realize that I wanted to teach young children. She continues to be an inspiration as she completes her college degree while working and crocheting cute cat beds for Ollie. I dedicate this work to my sons, Wyatt and Logan Heimerdinger. They have been with me every step of the way. I began this program seven years ago and they are now seven years old. They helped me remember to play during this process. Finally, I dedicate this work to my wife, Sally Brown. She has encouraged me to get it done, and that I have. 


\section{Acknowledgements}

This work would not have been possible without the support of my family, my teacher and student family, and my colleagues at PSU. I know that I have been stretched thin and this meant that I could not fulfill all the responsibilities in a way that I wish I could. Thank you for showing me that I need to be present with the time and energy I do have. Thank you for your commitment to supporting me along this journey and encouraging me to continue. This work was also made possible by the land that has been protected and preserved around my current home and place of teaching. This land has given me and my students wonder, excitement, and powerful experiences that deepen our learning. It has also given me solace and comfort when this journey has seemed too much. This land was first held dear by the people who have been here since time immemorial. Evidence of their presence adorns the rocks and is found in shifting sands. Descendants of these people were the Northern Paiute who protected these lands and loved these lands until they were forcibly removed. Their removal was a violent process that will forever scar these people and their relationship to the land I now call home. Acknowledging this violence and the benefit that it has brought me informs the way I go about my work and troubles me as I think about what is the right thing do. The answer is unclear but each time the land shows its brilliance I am reminded of what has happened and I am called to continue pushing forward towards a more just world. 


\section{Table of Contents}

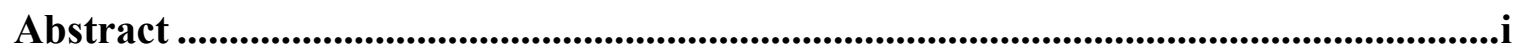

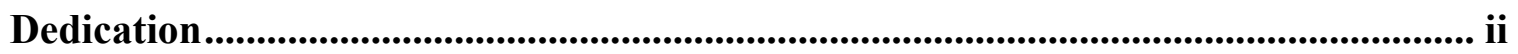

Acknowledgements ...................................................................................................... iii

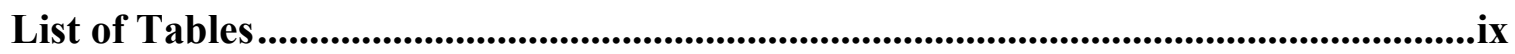

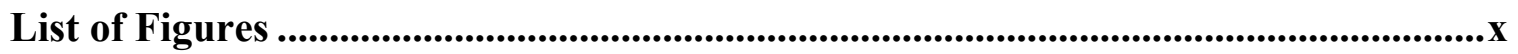

Chapter 1: Problem Statement............................................................................

Background to Problem: Entrenched Views on STEM Learning Reproduce Inequity...4

Research Problem: Increasing access to E-STEM .................................................

E-STEM teaching practices by teachers and students...................................... 11

Social and emotional learning integrated into STEM.................................. 11

Student interest and questions as launching points........................................ 13

Engineering design to solve locally relevant problems................................... 14

Summary of Research Problem ....................................................................... 15

Significance: Students and Teachers Can Create an Equitable Future.........................16

Participatory Action Research and Creating Equitable Learning Environments ..........17

Research questions and the methodology of inquiry ....................................... 17

Definition of Key Concepts ....................................................................... 21

Chapter 2: Literature Review ..............................................................................24

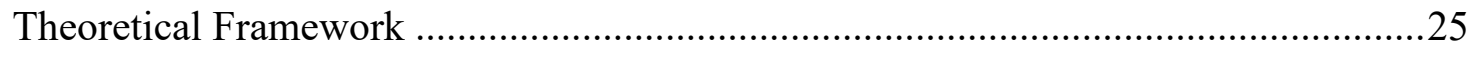




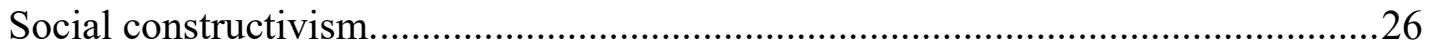

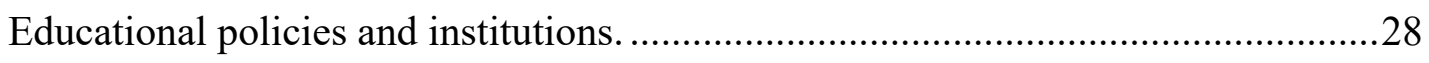

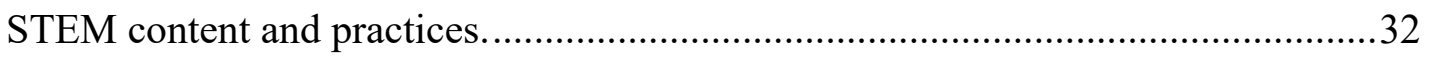

Cognitive demand, depth of knowledge, and student understanding....................33

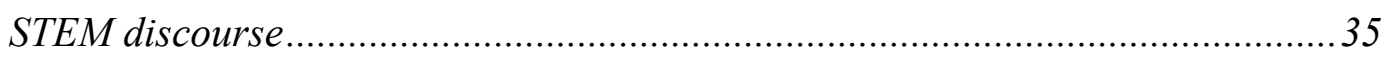

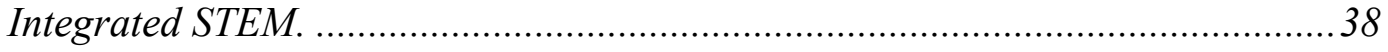

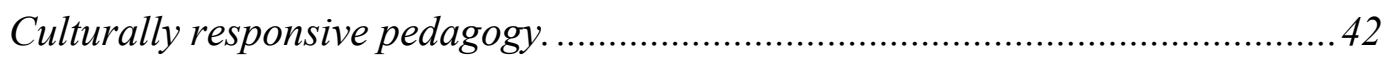

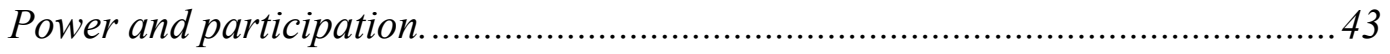



Drawing on multiple resources for knowledge. ...............................................49

Social and emotional learning. ........................................................................51

Critique of literature related to STEM inquiry, SEL in classrooms, and CRP in

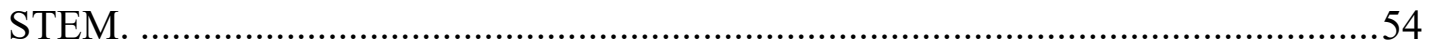

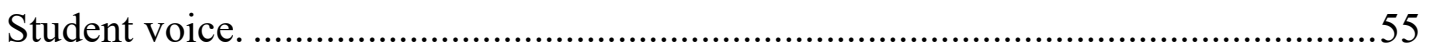

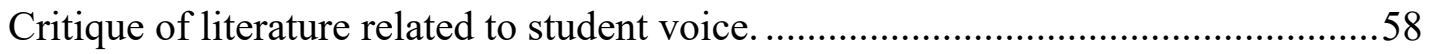

Review of the Methodological Literature.....................................................................59

Collecting data on student perspectives on equity-based teaching practices. ...........62

Collecting data on the role that student voice can play in a design process..............63

Summary

Chapter 3: Methods......................................................................................................................66

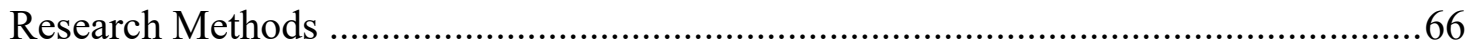

Paradigms guiding the project. ........................................................................66 


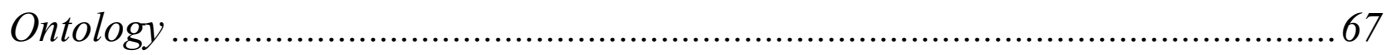

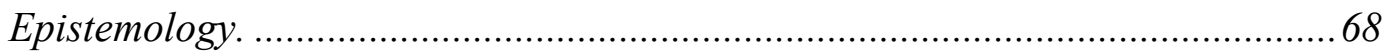



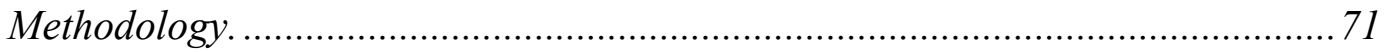

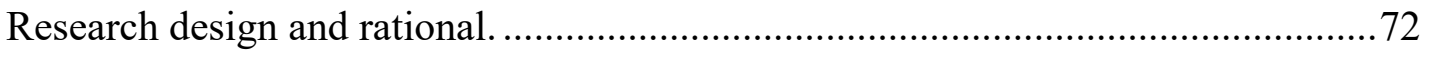

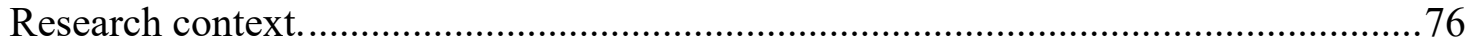

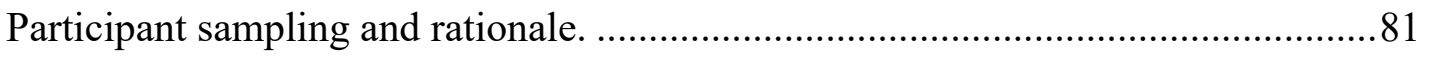

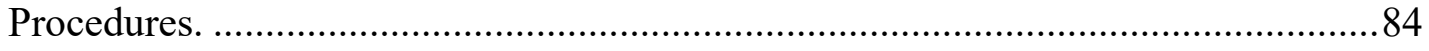

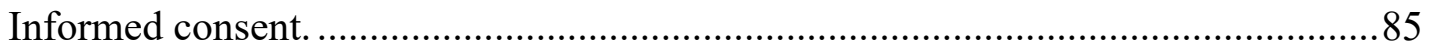

Procedures used to collect data and design interventions..................................86

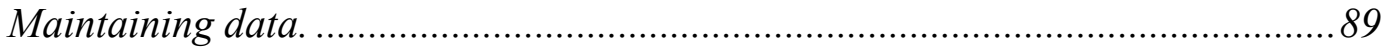

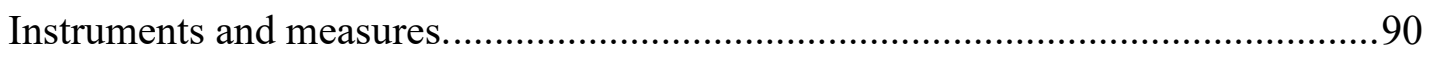



Teacher reflection/researcher analysis. I used .............................................93

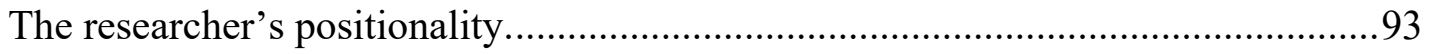

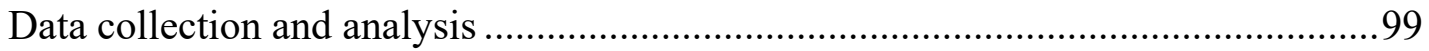

Figure 3.2 This figure shows the NGSS knowledge creation processes with practices in three categories including investigating, sensemaking, and critiquing practices........101

Countering Current Educational and Research Trends ...........................................102

Chapter 4: Data Analysis ........................................................................................104

STEM Learning Experiences in a Second Grade Class during the Research Project.105 
Social-Emotional Learning. .108

Developing relationships before the project begins.

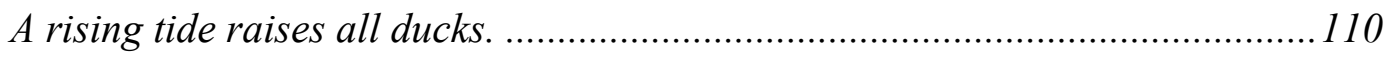

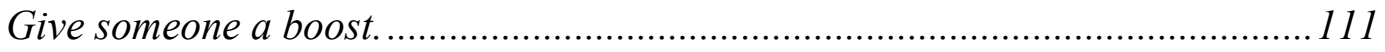

Sometimes group work seems impossible ............................................... 113

Reflecting on past experiences with collaboration........................................ 114

Sometimes a few of us need the help of everyone..........................................116

Stop the discord before it spreads...................................................... 123

Social and emotional learning on par with academic learning.............................126

Students' Interests and Questions Leading Instruction .......................................127

Exploring our backyard through the lens of NGSS .........................................129

NGSS performance expectations and local landforms provide a framework. ....130

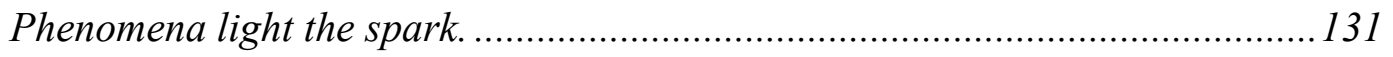

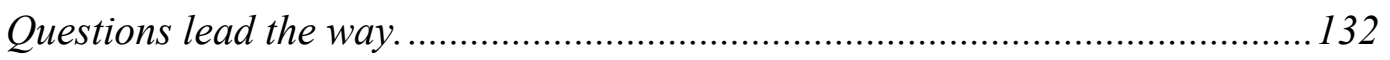

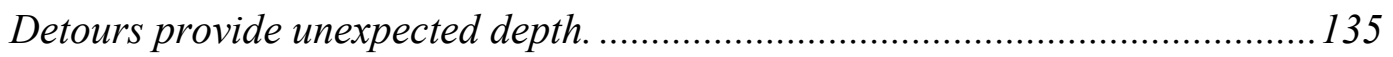

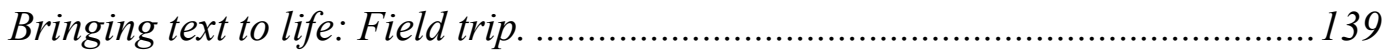

Moody Park: Service learning and exploration. ....................................... 143

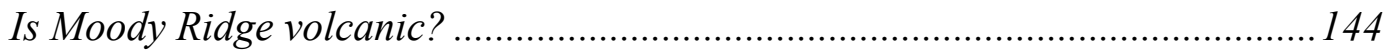

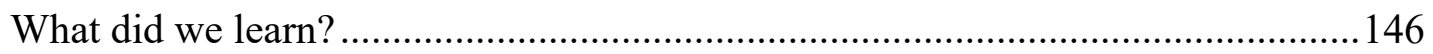

Engineering Design to Solve Relevant Problems ...................................................149

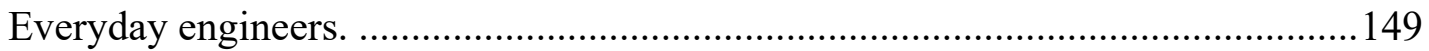

Curriculum from scratch: Designing snack containers. .....................................151

vii 
Adapting existing curriculum: hand pollinators.

Explanation of Discoveries

Co-enacting equity-based STEM teaching practices.

STEM teaching practices influence on student and teacher engagement.

165

Chapter 5: Discussions

Putting the Toothpaste Back in the Tube: Re-professionalize Teaching. .173

Beyond Red, Yellow and Green: Knowing Students 180

Curricular Structures across Content: Decentralizing Curriculum .183

Professional Development .186

Future Directions

References .194

Appendix A-Informed Consent Form for Parents .217

Appendix B-Child Assent Form.. .218

Appendix C-Lesson Plan and Notes Form 219 Appendix D-Data Analysis Form . .220 


\section{List of Tables}

Table 2.1 Research Questions and Data...................................61

Table 3.1 Research Designs and Paradigms..................................73

Table 3.2 Instruments Selected and Constructs Measured......................91

Table 3.3 Summary of Research Questions, Instruments, and Data Analysis.....100

Table 4.1 STEM Learning Experiences and NGSS Focus...................... 107

Table 4.2 Students' Questions Sorted into Categories for Instruction..............134

Table 4.3 OWL Chart for Three Different Types of Rock.....................137

Table 4.4 Teaching Practices: Structure and Flexibility......................... 164

Table 5.1 Resources to Re-professionalize Practice and Provide E-STEM Learning

Experiences...................................................... 175

Table 5.2 Knowledge of Students: Cornerstone to Creating E-STEM Learning

Experiences........................................................... 182 


\section{List of Figures}

Figure 3.1 Continuous Action Research Cycle...............................99

Figure 3.2 NGSS Knowledge Creation Process.......................... 101

Figure 4.1 Tumulus.............................................. 132

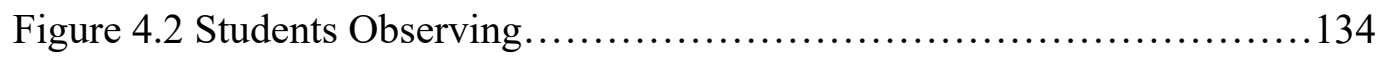

Figure 4.3 Lava Flow and Cinder Cone...................................... 141

Figure 4.4 Examples of Individual Designs.............................. 155 


\section{Chapter 1: Problem Statement}

Early childhood is a unique and precious time of life. Ask any early childhood teacher or parent and they tell you stories of curiosity, playful investigations, and a seemingly insatiable well of questions. Research has indicated that these early childhood dispositions are critical in the development of later cognitive abilities and subsequent achievement in school (Gopnik, Meltzoff, \& Kuhl, 1999; White, 2012.) Early child learning environments around the United States are reimagining themselves as newly released K-12 Framework for Science Education (National Research Council, 2012) and subsequent Next Generation Science Standards (NGSS) (NGSS Lead States, 2013) are shifting a focus towards creating STEM (Science, Technology, Engineering and Math) learning environments that extend children's innate capacity to build, explore, and create. However, this shift is not happening equally for all students. As is so often the case, children from privileged backgrounds are experiencing radically different types of educational environments than children from underrepresented backgrounds. In many cases, privileged families across the United States have greater access to informal STEM learning environments at science centers and museums, but also access to higher quality schools that have the necessary resources to create maker spaces, fund teacher professional developments, and provide teachers access to high quality partnerships. On the other hand, students from underrepresented background living in rural or urban areas may have less access to informal STEM learning environments (Hartman, HinesBergmeier, \& Klein, 2017; Penuel, Lee, \& Bevan, 2014; White, 2012). Furthermore, their pre-K and elementary schools are more apt to focus on basic skills that will prepare students for tested subjects of reading and math (Kempf, 2016; Kohn, 2000; McNeil, 
2002). As Alberto Rodriguez (2015) pointed out in his critique of current STEM education policy, implementing policies that ensure STEM education is accessible to all, have been slow to create change in educational environments frequented by many of our nation's underrepresented students.

The problem of who has access to equitable early childhood STEM learning experiences is more important than ever in an increasingly technological world with complex issues that require critical thinking and problem-solving skills. One perspective sees STEM as an avenue towards staying globally competitive with a diverse STEMcapable workforce that has $21^{\text {st }}$ century skills of problem solving, collaboration and critical thinking. In contrast, a humanistic perspective sees STEM education as providing students opportunities to reconnect with each other and the natural world, while also developing a critical lens for understanding patterns and systems that help us make sense of the world, and ultimately, become empowered to change the world through civic participation (Aguirre, Mayfield-Ingram, \& Martin, 2013; National Research Council, 2011; Tan, Barton, Turner, \& Gutiérrez, 2012). These arguments are examples that come from fundamentally different sets of assumptions and the question remains, who decides the purpose and goals of STEM education for our students, especially as it related to students that have been historically marginalized?

In the current political and educational climate, world competitiveness and economic prosperity have been given privilege over more humanistic interpretations of STEM education (Hursh, 2007). Though world competitiveness and economic prosperity may be a priority for some students and parents, it may not be a priority for all. It may even seem silly to think of a primary teacher cajoling a student into a learning activity so 
that our nation can be economically competitive in the near future, but that is exactly what is happening when teachers push children towards experiences that are beyond their developmental readiness in an effort to "get them up to benchmark" (Camarata, 2017). On the other hand, there is a growing body of literature that documents students' positive learning experiences when schools adopt pedagogy that emerge from the social and cultural lives of students and their families (Gutstein, 2006; Hand, 2003; HudicourtBarnes, 2003; Seiler, 2001; Seiler \& Elmesky, 2007). It can be interpreted that such an emphasis on relevance is included in Vasquez, Snieder, and Comer's (2013) characterization of STEM education: "an interdisciplinary approach to learning that removes barriers separating the four disciplines of science, technology, engineering, and mathematics and integrates them into real world, rigorous, and relevant learning experiences for students" (p. 4). Such a view of STEM education can hold great promise if educators can comprehend and problematize whose world-view is given the privilege. Currently, districts ask STEM curricular materials that many teachers to use are based on the worldview of the curriculum developer who may or may not have an understanding of the broad diversity in today's schools. I argue that the only way to know what is relevant for young students is to listen to the students and their teachers. Listening to students, their families, and their teachers and including these voices in decision making is an important process that needs to become integral in designing STEM learning experiences that students find equitable and empowering. 


\section{Background to Problem: Entrenched Views on STEM Learning Reproduce Inequity}

Following is a description of the background of the problem regarding who has access to equitable STEM (E-STEM) learning experiences across our country. Then, I describe how these same patterns of access are present in the context of the research study. The context of this research study includes West Elementary STEM school, and more specifically, myself and the $2^{\text {nd }}$ grade students I worked with during the 2016-017 school year.

The disparity in access to E-STEM opportunities is a problem facing urban and rural elementary school classrooms across the nation. Looking at National Assessment of Educational Progress (NAEP) data on science achievement one can draw some conclusions about who has access to E-STEM learning opportunities. One telling statistic is the continuing drop of instructional time dedicated to science in elementary schools. Since the introduction of No Child Left Behind (NCLB) $4^{\text {th }}$ graders receive the lowest amount of time on science instruction since 1988 - 2.3 hours per week (Blank, 2013). Not surprisingly, Blank (2013) indicated that students with lower time dedicated to science instruction perform at lower levels than those who receive more science instruction. Standardized testing and NCLB have many times had a disproportionate effect on schools with students deemed lagging "behind" (Kempf, 2016; Kohn 2000; McNeil, 2002). Therefore, it may be reasonable to conjecture that many students from schools lacking high passage rates on state mandated standardized tests, are experiencing even less science than the 2.3 hours per week. Additionally, this problem may be even more exacerbated in early childhood settings where teachers are under pressure to get 
students reading at grade level before $3^{\text {rd }}$ grade. However, the lack of science instruction for young students is not the whole story. When comparing NAEP scores for students eligible for free and reduced-price lunch with those that are not there is a 30-point gap. Even when students receiving free and reduced lunch benefit from additional time on science instruction, they still perform below privileged students that receive less time (Blank, 2013). This stubborn gap in science achievement may indicate that access to science instruction is not sufficient in creating equitable outcomes. Rather, children need access to equitable science instruction to make progress in eliminating achievement and participation gaps (Lee \& Buxton, 2010; Rodriguez, 2015).

Multicultural science education research has been examining the role that culture plays in creating E-STEM learning environments. One framework for understanding culture is that people "live culturally" (Gutiérrez \& Rogoff, 2003). Meaning that rather than looking at static traits belonging to people of a certain ethnic group we ought to think of culture as fluid set of practices that individuals participate in based on context. Such a framework may help us see students as they are, not as we think they might be, given our cultural assumptions. Such a nuanced view of culture is important when thinking about students that might on the surface seem to lack diversity in the conventional sense. Rather, seeing each student's unique learning needs and their social and cultural history is critical when designing E-STEM learning experiences. It is also important to think about broad societal trends and how educational policy and historical assumptions have played out in the education experiences of many our nations' children. Too many students in schools across America participate in traditional and transmissive science pedagogy that reinforces dominant stereotypes about who is good at Western 
Science (Rodriguez, 2015). These stereotypes have been shown to have a negative effect on students' desire to identify with science as a discipline because of the exclusionary nature of science education that intersects with their race, class, gender, and ability (Archer, Dewitt, \& Osborne, 2015). Even some young students in reform-centered classrooms that are designed to be more equitable, may see little to connect with as they try to attend to students engaging in scientific discourse or work together on projects that are disconnected from their lived experience. At issue is that educational policies and practices have created classrooms where teachers are generally ill equipped to develop nuanced strategies for engaging a broad array of students in STEM learning activities. There is too little pre-service and in-service teacher learning, too little flexibility in the use of curriculum, and too little time to listen to students and build on their interests and strengths. Rather teachers could be fully equipped to understand the myriad of ways that diverse people, practices, languages, epistemologies, goals, and values enrich our STEM learning experiences (Warren, Ballenger, Ogonowski, Rosebery, \& Hudicourt-Barnes, 2001). Postmodern curriculum theory indicates that understanding diverse perspectives is vital to a curriculum that reflects the modern world (Slattery, 2006). From such a perspective, Slattery wrote (2006), "Integral to postmodernism is the critique of reason, totality, universal principles, and metanarratives - grand explanations that seek to explain all the reality from a singular perspective" (p. 40). Currently, STEM learning experiences privilege Western science. However, STEM learning should incorporate dominant and non-dominant perspectives so that curriculum accurately reflects the world in which we live and so that all students can experience the joy of learning that wellcrafted E-STEM learning experiences can bring. If this were the case in classrooms 
across the United States, it would not matter what students scored on the NAEP because they would have already found success in learning environments and seek out more opportunities based on their interests.

West Elementary STEM School (a pseudonym) is located on the outskirts of a rapidly developing and gentrifying small city in the northwestern United States. When the school was built more than 30 years ago, this was in an entirely rural area. As subdivisions continue to grow and apartment buildings are developed, West Elementary boundaries broadened to include a mix of rural and suburban students. Incidentally, the students at West Elementary exhibit a high degree of economic diversity and diversity in learning abilities. We have homeless families as well as families that own their own successful businesses and live on hobby farms. In $2^{\text {nd }}$ grade, we have students who are non-readers all the way to students reading at the $4^{\text {th }}$ and $5^{\text {th }}$ grade level. In addition to such diversity within the classroom, teachers at West Elementary see a disparity between the educational experiences offered to students on the north side of town and what their students receive. The north side of town has higher income homes and includes families that have access to many educational resources. For example, several unique educational experiences that they can choose from include magnet schools, private schools, and afterschool science learning centers. Additionally, schools on the north side of town have higher state test scores. This means that teachers at these schools have more freedom to create learning experiences tailored to the unique needs and interests of their students. Similar to national trends in education, in the context of West Elementary, the students, parents, and teachers all have an interest in providing E-STEM educational experiences for their students that match those provided to students in more privileged zip codes. 
However, this has many times been an uphill struggle—one sustained with limited resources in the many times counterproductive educational climate of NCLB pressures to perform on state-tested subjects.

This research project took place in a $2^{\text {nd }}$ grade classroom within West Elementary STEM School. This was my $12^{\text {th }}$ year teaching but only my second year teaching in a new school district. My initial teacher education program and the first 10 years of teaching prepared me for a student-centered approach to educating children. In both of these experiences, I designed curriculum based on the standards and the need and interests of a diverse student population. My initial years of teaching propelled me into first attaining National Board for Professional Teaching Standards certification, and then, attending a doctoral program. As a developing researcher, I was interested in understanding how to create STEM learning experiences that helped all students engage in learning and develop strong identities as learners. As noted previously, West Elementary served a population with a high degree of economic diversity along with differing learning abilities. Yet, within a classroom of 20-25 students, we were unfortunately providing learning experiences that created unequal access. Some students were actively engaging in STEM learning experiences while others were having difficulty participating fully. Even though we were providing STEM learning experiences to all students, we were not seeing equitable participation by all students. In this research, as a teacher, my goal was to seek a fuller understanding of the problem of equitable participation for young children. I believed that creating more E-STEM classroom environments would help students to engage in learning. A key feature of this research project is acknowledging the asset of care and creativity that young children 
intuitively bring to solving issues of equity. However, listening to students and working with them to solve issues of equity is far from the norm in our educational system. Thus, instead of listening mindfully to the students' queries, we tend to focus on delivering preformulated lessons. For this reason, it is important to investigate how current educational policies and systems conflict with a system that would create inclusive E-STEM learning opportunities for all young children.

As briefly described in the previous section of this chapter, the disparity of young children's access to E-STEM learning opportunities is a pressing problem that is gaining more and more attention (Sarama et al., 2018; White, 2012). However, the broad historical, societal, and cultural influences that are at the root of this problem are deeply entrenched in our society and its institutions (Rodriguez, 2015). For this reason, young children have untarnished notions of justice and unique viewpoints on how to solve these issues of equity; they have not been fully indoctrinated in the cultural assumptions of presumed hierarchies that permeate our society. Working with students at West Elementary STEM School brings with it many challenges. We, like most schools that serve diverse populations, lack important resources such as professional development and investment of time allocated for planning. We are also a school that is under increasing pressure to raise reading scores. The experiences learned from this case study working with young students at West Elementary STEM School can offer valuable insights into the problem of equity in STEM learning from one unique context.

\section{Research Problem: Increasing access to E-STEM}

The problem of who has access to E-STEM learning environments is both a national and local problem. In this section, I state the research problem and briefly 
describe three areas of study that can be further developed in creating E-STEM learning experiences for young children. As described in the previous paragraphs, there is a disparity of who has access to E-STEM learning environments that is deeply entrenched in our society and permeates our education policies and institutions. For this reason, the problem is evident on not only a national or macro-level, but also at micro-level in many of our classrooms. Though educational researchers along with policy makers have been working on solving the problem of equity in our nation's schools the problem has not been fully addressed. One salient chorus of many voices that has been largely unheard in this discussion is that of classroom teachers and their students. Generally speaking, students and teachers are at best treated as objects of research inquiry and at worst treated as the creators, or source, of the problem. Thus, there is an urgent need for perspectives that highlight the voices of students and teachers working together to address issues of equity. Listening to teachers and students can help us understand the problems facing our classrooms and highlighting their collaboration can position both students and teachers as agents of change. In this research project, I sought to address the problem of equity in STEM learning environments for young students through engaging them and their teacher in a process that leads to two outcomes: new knowledge about the nature of teaching practices that can make STEM learning environments more equitable, and creating a more equitable classroom for the very same students and teacher that are engaged in this project. Three aspects of teaching and learning addressed throughout this research project are social and emotional learning integrated into STEM inquiry, students' interest, and student's questions as launching points for E-STEM learning experiences and incorporating engineering design to solve locally relevant problems. I 
briefly introduce each of these areas and build upon this introduction throughout subsequent chapters.

E-STEM teaching practices by teachers and students. Based on this research project, three categories of E-STEM teaching practices that may be especially promising for young children are social and emotional learning, following students' questions and interests, and engineering design to solve locally relevant problems. However, each of these three areas is currently underutilized in classrooms throughout our schools. This is lamentable because these teaching practices are attuned to the unique interests and needs of young children and the concerns and aptitudes that they have. One of the aspects that is discussed comes from the broad field of Social and Emotional Learning (SEL). This field is grounded in the premise that "explicit instruction focused on the social and emotional aspects of learning will result in improved academic learning (Frey, Fisher, Smith, 2019). The other two categories of equity-based STEM teaching practices reflect aspects of culturally relevant pedagogy (Ladson-Billings, 1995) and inquiry-based STEM (Vasquez, Sneider, \& Comer, 2013). In the following sections of this paper, I introduce each of these areas and briefly describe the research problem from each perspective.

Social and emotional learning integrated into STEM. There has been a recent focus on the need for Social and Emotional Learning (SEL) in schools that serve young children. Durlak, Weissberg, Dymnicki, Taylor, and Schellinger (2011) described SEL competencies as the ability to recognize and manage emotions, set and achieve goals, appreciate the perspective of others, maintain positive relationships, make responsible decisions, and handle interpersonal situations constructively. Students that lack these competencies can be the victims of marginalization and be pushed toward the fringe of 
school and community life. Poverty, neglect, and abuse are unfortunately problems that too many young students in our schools face. Though these challenging situations can build resilience and strength if children are supported, they are also at risk that can lead to life-long challenges (Felitti et al., 2019). Furthermore, I have experienced that many groups of $2^{\text {nd }}$ grade students focus on social and emotional concerns that are many times more meaningful to them than the academic topics that a teacher may want to cover. In Chapter 4 (p. 109), I describe in detail the challenges we faced regarding SEL and how my thinking in this area evolved due to listening to students.

STEM learning experiences provide a unique opportunity to learn and practice social and emotional skills. Many reform-based STEM lessons require students to listen to others, work collaboratively, and understand different perspectives. The SEL skills required to participate in reform-based STEM lessons may be strengths garnered from students' everyday practices. However, given the unique nature of families and individual students, some students have lagging SEL competencies. For this reason, it is important to think carefully about how to support all students in developing SEL attributes needed to participate in STEM learning without marginalizing students for which SEL is not a strength. A problem with many current SEL programs is that they are separate from academic content and social situations. Many times, young children go to an SEL class or participate in SEL lessons that lack contextual authenticity. For example, at our school we added an SEL class. Students go to this classroom twice a week and learn with a teacher about SEL topics. However, I have observed that students dislike this class and there is little transfer of skills to daily classroom life. Such decontextualized and separate SEL may feel like an imposed value system rather than a 
value system that was co-constructed by teacher and students working together to solve real problems that occurred during their school day (Frey et al., 2019). Reform-based STEM learning experience requires students to practice SEL skills in the relevant contexts of school and beyond. As I describe in Chapter 4, the approximation of these skills can many times lead to social problems during STEM lessons that can be recast as relevant learning opportunities and then be used to help students listen to each other, problem solve, and practice their solutions. This practice not only positions students as able problem solvers but it also gives students the opportunities to try again and find success. There is an urgent need to describe the types of experiences that happen in too few classrooms so teachers and researchers can begin to understand the importance of integrating SEL into STEM learning experiences for their students.

Student interest and questions as launching points. NGSS (Achieve, 2014) has highlighted issues of equity for diverse students in a collection of appendices at the end of the standards. Though there is a valid critique that such "add-ons" do not provide adequate weight to the intractable problem of equity in our nations' schools (Rodriguez, 2015), these appendices do offer some useful ways to move forward in providing ESTEM learning activities. One teaching practice indicated in the NGSS Appendix D is incorporating students interests and questions into teaching practices (Achieve, 2014). The problem of privileging student voice in this way is that there are few examples of teachers doing this in their classrooms (Buxton, 2006, Geier et al, 2008). It is much more common for school districts to invest in a science curriculum that may engage students' interests and questions but not actually change anything that happens in the classroom based on those interests and questions. For students and teacher to participate 
authentically in science inquiry there must be room for flexibility in the curriculum that can build on student input. As far as I know, designing mass-produced curriculum for such flexibility has not yet happened. Rather there is a move in curriculum publishing companies to "teacher proof" curriculum. In this way, no matter the skill of the teacher, it is thought that students receive the instruction that the curriculum designer intended (Taylor, 2013). With the advent of NGSS, and now the roll-out of NGSS-aligned curriculums across the country, there is an urgent need for models of teachers and students working together to create authentic STEM learning experiences through adapting curriculum, or co-designing curriculum based on the standards and students' interests and questions.

Engineering design to solve locally relevant problems. A final consideration for creating E-STEM learning experiences is using engineering design to solve locally relevant problems. Many young children are natural builders and crafters. They find cardboard and tape, or maybe a pile of sticks, and before you know it have repurposed these items into a shelter for their stuffed animal. These practices, as well as household practices shared with adults in the family, can provide important starting points for design thinking. Research into students' funds of knowledge (González, Moll, \& Amanti, 2006; Sandoval-Taylor, 2006) guides educators towards establishing trusting relationships with students and families to learn in which ways family's repertoires of practice may be included and built upon to create more equitable learning experiences for young children. Science education researchers have found positive outcomes for students when their cultural backgrounds and everyday knowledge are incorporated into learning activities (Barton \& Tan, 2009; Lee \& Luykx, 2006). However, there is currently a lack of 
examples of teachers and young children working together in such ways in engineering education. NGSS has highlighted engineering education and design thinking as an important disciplinary domain. This research project provides valid examples of how students' cultural practices and everyday knowledge can be incorporated into engineering design projects.

A further consideration is what types of problems are being solved during engineering lessons. Many times, engineering design problems are decontextualized events such as building a tower out of marshmallow and toothpicks or designing a paper airplane that will fly $10 \mathrm{ft}$. Though there is a time and place for these types of design projects, there are rich possibilities for teaching students to take ownership for local problems and work at solving them. Researchers are describing and advocating for models of STEM education the encourage students to become change agents in their communities using their scientific knowledge or ability to solve problems (Roth \& Barton, 2004; Roth \& Désautels 2002). Both of these examples come from informal science learning environments that are not constrained by class size and restrictive educational policies. There are still limited examples of teachers, with classes of 20+ students and restrictive educational policies, working with young children to design solutions to locally relevant problems. For this reason, this research project can describe important inroads into solving real problems with young students in second grade and make recommendations on how to expand these types of E-STEM learning experiences across our schools.

\section{Summary of Research Problem}


I briefly described three education strategies for including SEL in STEM learning, leveraging students' interests and questions, and solving locally relevant problems that are important for understanding the research problem. I also attempted to suggest some reasons as to why these aspects of pedagogy may be especially helpful in providing young children access to E-STEM learning environments. Furthermore, these three educational strategies are largely underutilized in educational settings because of a myriad of contextual factors. Throughout this paper, I further explore the research base that supports this pedagogy and the ways in which we, my students and I, came upon these specific aspects of teaching and learning in creating E-STEM learning experiences. I also describe ways in which a teacher, teaching with many of the same constraints shared across classrooms for young children, has implemented these strategies. In the following section of this paper, I describe the significance of this research problem due to the continued lack of progress in creating equity in STEM learning environments and how teachers and students need to be supported so that they can be the agents for change that our nations' underrepresented students deserve.

\section{Significance: Students and Teachers Can Create an Equitable Future}

The current educational policy and reform structure has done little to address the equity issues that plague our nations' schools. Because so little has changed, it can be argued that the current policy and reform structure is perpetuating the equity concerns that have unfairly treated students based on gender, race, culture, linguistic affiliation, ability, and class. It is idealistic to think that schools can solve all the problems of an unequal society. However, it is imperative that we uphold this sense of idealism as we work towards improving our society to be more just for as many people as possible. The 
current practice of changing schools through educational policies that focus on standards, accountability, and mass-produced curriculum have not been effective. Teachers and students working together with the support of new educational policies provide our best hope in changing our society to be more equitable. This research project is significant because as a teacher-researcher, I show an example of this type of collaboration, provide a basis for further projects, and advocate for a different policy structure that is supportive to students and their teachers.

\section{Participatory Action Research and Creating Equitable Learning Environments}

In this last section of Chapter 1, I present my research questions and briefly introduce the methods through which I investigate these questions. Finally, I list definitions of key concepts that are relevant to the research questions.

Research questions and the methodology of inquiry. There is a broad literature base detailing various types of STEM learning environments. However, few studies explore E-STEM learning environments for young children that highlight the collaboration between teachers and students to improve those environments to be more equitable. To move forward in the process of forging more E-STEM learning experiences for all students, it may be helpful to understand the struggles and aspirations of teachers and students that are on ground zero of this contested dilemma. Specifically, a neglected area of inquiry is how students and teachers can work together to develop equity-based practices in STEM learning environments. In such an area of inquiry there is a need for examples of what E-STEM teaching practices might mean empirically, clear goals for the purpose behind equity and STEM learning, and an understanding of the processes that educators, communities, and students enact in their pursuit of E-STEM 
teaching practices (Brown-Jeffy \& Cooper, 2011; Gutiérrez, 2002; Johnson, 2011).

Furthermore, there is great potential in students and teachers working together to overcome narrow views of STEM teaching and learning to create more equitable classrooms and ultimately a more just society (Freire, 1970/1993; Gutiérrez, 2002). Though the teachers' role is critical in designing equity-based practices it is also privileged in the classroom. However, the students' role in informing educational practice is many times overlooked. For this reason, the unit of analysis for this study is focused on how students and teachers use the student experience to inform the design of equity-based practices.

The focus on students and teacher in context, to inform a design process requires a research methodology that is both fine grained and context specific. Furthermore, engaging students and teachers in a research process for creating equity, can also be equitable. For these reasons, I looked toward two methodologies for this research project: (a) participatory action research, and (b) design research. Participatory action research is as a methodology that includes participants in democratic research processes that shifts the research stance from doing research on participants to doing research with participants (Kemmis, McTaggart, \& Nixon; 2013). Design research, on the other hand, attends to the local setting and seeks to understand how educational systems can become sites for envisioning a new future. Cobb, Confrey, Lehrer, and Schauble (2003) stated, "Design experiments ideally result in greater understanding of a learning ecology-a complex interacting system involving multiple elements of different types and levels - by designing its elements and by anticipating how these elements function together to support learning" (p. 9). Though it would be ideal to analyze all the aspects of such a 
learning ecology the focus of this project is on students and teachers working together regarding equity-based STEM teaching practices. However, an important backdrop to the student/teacher collaboration is the myriad of contextual factors that exist in a classroom including the teacher, school district, curriculum, standards, community, peers, and so on. The focus is on documenting student and teacher collaboration but essential input from parents, community partners, and teaching partners in designing and implementing classroom pedagogy is included as well.

One important consideration in understanding the methodology of this research project is recognizing how the context of the project constrained what is possible. However, working within these constraints is also a strength of this project as it provides an authenticity to the data that can only occur when spending a full school year with a group of $20+$ elementary age students. Although a teacher doing research with students while teaching presents several complicating factors that is described in further detail in the methodology section of this paper, it is worth mentioning that there needs to be a careful balance between the responsibilities of a teacher and the responsibilities of a researcher. As a teacher of young children, I contend that it is critical that the needs of children come before the needs of the research. This is an obligation of a teacher. For this reason, teacher participation in this project is limited by what can be done within the context of their role as the teacher. Furthermore, the constraints imposed by the Institutional Review Board to protect students from adverse risks in actively participating in a research project may have limited utilizing student participation in significant ways. However, even with such constraints, there were significant insights gained using a participatory action research and design research methodology. This research project 
took place from the beginning April to mid-June. It followed my students and I through several different STEM units as we explore designing a video game using a programming app, learning about local landforms, and learning about plants and pollinators.

Results from this study provide meaningful examples of student perspectives on equity-based STEM teaching practices and provide a model for how student voice can influence design processes in education. I gathered data using qualitative methods including participant observation, student work analysis, and notes from whole group discussions to provide for a triangulation of data that is both context specific and seeks to extend beyond the context. The following research questions guided this study:

1. What equity-based STEM teaching practices do student and teachers in this study perceive as supporting their interests and aspirations?

2. In what ways can student and teacher collaboration inform a design process for equity-based STEM teaching practices?

In the following section of this paper, I define key concepts that I used throughout the research process. Then, in Chapter 2, I review some of the relevant literature that informed my teaching and the research process. Throughout this paper, I highlight the voices of students and teachers. This is because students and teachers working together is a perspective that is often ignored and, ultimately, student and teachers will change what happens in classrooms. However, it is important to note, that though research by its nature is necessarily disconnected from classroom practice, it plays a critical role as an outside influence. The literature reviewed critiques educational institutions and policy structures in ways that deepened my understanding of the problems I was seeing in my 
classroom. This developed my understanding, informed my teaching practice in profound ways and helped me see how I could improve the experience of my students.

\section{Definition of Key Concepts}

Marginalized students are any students who have historically experienced education as an alienating or disempowering experience. This marginalization occurs because the educational system is ill designed to treat students coming from nondominant social, cultural, or academic backgrounds with the dignity and respect all human beings deserve. For this research project, I am looking specifically at marginalized students in STEM learning environments.

Culturally Responsive Pedagogy (CRP) is focused on three aspects of education:

“(a) students must experience an academic success; (b) students must develop cultural competence; (c) students must develop critical consciousness through which they challenge the current status quo of the social order" (Ladson-Billings, 1995, p.160). CRP is an essential aspect of this research proposal because it focuses on student academic achievement while maintaining cultural competence.

Funds of knowledge takes an anthropological perspective on households and social capital and conceptualizes households as repositories of knowledge developed as strategies for survival (González et al., 2006). These localized forms of knowledge develop across social networks and can be activated in classrooms, as schools become part of these social networks. Funds of knowledge have become increasingly relevant as educators work at bridging academic experiences with students' home community experiences. 
Equity can be defined as a desired endpoint, but in so doing may be confused with equality. A focus on equality seeks to provide the same level of inputs for all students. However, equality, or sameness, may be insufficient to address long-standing gaps in education. Equity, on the other hand, may be seen as a process that continually seeks to challenge and problematize the status quo in working towards the erasure of gaps in achievement, potential, and service (Gutiérrez, 2002; Perry, Steel, \& Hilliard, 2003; Rodriguez, 1998). Equity includes a focus on equality but goes beyond equality to move towards a focus on outcomes, as well as a critique of whose outcomes are valued. For this project, equity was being responsive to students and their social and cultural context.

STEM education is "an interdisciplinary approach to learning that removes that traditional barriers separating the four disciplines of science, technology, engineering and mathematics and integrates them into real-world, rigorous, and relevant experiences for students" (Vasquez et al., 2013, p. 4). In my words, STEM is using science, technology, engineering, and math for authentic learning purposes.

STEM literacy is the ability for students to work together to apply concepts, content, and practices from across the four interrelated STEM disciplines to improve the social, economic, and environmental conditions of their local and global community. However, it is not critical that all individuals know all STEM content to solve problems. Rather it is through the essential skills of communication and collaboration that the distributed nature of knowledge is harnessed to address relevant problems.

Agency is defined as "the bridge that connects new knowledge to action" (Rodriguez, 1998.) Furthermore, agency is "the conscious role that we choose to play in 
helping to bring about change for the benefit of all and especially the benefit of those who occupy disadvantaged positions in comparison with ours" (Rodriguez, 1998). 


\section{Chapter 2: Literature Review}

Equity and empowerment can be viewed as a goal, but more meaningfully, it may be viewed as a process (Gutiérrez, 2002; Rodriguez, 1998). Viewing equity and empowerment as a process allows our thinking to move away from static notions of equity and towards a more fluid and dialogic perspective that is constantly developing and changing based on contexts and new understanding. It also necessitates that we accept that we will never arrive at an endpoint where equity has been achieved, rather a constant vigilance and critical reflexivity (Lather, 1991) must be maintained as bias, stereotypical thinking, and societal processes are always around to pull us in less equitable directions.

My teaching experiences, the reflection on these experiences, and the role of teaching within larger social and political contexts helped me develop a conception of myself and augmented my identity as a questioner and pursuer of deeper understanding. In my view, being a person who asks questions (both internal and external), who works towards developing knowledge, and then who is moved into action by this knowledge, is what equity demands. However, it is important to note that internal barriers and biases are not always apparent in this process, which necessitates a stance of humility in the world. In my new role as a developing researcher, I see myself in a position where I can create a space for questioning, inquiry, and possibility, as I work with my students and share this work with a broader audience. An essential goal of this research was to develop equity-based STEM teaching practices using a participatory design process influenced and critiqued by students' perspectives. In Chapter 2, I elucidate the theoretical framework and review relevant research from the standpoint of my own 
experience as an educator, and developing researcher. Throughout the research process, I continue to adjust this framework to reflect the dialog between my students and I as well as what we find relevant. One important consideration regarding E-STEM is the limited research base regarding equity in STEM learning environments for young children. This research base shrinks even more when looking at E-STEM learning environments for STEM schools that work with low SES White students situated on the rural-urban divide of a mid-sized town. A necessary and productive aspect of this research project was taking a literature base developed in different contexts and applying it to our setting.

In this first part of Chapter 2, I describe the theoretical framework that informs the way I conceptualized the research problem. Then, I review the relevant research literature and discuss methodological considerations for this project.

\section{Theoretical Framework}

The proposed research project draws on four bases of literature. First, there is the literature base that looks at teaching and learning in STEM environments through an inquiry lens that focuses on the dialogic relationship between STEM processes and contents (Saxton et al., 2014; Shulman, 1987). Second, there is the framework of culturally responsive pedagogy that seeks to elevate the conversation around STEM with an eye towards issues of culture, race, and power (Aguirre, \& del Rosario Zavala, 2013; Greer, Mukhopadhyay, Powell, \& Nelson-Barber, 2009; Gutiérrez, 2002, 2008, 2013; Lee, 2003, Martin, 2009; Rodriguez, 1998). Third, there is the area of social and emotional learning that focuses on giving students the necessary skills and dispositions to productively participate in learning communities (Durlack et. al., 2011, Frey et al., 2019). Finally, there is also literature on the role of student voice in transforming 
educational spaces (Cook-Sather, 2006; Mitra, 2004; Smyth, 2006; Susinos \& Haya; 2014). My understanding of these four categories of literature is informed by social constructivism, combined with a critical perspective on the education policies and institutional structures that perpetuate the unequitable situation in our nation's schools. In the following literature review, I give an overview of social constructivism and critical perspectives education policies and institutional structures. Then, I describe the literature relating to STEM processes and content, culturally relevant pedagogy, and student voice.

Social constructivism. Social constructivists see an individual's voice or use of language as always embedded within the social context from which it originated. Wertsch (1991) explains that there is no such thing as voice that is not in relation to other voices. For this reason, all knowledge is seen as socially constructed and tied to the context in which it was constructed. If we extend social constructivism to an understanding of the nature of STEM subjects, we begin to see that STEM knowledge, regardless of an appearance of absoluteness, is situated in a sociocultural context (Atwater, 1996). Western science then, with its privileged status, is only one among many epistemological views of the world. Moreover, from a social constructivist viewpoint, student and teachers can "challenge the scientists' position of preeminence because they have just as much access to the standards for evaluating the impact of the social context of scientific actions on people's cultures and social lives as do scientists themselves" (Atwater, 1996, p. 828). White Western STEM epistemology has brought us many developments including cures to diseases and environmental pollution that cause new diseases, war-machines and bombs that ended wars but also threaten to end 
civilization; technology that produced unprecedented connectivity also impacted the way we as humans interact with one another and the world we live in. Thus, the STEM innovations in the world, as well as in the United States, have had both positive and negative consequences for people and the planet. For this reason, society needs a STEM workforce and citizenry that can be critical of knowledge claims and interrogate issues of power and privilege as it relates to what is happening in the world. Social constructivism, through a lens of understanding the construction of social worlds and the products of these worlds, provides an opportunity to develop a deeper understanding of not only what knowledge is being generated, but also how these knowledge claims are implicitly value laden and tied to a social context.

If we accept that knowledge is socially constructed and mediated by cultural, historical, and institutional contexts and that the current educational and sociopolitical context is unjust, what implications does this have for research and practice? Put simply, we have to do something about it. There is a rich and varied history of educators "doing something about it" that has been theorized and documented in the critical education literature (Barton \& Tan, 2010; Frankenstein, 1990; Freire 1970/1993; Gutstein, 2003, 2006; Gutstein \& Peterson, 2005; Skovsmose, 1990; Skovsmose \& Greer, 2012; Tan \& Varley, 2007; Tan et al. 2012). This literature informs my understanding of sociocultural constructivism, which helps me envision teaching and learning as a political activity where students and teachers work together in a struggle to develop new knowledge and connect this new knowledge with transformative action in a Freirean sense. In the following sections, I briefly describe some of the literature critiquing educational policies and institutions that influenced the context of this research project. In so doing, I hope to 
highlight the social and cultural contexts that spur me onward to change the practices in my classroom and advocate for changes across educational settings more broadly.

Educational policies and institutions. If teaching and learning are situated in a social and cultural context as described in the previous paragraphs, it would be important to ask why the current teaching and learning context continues to perpetuate inequity in our society. As a classroom teacher, I take a ground-up perspective. First and foremost, what are the barriers that exist in my classroom that keep my students and me from actualizing a more equitable situation. There is more to be said about larger social and cultural issues that reinforce inequity such as the perpetuation of generational poverty, racism, and anti-immigrant policies to name a few. This year in my class I have a student whose father, a war veteran, committed suicide in front of his family; a mother who is an opioid user and abandoned her son; another father who asked his family "should I kill myself or go to jail" and then killed himself; and a mother who is incarcerated. This situation, that students must live with every day, is not right. However, these stories are not uncommon in many communities that bear the brunt of the negative effects of our society's historical and current marginalization of others. These social and cultural factors causing deeply felt traumas have a lasting negative impact on students' access to education that cannot be ignored. There needs to be much more work done on transforming our society so that all children and families are well supported in and out of school. Because this is currently not the case, classrooms and schools are called to help heal what is broken. Too often, instead of healing, under-resourced classrooms with under-prepared teachers implement education policies that perpetuate the negative impacts of society. From a classroom research perspective, two areas that stand out as 
needing attention are: (a) lack of decision-making power of educators and underrepresented communities and (b) unprecedented reliance on standardized testing and the culture of standardized curriculum that tends to deskill teachers.

The perspectives of underrepresented communities and that of teachers in the field are not included in everyday educational decisions that impact the students. What counts as legitimate knowledge, what is a just society, and what is a good student have been much-contested issues since the dawn of formal education (Apple, 2001). Different perspectives in society influence and change directions in education. I have heard some teachers describe this as a pendulum. In an informal conversation with a long-time educator, I asked how she had stayed in education for so long. Her answer, "The pendulum swings and I try just not to get hit." Though this may be a necessary survival tactic, it is important to think about who is "getting hit" by this pendulum. As critical educators point out, disadvantaged communities usually do not have a voice in important educational decisions that affect their children's lives and futures (Apple, 2001). For example, a recent review of the K-12 Framework for Science Education found that the voices of diverse communities and teachers were largely absent, while members of the established scientific community were privileged (Rodriguez, 2015). When deciding what knowledge to include in this influential framework, the everyday knowledge of the most disadvantaged members of our community was not included. Similarly, the relatively privileged positions of teachers and school administrators were not included in this important document (Rodriguez, 2015) and in important educational decisions more broadly (Bailey, 2000; Hargreaves \& Fullan, 1998; Ravitch, 2016). Instead, we are asked to carry out policies, such as state-mandated tests, that we know are not fair or just for 
our students. We, as educators, can dodge the pendulum of educational policy, whereas most of our students do not have this opportunity - they get hit over and over. Paulo Freire (1970/1993) has called on educators to ask critical questions regarding educational institutions and the larger society as a whole. Such a critical lens is important when looking at STEM education because STEM education policies, and policies that effect teaching and learning more broadly, have created a system with clear winners and losers.

In a general, the current focus on high stakes testing negatively impacts who have access to STEM education. This is seen clearly in Blank's (2013) analysis of the declining time spent on science instruction in elementary schools but also in research describing the narrowing of curriculum across schools (Au, 2016; Kempf, 2006). In Au's 2016 meta-synthesis, she found that in addition to narrowing curriculum, high stakes testing increased knowledge fragmentation into bite-sized pieces, and more teacherdirected learning. These scenarios are especially true in schools that have lower test scores, as educators are forced to attempt to "fix" students so they can attain better scores on state tests (Kempf, 2006). Each of Au's (2016) conclusions are especially troubling for equitable STEM education in elementary schools. Science content is only lightly tested, teacher-directed learning makes it especially difficult to develop STEM practices and dispositions, and fragmentation of knowledge pushes learners away from the integration that makes STEM learning compelling for students.

An additional aspect to consider is how mass-produced curriculum that is being designed for standards limits the role of the teachers and their sense of agency. Following Dewey's (1938) vision of curriculum as stemming from a lived experienced of students and teacher, Clandinin and Connelly (1992) described a teacher-as-curriculum- 
maker image in contrast to a teacher-as-curriculum-implementer. With the advent of national standards and testing, textbook publishers sold billions of dollars of new curriculum materials to support students and teacher in meeting these standards. However, curriculum mandates changed the role of the teacher as our responsibilities shifted form "curriculum maker" to "curriculum implementer" (Craig, 2012). This loss of control over what we teach and how we teach it was not written in the stars as new standards came online. Rather, curriculum marketers seem to have pushed states and district to adopt "research-based" materials with a motive on profit. Having previously worked at a district that supported a teacher-as-curriculum-maker model, I was witness to the pressure curriculum companies put on districts who do not adopt their resources. A casualty of school districts investing in expensive curricular materials is the lack of money available for high quality professional development. This is especially true in states that already spend a minimal amount of money on education. What professional development does happen in elementary schools is on common core-tested subjects such as math and reading. I describe specific impacts to my schools' access to STEM professional development in later chapters. However, research clearly documents that most elementary school teachers are not sufficiently prepared to provide equitable STEM learning experiences (Lee \& Buxton, 2010; Lee, Hart, Cuevas, \& Enders, 2004). I argue that a key factor is that teachers are now being cast as curriculum implementers rather than curriculum makers; the financial resources are being directed toward curriculum companies instead of investing in teachers' learning and professional development, In the preceding description of some of the literature critiquing education policy and institutions, I emphasize that the context in which all schools operate is a contested 
and political arena. Powerful actors beyond the classroom influence and create educational policy with little input for underrepresented communities and educators. However, there is some hope as discussions around equity in STEM education and equity in education more broadly are gaining traction. As Rodriguez, (2015) pointed out, recent NGSS standards do have an appendix that discusses implication for equity. This appendix includes promising equity-based teaching practices and classroom descriptions written by educators. However, he goes on to point out that such add-ons, though notable in their vision, have little chance of creating change in the larger educational context. If we want to see equitable STEM learning experiences for all students, then we as educators must begin the important work that lies beyond our classrooms walls to advocate for system-wide institutional changes. In Chapter 5, I detail specific recommendations from the findings of this research project for how institutions could be changed to support equitable STEM learning experiences. In the following section of the literature review, I describe the literature that was influential in designing the classroombased research project and subsequent interventions in the classroom with my students.

STEM content and practices. Inquiry learning in STEM classrooms positions students in the role of active learner and the teacher in the role of facilitator. This shift in classroom hierarchy can create a shared authority over learning process and can support students in active engagement (Saxton et al., 2014.) However, a challenge in inquiry environments is how to move towards a more student-centered approach where students also able to pursue their own interests as it relates to their social and cultural lives while also ensuring that all students are given access to standards (Lee \& Buxton, 2010). Furthermore, NGSS is calling for heightened integration of STEM content within such 
inquiry environments. Though this creates an opportunity to understand real-world problems from interdisciplinary perspectives, it also presents significant challenges to implementation in classrooms and across schools (Roehrig, Moore, Wang, \& Park, 2012). The following sections review literature on academic rigor, discourse processes, and STEM integration.

Cognitive demand, depth of knowledge, and student understanding. An essential component of equity-based STEM teaching practices is that they require sufficient cognitive demand to develop deep content knowledge and student understanding without marginalizing students (Aguirre et al., 2013; Saxton et al., 2014). It has all too often been the case that marginalized students are provided diminished learning experiences based on an urban deficit pedagogy that focuses on direct instruction and development of basic skills (Aquirre et al., 2013; Emdin, 2010a; Lee \& Buxton, 2010). There are some substantial issues with the newly adopted NGSS and Common Core State Standards for Mathematics (CCSSM) (2010) especially in terms of implications for standardized testing and accountability measures. Having high expectations for students to strive for can provide access to increased opportunities for marginalized students that have been historically discounted for their intellectual contribution to STEM subjects. However, if not addressed with a focus on equitable teaching practices that seek to respect the multifaceted nature of students' social and cultural backgrounds, these same high expectations may also marginalize students. The following studies are representative of a larger body of work that looks at the relationships between cognitive demand, depth of knowledge, and student understanding. Henningsen and Stein (1997) explored how inquiry-based mathematics engages students 
in acquiring a "mathematical disposition" or a "mathematical point of view" (Schoenfeld, 1992), as well as acquiring content knowledge. In their study, they looked at middle school classroom mathematics instruction of teachers who are involved in the Quantitative Understanding: Amplifying Student Achievement and Reasoning (QUASAR) project, a five-year research and professional development project focused on strengthening student understanding of mathematics using challenging mathematical tasks in several sites across the United States. They described how rich mathematical tasks that are longer in duration and notably more complex are solved within a classroom environment. They found several important classrooms factors that had positive effects on engagement including: tasks build on student's prior knowledge, appropriate scaffolding, appropriate amount of time, high level performance modeling, and sustained pressure for explanation and meaning (Henningsen \& Stein, 1997). This research indicates that when students are properly supported to engage in rich tasks they develop deep content knowledge that is connected to the development of "mathematical dispositions." This research is important to consider because it indicates that an inquirybased learning environment develops both content knowledge, and the dispositions that can extend that content knowledge to future learning.

Similarly, research suggests that a focus on generic science practices and direct instruction of content is an ineffective way to support reasoning when compared with knowledge-rich tasks designed to examine content and domain-specific reasoning and problem solving (Zimmerman, 2000). One particularly applicable area of research that influenced NGSS looks at design-based science and student learning (Fortus, Dershimer, Krajcik, Marx, \& Mamlo-Naaman, 2004). In this study, the researchers crafted cyclic 
design units for three $9^{\text {th }}$ grade science classrooms that focused on design problems that were chosen to be both challenging and interesting for students. Though a $9^{\text {th }}$ grade classroom is far removed from the daily working of a learning environment for young children, this research is relevant because it shows the cyclic design processes that were adapted to engineering experiences with my students. In the study involving $9^{\text {th }}$ graders, students worked together to design structures that can withstand extreme environmental conditions, non-toxic batteries, and a cell phone that does not emit radiation. The research team looked at the development of science knowledge as students designed artifacts to solve these real-world problems. This study found a significant change in student thinking and in their ability to apply this thinking to novel situations (Fortus et al., 2004).

However, in a similar study in an urban context (Tobin, Elmesky, \& Seiler, 2001) where high school students studied physics of motion by designing, building, and testing a model car, researchers found that such enactments of curriculum must be carefully balanced with the social needs and realities of students if all students' potentials are to be tapped. In this study, some students were able to access the rich learning opportunity while others resisted and used learning opportunities to reify social stratification and cliques associated with neighborhood contexts. Though inquiry based, cognitively demanding tasks are undoubtedly an important component of any STEM classroom, careful consideration of unintentional marginalization must be taken into consideration.

STEM discourse. Central to a classrooms' development as a learning community is the co-construction of ways students and teachers participate in discourse. Research has indicated that STEM teaching and learning will benefit from teachers who facilitate 
active engagement through discourse strategies (Anderson, 2002; Buxton \& Lee, 2010; Chapin \& O’Connor, 2007; Hiebert, 1997, Saxton et al., 2014; Stein, Engle, Smith, \& Hughes. 2008). In a classic study, Cazden (1988) described the traditional and still everpresent pattern for interaction in a classroom as consisting of a three-part sequence named IRE: teacher initiation, student response, and teacher evaluation. This pattern creates a kind of asymmetrical power dynamic where teacher-centered learning environments dominate and limit opportunities for marginalized students to engage in learning (Cazden, 1988). Furthermore, "in mainstream classrooms, students whose cultural and linguistic knowledge differs from the teacher's pattern of acceptable response tend to withdraw from participation" (Hudicourt-Barnes, 2003, p. 77). A more process-oriented approach to teaching and learning does not necessarily mean that students will not be marginalized (Delpit, 1988, 2006). Careful attention to making explicit the rules and roles in student-centered discourse and connecting classroom discourse with students' cultural and linguistic experiences may help students engage in classroom discussion at a deeper level (Warren et al., 2001).

There is a rich literature base describing the evolution of discourse practice in science and math classrooms including the challenges and opportunities as related to social and cultural contexts. In mathematics, there has been a theoretical distinction between social and sociomathematical norms that govern discourse (Yackel \& Cobb, 1996). Social norms structure how students participate in classroom activities whereas sociomathematical norms are specific to a person's mathematical thinking. Kazemi and Stipek (2001) researched what types of sociomathematical norms emerge in classrooms where teachers actively engage students in discourse. The context of this study was four 
primarily low-income upper elementary grade classrooms in a large urban and ethnically diverse neighborhood in California. They used examples of interactions to propose that a high press for conceptual thinking is characterized by the following norms: (a) an explanation consists of a mathematical argument not simply a procedural description, (b) mathematical thinking involves understanding relations among multiple strategies; (c) errors provide opportunities to reconceptualize a problem, explore contradiction in solutions, and pursue alternative strategies; and (d) collaborative work involves individual accountability and reaching consensus through mathematical argument. (Kazemi \& Stipek, 2001, p. 59).

In a similar study, Hufferd-Ackles, Fuson, and Sherin (2004) conducted an intensive oneyear case study in an urban elementary classroom with Latino children. They described the developmental trajectories of the evolution of the math-talk learning community. Both of these studies were instrumental in changing my teaching practice because they helped me notice ways in which students were participating and how this participation was structuring the norms within the classroom. This allowed me to adapt teaching practices so that students had increased opportunities to co-construct discourse practices. However, in both of these studies the social and cultural contexts of students' lives outside of school were not taken into account. Other studies have looked at students' out of school and past schooling experiences as important contexts that present important opportunities and challenges for enacting discourse practices.

For example, Civil and Planas (2004) carried out research where they were primarily concerned with "seeking out ways to develop approaches to mathematics education that are sensitive to the context and lived experience of all learners" (p. 7). In 
their study, they found that certain groups of students, such as immigrants, members of ethnic and or language groups, and economically underprivileged students, have constrained experiences in participating in mathematics classrooms due to social and organization structures. Most strikingly, it seems that the students themselves were often the conveyers of marginalization as they reinforced issues of status on themselves and their peers which may have had roots in broader societal and organization structures. On the other hand, Hudicourt-Barnes (2003) described how students are able to overcome such societal and organizational structure when teachers allow their cultural worlds to become a resource for developing academic discourse. She drew on her own experience as a bilingual science teacher and education researcher to highlight how Haitian children use the cultural practice of odyans, a form of discourse similar to scientific argumentation, to engage in scientific argumentation. This study is noteworthy because it describes how minority students that had been previously characterized in deficit terms (Lee, Fradd \& Sutman; 1995) can achieve at the highest levels when given opportunities to connect learning experiences connected to home-community experiences.

Integrated STEM. The challenges that our rapidly changing, increasingly global society will face are multidisciplinary in nature. Global warming, diminishing natural resources, and food distribution are several examples that come to mind. Recent national calls for an improvement in integrated STEM education have created policies, and standards documents reflect this growing awareness (Roehrig et al., 2012). An underlying reason guiding the call for integrating STEM subjects is that strengthening students' understanding of the disciplines and creating an appreciation for the interconnectivity and applications between the disciplines is essential for developing 
knowledge and practices that have applicability is solving real world problems (Frykholm \& Glasson, 2005, Roehrig et al., 2012; Vasquez et al., 2013). However, most of our schools still teach STEM subjects in isolation and have little incentive or pressure to change the status quo (Weber, Fox, Levings, \& Blouwma-Gearhart, 2013). When interviewing a sample 20 high school teachers representing each STEM discipline Weber, Fox, Levings, and Blouwma-Gearhart (2013) found that teachers had an awareness of the need for integration, but did not feel that that change was being supported or asked of them. While there is a strong definition of STEM integration in the new NGSS documents, most teachers having not yet moved to change classroom practice and the lack of teacher preparedness is a major barrier that needs to be overcome (Czerniak, 2007). Two important questions within the research literature that focus on dismantling these barriers are: (a) what type of knowledge is required to integrate STEM learning, and (b) what type of school structures are most conducive to integrating STEM? In the following review, I briefly describe several of the studies that focus on these aspects of STEM integration.

In the process of investigating the types of knowledge required for integrating STEM disciplines, Herschbach (2011) noted that each STEM field has its own organizational structure that consist of three substructures-the formal, substantive, and syntactical. Weber et al. (2013) built on Herschback's description of STEM fields as they hypothesize that "conceiving of the structure of knowledge in light of the boundaries (formal), the questions and theories (substantive) and the methodologies (syntactical) from each of the disciplines promotes not only an understanding of each discipline, but also the ways in which they are compatible with one another" (p. 3). In their recent 
research, they found that most of the teachers they interviewed felt that STEM integration was important but only thought of integration in terms of formal structures. In other words, teachers' conceptions of STEM integration focused on integrating content as opposed to thinking about the different types of questions and theories, and different types of methodologies presented in each domain (Weber et al., 2013). For example, in planning a $3^{\text {rd }}$ grade curriculum unit on ecology it may be that a teacher provides rich learning experiences learning about local ecosystem using scientific practices. The teacher integrates math in terms of counting the number of plants in a certain area. In this case, students are learning science content and practices; however, they are only getting a limited experience with mathematics and are not engaged in the same level of content and mathematical practices as in science. Such asymmetry is representative of many attempts at integration and indicates a need for professional development that supports in-service teachers in developing a deeper understanding of domains and how to integrate instruction.

One specific strategy that may promote integration was described in Frykholm and Glasson's (2005) research describing pedagogical context knowledge. They drew from Shulman's (1986) notion of pedagogical content knowledge to argue for pedagogical context knowledge as an instrumental type of knowledge that will support integrating STEM subject matter. They worked with a group of prospective secondary science and mathematics teachers to design integrated units of instruction. Though the prospective teachers had rarely experienced integrated instruction as learners, when given time to plan together they easily found connections among content. Especially useful were situated contexts that were naturally sites for integration that many times came from 
the sciences. An example of this collaboration is a unit designed by a biology/mathematics team that explored tree growth. This unit included investigations that integrated STEM as students explored (a) tree age based on cross-section of a trunk, (b) ring width as a function of rainfall, (c) tree population and density, (d) leaf size, shape, and symmetry, and (e) comparison of age, ring width, climate, and trunk diameter of species. Using the scientific context of tree growth, this team was able to find many connections between STEM content and practices. Incorporating environmental engineering components that help solve forestry-related problems related to tree growth could further strengthen this unit. Frykholm and Glasson (2005) described prospective teachers' use of situated contexts as a way to "avoid the common anxieties and gaps in understanding that these prospective teachers brought to the experience" (p. 138). Building on pedagogical context knowledge, described as the knowledge of contexts that are conducive to integrating STEM content, may be an avenue to overcome some of the barriers described by Weber et al. (2013).

Though content knowledge and pedagogical context knowledge are important there are significant considerations regarding the practicality of integrating STEM courses in the current structure of schools. Roehrig and colleagues (2012) conducted an in-depth investigation of secondary STEM teachers' implementation of STEM integration during a yearlong professional development. They looked at several different school structures that allowed for integration including (a) science and math teacher collaborating in one class; (b) science and math teacher collaborating but then teaching in separate content classes; and (c) individual content teachers teach multidisciplinary units in their separate content classes. They found that the strongest outcomes in lesson design 
where when the science and math teacher collaborated in lesson design and then either co-taught or taught in separate content classes. On the other hand, they found that the weakest unit design happened when individual content teachers tried to write integrated units without the benefit of content expertise from a colleague. What seems clear is that collaboration may be able to overcome some of the barriers that exist in current classrooms, but co-teaching may ultimately create the most potential for integrating STEM learning. However, both collaboration and co-teaching require additional resources and pressure that currently have little traction with educational leaders that make decisions regarding funding (Weber et al., 2013). Because additional funding will continue to elude most education systems working at integrating STEM, it will be important to investigate practical approaches to collaboration and co-teaching that promote strengthened lesson planning. Furthermore, there is a need to not only integrate STEM disciplines but also integrate students' home-community experiences and practices. Home-community contexts may provide the glue that holds together STEM integration while simultaneously valuing student experiences and cultures as called for in culturally responsive pedagogy.

Culturally responsive pedagogy. Though inquiry learning in STEM environments is a necessary component in creating equitable teaching and learning situations, I argue that it is not sufficient. It does not focus enough on the contextual factors that influence how students learn. The power of culturally responsive teaching lies in the fact that it elucidates and addresses micro (personal), mid (institutional), and macro (societal) level factors related to equity (Brown-Jeffy \& Cooper, 2011; Gay, 2010; Ladson-Billings, 1995). Equity-based teaching practices that address these factors need 
to go hand-in-hand with STEM inquiry. Three such practices found in the research literature include; (a) teaching to empower and increase participation, (b) promoting language acquisition through balancing everyday language resources with academic language, and (c) drawing on students' multiple resources for knowledge (Aguirre \& del Rosario Zavala, 2013; Turner et al., 2012). Following, I describe the literature related to these practices in detail.

Power and participation. My initial interest in this body of literature began because I noticed that some students in my class did not participate in the inquiry learning and classroom discourse. Often, these students were bilingual, of lower socioeconomic status, and/or labeled as having a learning disability. For this reason, I particularly wanted to investigate research literature that describes how White, middleclass and male ways of knowing and interacting affect patterns in STEM disciplines (Fusco \& Barton, 2001; Rodriguez, 1998; Roth \& Lee, 2004). Research indicates that STEM disciplines and content are presented as a set of objective and universal facts and rules that are value and culture free (Atwater, 1996; Eisenhart, Finkel, \& Marion, 1996). Therefore, traditional STEM classrooms can marginalize students from non-dominant groups through a focus on memorization and quick recall, correctness of answers versus thought processes, and an obsession with procedures. Classroom practices such as these have inadvertently reinforced issues of status and limited opportunities to participate.

Research has found that STEM classrooms are "cultural and social spaces that can perpetuate social inequities by privileging certain forms of discourse and ways of reasoning, or reorganize them by positioning multiple forms of knowing as having clout" (Bannister, Bartell, Battey, Hand, \& Spencer, 2007, p. 407). Moreover, this research 
suggests that issues with STEM achievement for marginalized students is not only connected to the gap between home and school cultures, but also has to do with the sociopolitical organization of STEM classrooms (and STEM education in general) (Barton, 1998, Gutiérrez, 2013, Tan et al., 2012). In this light, it is not only an issue of cultural discontinuity but also a structural issue embodied in political and educational institutions that perpetuate inequity. The following sources provide examples from the growing body of work that looks at the micro- and macro-level factors that influence participation and power in STEM learning environments.

Cobb and Hodge (2002) focused on practice and participation of students in their analysis of mathematics research carried out in classrooms with racially and ethnically diverse students. They described a relational perspective that highlights "the relations between the specifically mathematical practices in which students participate in the classroom and the practices of the out-of-school communities of which students are members" (p. 251). This analysis of research suggests that shifting the norms of STEM classrooms to be more inclusive of the practices of out-of-school communities may reframe STEM disciplines in a way that is more continuous with student experiences. Further research related to participation and power relationships in STEM classrooms looks at implications of situations where students' everyday practices are not congruent with classroom practices and how this affects students' social and academic positioning (Hand, 2003; Nasir, 2004). Hand (2003) argued that "open" participation structures that afford negotiation around the framing and positioning of participation are more likely to encourage engagement for marginalized students. Seiler (2001) argued that the negative influence of standardization on the positioning of students has led to a lack of 
empowerment and participation in learning environments. To "reverse" this trend she makes space for students' voice and choice in curriculum design and for deciding "what counts" as science. In so doing, the hegemonic power structure in place is lifted and students are able to engage in science practice on their terms.

Another essential area of research for power and participation in STEM disciplines examines the areas of equalizing status and expanding conceptions of competence. This represents a major shift in thinking about who has authority for what counts as knowledge from teacher to students. It corresponds with a shift of focus from achievement, towards teachers and students co-constructing competence based on opportunities to learn and participation in diverse and non-linear ways (Cohan \& Lotan, 1996; Featherstone, Crespo, Jilk, Oslund, Parks, \& Wood, 2011; Saxton et al., 2014). Boaler and Staples (2008) described the case of Railside School, where teachers and students worked together to create a classroom environment with a deep sense of commitment and respect for their peers within a classroom mathematics community. Rather than being held accountable to a teacher-centered environment, tenets of "complex instruction" were employed to equalize status and help students develop relational equity. "Complex instruction" is a set of protocols that influence task design to ensure that all students are able to contribute to mathematical group work in ways that asserts their competence and builds their confidence. A key to complex instruction is developing relational equity. Boaler (2008) described relational equity as focusing on how "students learn to treat each other and the respect they learn for people from different circumstance to their own" (p. 5). Emdin (2010b) described a similar stance as he explained the importance of students developing an appreciation for diverse 
perspectives in science classrooms through an emphasis on cosmopolitanism (being at home all over the world). In a slightly different approach, Rosebery, Warren, Ballenger, and Ogonowski (2005) developed a practice that asked students to interrogate situated meanings of scientific phenomena and in this process make explicit assumptions of use, purpose, and context. This practice shifts the focus away from static notions of competence and towards the process of asking questions, challenging ideas and deconstructing responses in ways that support learning.

Language. Another critical element in providing equity and access for marginalized students is building on the language resources of students as classroom communities engage in learning academic language of STEM disciplines. In traditional classrooms, marginalized students may remain at the periphery of discourse because of the lack of equity in whose language resources are given privilege (Flores, 2007; Fradd \& Lee, 1999; Moschkovich, 1999, 2007). Furthermore, language is inextricably linked to identity (Gee, 2000; Holland, Lachicotte, Skinner, \& Cain, 1998). When students are supported in negotiating and bridging their home-community language resources with discipline-specific academic language, they are more likely to develop positive academic identities connected to their racial or ethnic identities (Aguirre \& del Rosario Zavala, 2013; Bay-Williams \& Livers, 2009; Brown, 2006; Celedón-Pattichis \& Ramirez, 2012; Moschkovich, 1999, 2007; Turner et al., 2012).

The following is a brief vignette to describe my own experience with language and some of the tensions that arise between every day and narrow Western consideration of what counts as scientific language. At a recent regional science conference, I had an interesting interaction with a high school science teacher. I was sharing my own 
experience of knowing the name of a plant in my first language through interactions with my mother in our garden as a child. I only later learned the name of the plant in English, but had a special connection to the name of the plant because I learned it from my mother. As I matured, the language that I once held in contempt while trying to become more American became an important aspect of my identity. Now that I have children, I want to pass this language on to them. It is the language that I first heard my name in, first laughed in, and first learned about who I am as a person separate from others. However, at this science conference the high school educator pointed out that it does not matter what language I first experienced as this plant has a Latin name that is universal. That is, the Latin name of the plant is privileged over other language types in science. Though we have come a long way in what we understand about language and identity, it seems that privileging academic language over everyday language may still be the norm for many science educators.

Moschkovich (1999) researched how a group of bilingual $3^{\text {rd }}$ grade students negotiated mathematical meaning in a discourse community using their language resources. These resources include both standard and non-standard English, vernacular/first or home languages, gestures, drawing, and manipulatives or realia. Moschkovich found that when students were describing and comparing shapes within a Tangram puzzle, they struggled to communicate their understanding and negotiate meanings. However, this struggle helped conceptual structures emerge and then positioned students to learn easily academic terms because they had already established meaning and descriptions for the geometric shapes. Brown and colleagues (Brown \& Ryoo, 2008; Brown \& Spang, 2008) examined how teachers use innovative practices to 
bridge language, identity, and science content. They found an especially effective practice to be a hybrid form of vernacular and scientific language, termed double talk, when explaining science. Students adapted this same strategy when they engaged in scientific discourse. Furthermore, Varelas, Becker, Luster, and Wenzel (2002) investigated how students' identities are intertwined with language use in the forms of plays and hip-hop lyrics. In working with students in a $6^{\text {th }}$ grade all African-American urban science class, they found that using students everyday discourse practices helped students learn scientific language while also strengthening racial and discipline specific identities.

Additionally, educators may at times either fail to provide support for diverse students, or provide too much support that ends up lowering the cognitive demand required for a mathematics task (Bay-Williams \& Livers, 2009). Educators must carefully decide what linguistic structure will make the STEM learning accessible for students, (e.g., language relating to contexts and everyday usage) while also introducing STEM language that requires a conceptual structure before it can be meaningfully learned. All too often it is the case that students are asked to adopt academic language before being able to negotiate meanings and identities. This practice risks marginalizing students and perpetuating the status quo. Though there have been some studies that look at how to support pre-service and in-service teachers in changing language practices in STEM classrooms (Aguirre \& del Rosario Zavala, 2013; Lee, 2004; Johnson, 2011; Tan et al., 2012), there is an urgent need for further studies in this area that help bridge the gap between research and practice. One interesting aspect that needs to be further theorized is how teachers' own experience and familiarity with different languages and 
the educational context they work in influences how they negotiate top-down standardization. For example, my experience as a bilingual child helps me realize the importance of first languages and therefore, I value balancing students' language resources with more formal academic language. This research on language acquisition is important for this research because all students are language learners. This is especially true in the $2^{\text {nd }}$ grade classroom where students' everyday language practices are developed to describe their thinking, and the teacher must extend that thinking as new ideas are introduced.

Drawing on multiple resources for knowledge. Educators in schools serving marginalized students have traditionally had a difficult time making STEM teaching and learning relevant for their students (Emdin, 2010a). A lack of awareness about student culture, or worse, a deficit view of student's home community, has often led to teaching and learning situations that are disengaging and marginalizing. Equity-based teaching in STEM classrooms demands that educators develop the "capacity to recognize and intentionally tap students' knowledge and experiences-mathematical, cultural, linguistic, peer, family, community-as resources" of teaching and learning (Aquirre et al., 2013). Drawing on students' funds of knowledge (González et al., 2006) has been described across STEM disciplines in a broad literature, including recent NGSS standards, as a key practice for sustaining equitable teaching (Aquirre et al., 2013; Celedón-Pattichis \& Ramirez, 2012; Lee \& Buxton, 2010; Saxton et al., 2014; Tan et al., 2012). Furthermore, drawing on students' funds of knowledge includes helping students forge connections across borders between academic and everyday spaces, building on students' linguistic resources, recognizing family or community STEM practices, and helping students learn 
to use STEM disciplines to solve problems that affect their lives (Civil, 2007, Gutstein, 2006; Lee \& Buxton, 2010, Moschkovich, 1999; Tan et al., 2012; Turner \& Varley, 2009; Vasquez et al., 2013).

González, Andrade, Civil, and Moll (2001) developed a research paradigm investigating "Funds of Knowledge" of diverse populations. In this research, their focus has been on using ethnography to document context-specific household practices in the SW borderland spanning Mexico and the United States. One such study focused on "understanding the mathematical potential of households, as well as "mathematizing" household practices” (González, Andrade, Civil, \& Moll, 2001, p. 115). Civil joined a Latina mothers' study group where they investigated the mathematical potential of the cultural practice of designing dresses. Out of this work emerged the notion that through creating "zones of practice" educators can "invite children into a world with a concrete motivating activity in which the everyday and spontaneous come into contact with the scientific and schooled" (González et al., 2001, p. 128). Similarly, scholars advocate for creating a hybrid or third space in classrooms that allow "cultural, social, and epistemological change where competing knowledges and discourses challenge and reshape both academic and everyday knowledge" (Tan et al, 2012, p. 34). In one such study, Barton and Tan (2009) described a design experiment conducted at a low-income urban middle school where the teacher was supported by the research team in using teaching practices that draw on students' funds of knowledge during a $6^{\text {th }}$ grade unit on food and nutrition. They found that when students and educators worked together to incorporate everyday day knowledge and practices hybrid spaces emerged where academic and everyday discourses transformed each other. 
In a related vein of research, teaching math and science for social justice focus on critiquing and transforming students' realities by using STEM subjects to solve authentic problems in their lives (Aguirre et al., 2013; Greer et al., 2009; Gutstein, 2006; Rodriguez 1998; Tan et al., 2012, Wager \& Stinson, 2012). Gutstein (2003) worked with middle school students over the course of two years to develop a network of critical (critiquing society), classical (standards-based math), and community (everyday) knowledge of mathematics. His teaching employed a high-quality standards-based curriculum and 17 real-world projects designed specifically to privilege the development of critical mathematical knowledge in real world contexts. Each of the three "C's" draws on a specific fund of knowledge that many home communities of marginalized youth possess. It is noteworthy that one aspect of knowledge focused on by Gutstein was critical knowledge. Critical knowledge is especially salient for marginalized communities because of student home communities' critical lens that has developed out of historical oppression and colonization (Emdin, 2010a; Freire, 1970/1993). School institutions many times perpetuate this historical marginalization and that teaching as a critical endeavor maybe especially important for marginalized students (Gutstein, 2006, Wager \& Stinson, 2012).

Social and emotional learning. Social and emotional learning (SEL) is the process of learning the self-awareness, self-control, and interpersonal skills that are vital for school, work, and life success (Frey et al., 2019). Implicit in this description of SEL is a set of values that are culturally bound and could marginalize students if not set within a larger context. In this section of the literature review, I present an overview of the literature base exploring SEL and critique this literature base using the added frameworks 
of STEM learning, and CRP. As a teacher/researcher, I find it is essential to use multiple frameworks and/or perspectives when thinking about teaching and learning. This helps support my understanding of these frameworks and my understanding of my students. A broad critique of SEL that I explore in this later section reveals that many times SEL is taught in isolation of real problems and contexts. This can position students in deficit terms if not thoughtfully presented. Furthermore, SEL instruction can take important instruction time away for STEM. However, according to the data from this research project, SEL was a significant interest for my students. Students responded positively towards SEL learning opportunities, and for many, these additional supports allowed them to more fully participate in STEM learning activities.

Current efforts to improve the social and emotional skills of students is described in education research beginning with Waters and Sroufe (1983). They indicate that students need to coordinate flexible and adaptable social and emotional responses to their environment to be successful in school and life. In other words, education should prepare students to respond to situations in appropriate ways, adapt to their environment, and seek out opportunities in the community. This thinking has evolved over the years, and key competencies have been established. Durlak, Weissberg, Dymnicki, Taylor, and Schellinger (2011) described these competencies as "the ability to

- Recognize and manage emotions

- Set and achieve positive goals

- Appreciate the perspectives of others

- Establish and maintain positive relations

- Make responsible choices

- Handle interpersonal situations constructively" (p. 406) 
This list of competencies appears quite straightforward and generally positive. However, the educational literature is full of well-intentioned practices that end up marginalizing students. Frey, Fischer, and Smith (2019) pointed out that focusing on SEL can take time away from academics, co-opt the role of parents/families, and can be culturally insensitive from various perspectives. Furthermore, focusing on SEL competencies can lead teachers to see diverse students as having another layer of deficits. Phrases such as "my kids can't ..." are all too common, and SEL could be just another thing that some students can't do. SEL is an emerging field in education and it is important to consider carefully how SEL is implemented so that all students are benefitting.

Though SEL learning is a contested subject fraught with implications for equity, it is also a curriculum area that needs to be addressed. Frey et al. (2019) argued the social and emotional aspects of teaching and learning are happening every time a teacher walks in front of the classroom. They discussed that SEL has always existed in the hidden curriculum. The expectations that teachers give, and the values they reinforce through phrases such as "listen to the teacher," "boys don't cry," or "girls need to be polite," mold students in certain ways and can reinforce powerful negative stereotypes. When this curriculum is not examined thoughtfully and presented to students in explicit ways, there can be gaps in learning and some students will invariably be marginalized. However, Frey et al. (2019) went on say that when teachers thoughtfully consider how to approach SEL subjects, make SEL learning explicit, and integrate SEL into the fabric of their classrooms, students benefit with increased academic success. In some ways, this is similar to Lisa Delpit's (1988) description of the culture of power and her assertion that teachers have a responsibility to prepare students for this culture so that they are prepared 
for success in school and society. In the following section of the paper, I critique this literature base as well as the literature focusing on STEM inquiry and CRP in STEM.

\section{Critique of literature related to STEM inquiry, SEL in classrooms, and CRP}

in STEM. The literature reviewed briefly describes some of the relevant research literature important to this project. In the ideal world there would be more time and space provided for practicing teachers to read and discuss the research literature. However, this is not currently supported in the institutional context where I work. The time I spend reading the research literature is also time I do not spend investing in the community that I serve as a teacher. It is a tricky balance where one foot is in the very real struggle of what do I need to do for my students tomorrow and the other foot is in the struggle of what do I need to do for my profession for the next 100 years. From this perspective, the literature I reviewed has very important implications for practice. However, as mentioned throughout the previous section of the review, there is still a large gap between research and practice in many classrooms. I argue that one of the main barriers that must be overcome is moving beyond prescriptive ideas about equity and towards context specific enactments. What is equitable in one situation, may not be equitable in another. For example, students living in rural areas have markedly different life experiences than students living in urban areas. When adapting teaching and learning experiences to students' social and cultural backgrounds the differences in life experience need to be taken in account. For this reason, there needs to be an emphasis on describing equitable learning environments in various contexts so that educators can begin to see how contextual factors influence equitable learning environments. In addition to equitybased frameworks that can be used to guide pedagogy, teachers need stories that bring to 
life the possibilities of equitable teaching that they can apply to their own setting. Some of the research described previously does this. Generally, researchers "drop by" for some time, whereas classroom teachers live and breathe the classroom every day and have important perspectives to share.

On a final note, I argue that more research needs to look at the outcomes that combine CRP, STEM learning environments, and SEL teaching strategies. Currently, the research looks at single factors of CRP in STEM learning environments or SEL as separate entities. In teaching, one never uses a single strategy. Rather, teachers employ a wide range of practices; moving back and forth within a collection of practices to reach their students. Now that we are developing more holistic models of CRP in STEM learning environments and SEL it will be important to document how teachers enact these equity-based practices and how students respond. One significant question will be to document how CRP and SEL in STEM learning ecosystems influence the formation of identities and the development of agency.

Student voice. Educational policy regimes characterized by top-down mandates in the form of standards, standardized testing, and accountability measures promoted by the still present No Child Left Behind policies have dire consequences for the engagement of students. Student voice has been called for as an important construct to counteract the current trend in national contexts (Mitra, 2004; Smyth, 2006) as well as international context also suffering from the global test-based paradigm (Cook-Sather, 2006; Jenkins, 2005; Susinos \& Haya;, 2014). John Smyth (2006) argued that the question of how to pursue educational systems that "listen to and attend to the voices of the most informed, yet marginalized witnesses of schooling, young people, has to be the 
most urgent issue of our times" (p. 279). The argument for centering educational change process on student voice is grounded in the notion that school transformation will meet the needs of learners if students are involved in the processes. Educational researchers have proposed that young people "have unique perspectives on learning, teaching, and schooling" (Cook-Sather, 2006, p. 369). Moreover, the focus on student voice is premised on the conviction that students should be "afforded opportunities to have an active role in their own education" (Cook-Sather, 2006, p. 369). Though student voice has been called on to transform educational systems, there is a lack of consensus on what transformations are needed and how such research can be carried out. Some of this lack of consensus may be attributed to the diversity of perspectives when working with students with different cultural and social backgrounds. However, it may also be the case that certain studies are more adept at surfacing contradictions and criticality in students. The following review includes research regarding student voice in STEM disciplines and in educational contexts more broadly.

Susinos and Haya (2014) described a case study of one of six schools involved in a project whose objective "was to promote and document processes of school change and improvement carried out by virtue of the student voice experiences set in motion in different schools" (p. 385). In their project, medium to low income primary school students in Spain designed and developed different initiatives around the following question: What would you like to change in your school? Their project focused on being genuinely participative. It could be recognized as a "qualitative collaborative" (CochranSmith, 2009) approach designed through an open process promoting non-hierarchical relationships with teachers, school counselors, and students throughout the project. The 
careful design of the project goes through five stages. It begins with ensuring that relationships of trust are established and ends with collective assessment of the impact of the project. Throughout the bulk of the project students make choices about how to run meetings, about what they would like to change, designing and implementing improvements, and on gathering data as to their efficacy. This project along with others like it (Mitra, 2004) stands out as quite exceptional when compared to projects that focus on gathering student perspectives but do little to establish relationships and involve students in creating change (DeFur \& Korinek; 2010; Jenkins, 2005; Parsons, Travis \& Simpson, 2005).

Specific to the research literature on science learning, Jenkins (2005) described a large project that documents student voice in relation to science education in the United Kingdom, while Parsons, Travis, and Simpson (2005) described student preferences regarding culturally congruent science instruction with respect to Black Cultural Ethos (BCE) in the United States. Jenkins (2005) reported on a Student Review of the Science Curriculum that was undertaken in England in 2002. In this study, 1,493 students participated in a web-based questionnaire involving 55 questions. These questions came from a range of issues that concerned young people based on several regional meetings in England. The results of the study concluded the students want more discussion in science, more relevance especially in the physical sciences, and they want to engage with ethical and controversial issues in science. Parsons, Travis, and Simpson (2005), on the other hand, used a questionnaire to gain information regarding students' preferences in teaching practices in a middle school located in a large school district in the southeastern United States. The preferences for culturally congruent teaching practices indicated by 
students where then integrated into the design and enactment of curriculum. However, in contrast to more participatory approaches, students did not give input regarding how these changes were to be enacted and if they actually were beneficial to learning. Instead, teachers planned the improvements and pre- and post-tests based on standardized tests were used to compare students who received the intervention with those who did not. The outcomes did show that students test scores increased when teachers used teaching practices related to $(\mathrm{BCE})$ but there was no documentation of why or how this came to be. Furthermore, in both of the studies described in this paragraph there is little focus on building trusting relationships with students and on gaining a deep understanding of students' perspectives.

Critique of literature related to student voice. Research projects that focus on student voice present important opportunities to change mainstream educational policies to be less marginalizing, to transform schools, and to create an engaged citizenry. However, this will only come about if projects are designed in a way that students' voice is paired with building relationships of trust with students and with following through in creating transformational change. Susino and Haya (2014) and Mitra (2004) described such transformational projects. Though other projects (Jenkins, 2005; Parsons, Travis, \& Simpson, 2005) highlighted important aspects regarding student perspectives and avenues for improving teaching practices they do little to engage students in becoming part of the solution to the problems presented. The risk of such a project is that it may ultimately disempower students who are heard but who do not have a chance to act. These projects are powerful examples that will influence my research design and methodology as described in the next section. 


\section{Review of the Methodological Literature}

One's research methodology is inextricably linked to "the research question, the context in which one is trying to answer it, and the objectives of the research" (Vogt, Gerner, \& Haeffele, 2012, p. 49). Given this, it may be helpful at this point to unpack the three considerations mentioned in the above sentence before going further depth into the design of the study. First, I would like to be clear that the objectives of the study were (a) to document student perspectives on equity-based STEM teaching practices in the context of one classroom, and (b) to understand the role that student voice can play in informing a design process focused on creating equity-based teaching STEM practices. These objectives are linked to the context of classrooms and extend to the scope and magnitude of educational problems that have led to the current lack of equity in STEM learning environments. This demands research that is more effective in creating changes in these very same environments (Gutiérrez, 2002; National Academy of Education, 1999). Traditional research studies focused on generating new knowledge, while traditional design work focused on designing practical solutions to practice-based problems. Both of these approaches do not sufficiently address the complexity of classroom life and have fallen short on creating equitable experiences for students. Design experiments in educational research, on the other hand, seek to combine these two domains to create a methodology that is simultaneously pragmatic and theoretical (Cobb, Confrey diSessa, Lehrer, \& Schauble, 2003). In other words, design research looks to develop interventions that create robust learning ecologies (pragmatic) while also explaining why the particular design works (theoretical). In so doing, design research addresses the gap 
between theory and practice because theory and practice are two sides of the same coin in design experiments (Cobb et al., 2003; National Academy of Education, 1999)

Another aspect of design experiments that lend themselves to the objectives of this project and the context of the study is the possibility to involve a diverse group of stakeholders in the design process. Traditional research may dehumanize research participants. In these cases, participants are treated as objects or numbers in a data set and do not have opportunities to share their individuality, creativity, or humanity (Smith, 1999; Paris \& Winn, 2014). It has all too often been the case that these outcomes further disempowered marginalized populations who are objectified and described in terms of deficits. However, participatory and critical paradigms seek to do research "with" participants in contrast to "on" participants (Heron \& Reason, 1997; Skovsmose \& Borba, 2004; Smith, 1999). This explicit move positions participants as knowledgeable about their context and shifts the locus of control from that of the researcher holding the power to a dialogue between researcher (who is now also a participant) and participants. A very recent emerging methodology that draws on similar work in community health projects is Community-Based Participatory Research (CBPR) by Cadwell et al. (2014). CBPR "is a "participatory research" approach, which has a core philosophy of inclusivity, emphasizing community engagement in the design of the research that responds directly to the community needs" (Cadwell et al., p. 2). Emphasizing community engagement and community needs changes the power dynamic that currently exists in educational institutions and in traditional research projects, which both have failed to create equity using top-down approaches. Rather CBPR taps into the collective wisdom of community members to not only create equitable learning environments, but 
also to empower stakeholder groups to become more involved in their local education institutions. One important consideration when designing the methodology for this research project is working within the constraints of doing action research and teaching. Both of these roles have important responsibilities that create constraints for doing research. These constraints can be viewed as an opportunity for a "reality check" about what is actually possible in a classroom environment as a teacher of young students.

In Table 2.1, I restate my two research questions and identify the data I collected to answer them.

Table 2.1

Research Questions and Data

Research Question Data

What equity-based STEM teaching

Observation practices do students in this study Student work perceive as supporting their interests and aspirations?

Discussion notes

In what ways can student voice inform a design process for equity-based STEM

Observation teaching practices?

Student work

Discussion notes

Each research question uses the same data set but looks at the data from different vantage points. For example, question 1 concerns how students perceive equity-based practices as it relates to their interests and aspirations. Question 2 is not focused on the student perspective, but on the role that student voice could play in a design process more broadly. You will notice that interviews have been crossed off. In my initial IRB 
proposal, I worked as an outside researcher with a participating teacher and middle school students. When I changed my context to that of my own $2^{\text {nd }}$ grade classroom, the IRB did not approve interviews with students because of a perceived threat to their wellbeing. This points to the need to understand the relationship between student and teacher and how this may change or not change when doing research. Undoubtedly, more work is required to understand how a teacher can do participatory research with their own young students if we value these types of projects.

\section{Collecting data on student perspectives on equity-based teaching practices.}

The first question used several different data sources. I followed Cobb and colleagues' (2003) recommendation to gather a broad range of data but to focus within this broad range on data that would inform the research question, in this case, the teachers understanding of student voice. It is important to note, the student voice is filtered through teacher understanding to make sense of the different ways that young students communicate their viewpoint. For example, when engagement in a learning activity is lacking, I see that as feedback that the learning activity is not meeting the needs of some students. Young children will not always be able to articulate that they were disengaged or why they were disengaged. However, by making observations, interpreting those observations, and then testing those interpretations one can get a feel for a student's perspective. Such data collection and interpretation requires a coordination of data sources regarding the teacher (myself) and the students. These include how the teacher implements equity-based practices, artifacts of learning, and classroom interactions. Of special interest is how whole-class conversation notes reflect on the teaching and learning experience with the teacher and students. This helps to create a shared understanding of 
what happens in the classroom and attribute meaning to salient events. These wholeclass discussions are a scaffolded reflection on classroom events and are critical in creating intersubjectivity (Heron \& Reason, 1994) regarding the experiences. Such an intersubjectivity is created when incorporating multiple perspectives about events into a holistic understanding of what happened. Within this broad set of data, I focused on instances where students evaluated equity-based STEM teaching practices.

\section{Collecting data on the role that student voice can play in a design process.}

Student voice plays a critical role in designing equity-based STEM teaching practices. Hence, it is important to use the data set to answer the question as to how student voice influences the design process. What would we not know if we do not ask students? What is essential about their involvement? Moreover, keeping track of modifications we make to equity-based STEM teaching practices and how students perceive these modifications should help the research team understand in how student voice is an irreplaceable component. The research process might have a positive or negative impact on students. As researcher we have an ethical mandate to think critically about the appropriate role for students, how the research team positions students, and in what way this influences their experience, so that this project did not become a marginalizing research experience for participants.

\section{Summary}

Social constructivists see all knowledge, including STEM subjects, as situated in a sociocultural context. Western STEM disciplines have a privileged status in the current market-based Eurocentric sociocultural context and this has led to education practices that further disempower historically marginalized communities that do not share this 
same sociocultural context. Equity-based STEM (or, E-STEM) teaching practices related to STEM content and process, CRP, and SEL seek to counteract this marginalization on various levels. However, an important question to ask is who decides what is equitable. Research indicates that student voice can play a transformational role in informing decisions and design processes in educational environments. This project incorporated a participatory design process that centers on student voice in designing equity-based STEM teaching practices. In the following chapter, I more fully present the methodology of the research project, while in the subsequent chapters, I present the data analysis and synthesize the data to make specific recommendations for practice. 


\section{Chapter 3: Methods}

Teacher researchers pause each morning as they walk into their classrooms and ask, "What will my students teach me today?" To answer that question, they listen to and watch their students engage in authentic work; collect work samples, photographs, and transcripts to document what their students say and do; and use that information to evolve their practice as they celebrate and support the voices and experiences of the children they teach. In this sense, teacher researchers are innovators, curriculum drivers, agents of school change, and directors of their own professional development. (Suskind, 2016, para. 1)

Providing all students equitable access to STEM education is a pressing concern for our society. Whether it is to increase economic participation, to empower learners to understand and change current societal conditions, or to become happy and healthy citizens, there is an urgent need to improve educational outcomes for all students. New policy mandates, particularly since the No Child Left Behind Act of 2001, including standards documents and accountability measure, are being adopted by individual states (Darling-Hammond, 2007, Dee \& Jacob, 2011). Standards and accountability measures resulted in scripted curriculum, loss of teacher autonomy, and a hyper focus on academic outcomes. However, adopting standards, accountability measures, and relying on commercially produced curriculum did little historically to change educational outcomes (Darling-Hammond, 2007, Dee \& Jacob, 2011). As described in Chapter 2, research suggests that classrooms become high quality learning environments when teachers and students are engaged in productive teaching and learning practices that support all students' social, emotional, and academic growth. Teacher researchers, as described in the above quotation, are at the forefront of working with their students to develop and disseminate knowledge about how to create such learning environments. In Chapter 2, I described the research evidence supporting the idea that students and teachers can co- 
create learning environments that support high levels of engagement using equity-based STEM teaching practices. However, there are limited examples of how teachers and students can work together to create such sustainable learning environments. For this reason, in this study, I investigated the following questions:

1. How do students and teachers negotiate equity-based STEM teaching practices?

2. How do different enactments of STEM teaching practices influence student and teacher engagement?

The purpose of this project and research questions influenced my choice in methodology. In Chapter 3, I build on the methodological review to explain further the chosen methods and the reasons for their selection. I also describe the actions and rationale for the following aspects of the study: participants, procedures, instruments, and measures, role of the research, and data collection and analysis.

\section{Research Methods}

Paradigms guiding the project. Guba and Lincoln (1989) argued that inquiry paradigms are basic sets of beliefs about the nature of reality and how it can be understood. These beliefs may be instilled throughout the course of our lives, and engaging in scholarly research is an extension and refinement of these beliefs. Qualitative research is guided by a set of assumptions that answer four following underlying questions:

- The ontological question, "What is the form and nature of reality and how can we know it?" 
- The epistemological question, "What is the nature of the knower and known?";

- The axiological question "What is the role of values?"; and

- The methodological question, "How can the researcher answer his or her question?" (Creswell, 2013; Guba \& Lincoln, 1989; Heron \& Reason, 1997).

In the following section, I briefly describe my positions on these questions and explain the rational for why I chose to use a participatory design grounded in a qualitative worldview for this study.

Ontology. An action research study grounded in qualitative inquiry seeks to interrogate reality from multiple points of view throughout a design process (Cobb et al., 2003). Creswell (2013) stated, "When researchers conduct qualitative research, they are embracing the idea of multiple realities" (p. 56). Given this assumption in a qualitative worldview each individual has their own reality and the researchers task is to report on different but not competing realities, as they exist. An essential component of the proposed design research project is reporting on the different experiences of participants who are taking part in the designed interventions and design process pertaining to my investigation. However, merely reporting on realities of groups of people does little to change these realities. As an educator, I have an ethical commitment to intervene to create positive outcomes for my students. Therefore, I argue for a transformative or participatory study that is characterized by participation between the researcher and communities/individuals being studied (Creswell, 2013; Heron \& Reason, 1997). Such a study hopes to mirror closely classroom practices that encourage student voice and choice in the classroom. 
Epistemology. A participatory worldview assumes that knowledge is constructed through participation where we simultaneously shape reality as we meet reality. Heron and Reason (1997) described experiential knowing as participation, "and to participate is both to mold and encounter; hence, experiential reality is always subjective-objective" (p. 279). In other words, in whatever we do, our thoughts inform how we see the world while simultaneously shaping the world that exists. In teaching, this co-creation of experiential reality is an important avenue for improving student engagement and learning as teachers are increasingly asked to facilitate learning rather than rely on more passive forms of learning such as direct instruction. Much of the research done on students does not acknowledge this co-creation of experiential knowledge and consequently sets up an imbalanced power dynamic (Paris \& Winn, 2014; Smith, 1999). For that reason, a transformative or participatory study positions the participants on equal footing as the researcher, and research is thought of in terms of doing research "with" people as opposed to "on" people. This equalizes power differentials between researcher and participant and takes a political stance towards the empowerment of individuals and communities. A complication of this study that I address more thoroughly in later sections of this chapter is that a teacher doing research "with" young students is seen as inherently risky due to the power dynamic that has been socially constructed by even very young students.

A participatory worldview informs an epistemology that sees knowledge as a coconstruction where multiple points of view inform the creation of new knowledge (Creswell, 2013). Central to such an epistemology is to encounter or experience what is to be co-constructed (Heron \& Reason, 1997). For this reason, the researcher's role is 
intractably tied to participation in the context. Participants' voices are strengthened due to privileging the knowledge that is being constructed, through participation. However, with such multiplicity how does one contend with coming to a conclusion that is not purely subjective?. Heron and Reason (1997) contended that critical subjectivity, which integrates experiential ways of knowing with intuitive, conceptual, and practical knowing, allows such conclusions to be made.

It means that we do not suppress our primary subjective experience but accept that it is our experiential articulation of being in the world., And, as such it is the ground of all our knowing. At the same time, we accept that, naively exercised, it is open to all the distortions of those defensive processes by which people collude to limit their understanding. So, we attend to it with critical consciousness, seeking to bring it into aware relations with the other three ways of knowing so that they clarify and refine and elevate it at the same time as being more adequately grounded in it. (p. 282)

In other words, there is an interplay between subjective and objective, which creates a grounded knowledge that is self-aware, and through this awareness is able to reach towards the development of theory. In participatory design research, it is essential to garner a diversity of perspectives, and then use the lens of critical subjectivity to develop an understanding of the context that can lead to better-informed action. As this process of reflection, revising, and action iterates, ideas and theories are continuously being co-constructed, tested, and revised bringing about enhanced activity within the learning context. In this way, the research process closely mirrors what teachers do on a daily basis. The difference is that in such a research process the data collection and analysis formalizes the learning and allows participants to develop deeper understanding of the situation. 
Axiology. Given that the participatory design process of this project has a goal of empowering young students, it is important to think critically about the axiological question of what we value and think about how this informs our interactions. The axiological question is essential if we wish our projects to be successful in creating positive changes in the world. Participatory and transformative qualitative studies have a respect for values of the participants and see researcher values as needing to be problematized due to their inherent bias (Creswell, 2013). Similar to a sociopolitical perspective that asks important questions about whose values are privileged and who has access to influencing dominant discourse around education, participatory and transformative studies ask these same questions about whose values within the research are privileged and who has access to influencing that course of the study. Central to the participatory paradigm is being explicit about our own values and biases and drawing out participants' values and biases to create a context where there is a balance between who we are as a collective and who we are as individuals. In the section on positionality, I detail my own assumptions and discuss how these preconceived notions changed during the course of this research. Heron and Reason see this "re-shaping" as a state of human flourishing, which is described as "an enabling balance within and between people of hierarchy, cooperation, and autonomy" (Heron \& Reason, 1997, p. 287). In their view, research projects are successful when the tensions that exist when deciding for others, with others, and for oneself are managed to create practical knowing that allows human flourishing. Participatory and transformative projects explicitly value understanding one's own values, the values of others, and then improving the current situation to one that is more beneficial for all participants. 
Methodology. The last question, methodology, is concerned with how can participatory design projects achieve the goals of improving educational contexts and developing theory about these same educational contexts. In qualitative inquiry, researchers work with details of a study before making generalizations, include detailed descriptions of context, and continually revise thoughts and questions from the field (Creswell, 2013). The researcher has various ways that they can access sites, work with participants, and gather data. Similarly, with design research there are many methodologies that can be used to design successful interventions and develop theory (Cobb et al, 2003). In the case of participatory design research, there is an emphasis on developing relationships with participants and involving them in the design process that is not included in general forms of qualitative inquiry or design projects. An inquiry methodology that involves participants in the design process enhances critical subjectivity with critical intersubjectivity as a "collaborative form of inquiry, in which all involved engage together in democratic dialogue as co researchers and co subjects" (Heron \& Reason, 1997, p. 283). Such a collaboration, in both an iterative design process and a cyclical research process, allows participants and researchers to come to new ways of knowing that are grounded in their shared way of knowing. Given that this collaborative form of inquiry involves $2^{\text {nd }}$ grade students and their teacher, what counts as participation and how participants voice their perspective looks different than if this study had been done with older students who have more direct ways of expressing their perspective. Furthermore, as previously mentioned, there are important considerations regarding the socially constructed power differential between student and teacher that must be carefully planned for so as to not create an uncomfortable situation for students. 
These points will be addressed further in the research design and rational section. The methodology of this study is effective when the researcher and participants gain a better understanding of the research questions and/or teaching and learning is enhanced because of the better developed understanding.

In summary, each of the questions regarding ontology, axiology, methodology, and epistemology are linked to one another. Such an interdependent and related web of beliefs and assumptions is essential in designing a study that is flexible to context, yet rigorous throughout (Maxwell, 2013). Similar to good teaching, good qualitative research is very much context dependent. Having a clear understanding of beliefs and assumptions and how they are interconnected allows the practitioner to adapt and adjust to context- specific conditions without changing the nature of the overall goals and objectives. This does not mean that such flexibility is not fraught with tensions. It may be that the skill of the researcher is how one manages these tensions to achieve the overall goals and objectives of the project while continually remaining grounded in the beliefs and assumptions underlying the project.

Research design and rational. The following section connects the previously described philosophical assumptions with the chosen research methodology. Participatory design research draws from design research, the participatory or transformative paradigm, and may most closely resemble Community Based Participatory Research (Cadwell et al., 2014). It differs from CBPR because it is not as strongly focused on community stakeholders and more ardently focused on educational stakeholders, with an emphasis on strengthening student and teacher voice. Currently few studies use this design. However, aspects of the research design that synthesized in 
this study are discussed throughout the current literature regarding educational research

design (Cobb et al, 2003; Creswell, 2013; Heron \& Reason, 1997; Maxwell, 2013).

Table 3.1 includes the four phases of the design research in the left column. The

remaining four columns contain the four paradigms guiding the research project. Each of the cells in these columns describe the specific research phase in relation to the paradigm questions discussed in the previous section

Table 3.1

Research Design and Paradigms

Paradigms Guiding the Project

\begin{tabular}{|c|c|c|c|c|}
\hline $\begin{array}{c}\text { Aspects of } \\
\text { Research Study }\end{array}$ & $\begin{array}{l}\text { Ontology: } \\
\text { multiple points } \\
\text { of view }\end{array}$ & $\begin{array}{l}\text { Epistemology: } \\
\text { knowledge } \\
\text { through } \\
\text { participation }\end{array}$ & $\begin{array}{c}\text { Axiology: What } \\
\text { we value }\end{array}$ & $\begin{array}{l}\text { Methodology: } \\
\text { How it is done }\end{array}$ \\
\hline $\begin{array}{l}\text { 1. Developing } \\
\text { relationships } \\
\text { with students }\end{array}$ & $\begin{array}{l}\text { Relationships } \\
\text { helps students } \\
\text { share their } \\
\text { points of view. }\end{array}$ & $\begin{array}{l}\text { Relationships are } \\
\text { built through } \\
\text { negotiation about } \\
\text { aspects of } \\
\text { classroom life. }\end{array}$ & $\begin{array}{l}\text { Valuing } \\
\text { relationships } \\
\text { ensures that } \\
\text { participants have } \\
\text { a positive } \\
\text { classroom } \\
\text { experience. }\end{array}$ & $\begin{array}{l}\text { Building } \\
\text { relationships } \\
\text { happens as } \\
\text { participants are } \\
\text { given influence } \\
\text { over aspects of } \\
\text { classroom life. }\end{array}$ \\
\hline $\begin{array}{l}\text { 2. Developing } \\
\text { and } \\
\text { understanding of } \\
\text { beliefs and } \\
\text { biases }\end{array}$ & $\begin{array}{l}\text { Listening to } \\
\text { multiple points } \\
\text { of views allows } \\
\text { participants to } \\
\text { become aware } \\
\text { of beliefs and } \\
\text { biases. }\end{array}$ & $\begin{array}{l}\text { Discussions } \\
\text { about beliefs and } \\
\text { biases help } \\
\text { participants } \\
\text { negotiate a } \\
\text { shared set of } \\
\text { understandings. }\end{array}$ & $\begin{array}{l}\text { As participants } \\
\text { develop an } \\
\text { understanding of } \\
\text { the group's } \\
\text { beliefs and } \\
\text { biases they are } \\
\text { able to generate } \\
\text { more positive } \\
\text { experiences. }\end{array}$ & $\begin{array}{l}\text { Students develop } \\
\text { an understanding } \\
\text { of their own } \\
\text { beliefs and } \\
\text { biases and move } \\
\text { beyond them as } \\
\text { they develop a } \\
\text { collective } \\
\text { understanding. }\end{array}$ \\
\hline $\begin{array}{l}\text { 3. Planning } \\
\text { Intervention } \\
\text { with Students }\end{array}$ & $\begin{array}{l}\text { Including } \\
\text { participants in } \\
\text { planning the } \\
\text { intervention } \\
\text { allows their }\end{array}$ & $\begin{array}{l}\text { Participation in } \\
\text { the planning of } \\
\text { the intervention } \\
\text { generates a } \\
\text { shared }\end{array}$ & $\begin{array}{l}\text { Valuing student } \\
\text { input helps } \\
\text { participants feel } \\
\text { involved in the } \\
\text { project. }\end{array}$ & $\begin{array}{l}\text { Intervention will } \\
\text { be planned in } \\
\text { response to } \\
\text { student } \\
\text { feedback. }\end{array}$ \\
\hline
\end{tabular}


viewpoint to be understanding of

included. what is be tested.

$\begin{array}{lllll}\text { 4. Participatory } & \text { Including } & \text { Discussion of } & \text { Including } & \text { Participants } \\ \text { Design Process } & \text { participants in } & \text { what happened } & \text { participants in } & \text { discuss what } \\ \text { to adjust and } & \text { giving feedback } & \text { helps participants } & \text { reflection helps } & \text { went well and } \\ \text { Revise } & \text { ensures the } & \text { create a shared } & \text { participants see } & \text { would could be } \\ & \text { potential } & \text { understanding of } & \text { that their input } & \text { improved about } \\ & \text { problems are } & & \text { causes changes } & \text { instruction }\end{array}$
fully explored

Each phase of this research project is connected to and supports the others.

Furthermore, each research phase is connected to the overall guiding paradigms. In the next several paragraphs, I briefly discuss each of the phases and further explain the rationale behind emphasizing these phases during the design research. In the "Procedures" section of this chapter, I discuss the process for each phase and special considerations in doing such research with $2^{\text {nd }}$ grade participants as a teacher/researcher.

Essential for a research methodology that seeks to empower individuals and communities is to develop relationships. Maxwell (2013) stated, "The relationships that you create with participants in your study... are an essential part of your methods" (p. 90). He went on to describe the need to develop relationships that allow for access to authentic data collection and as a means to get the research done. However, such a view of relationships positions the relationship as a means to an end and may inadvertently marginalize participants. The participatory or transformative paradigm, on the other hand, sees relationship as an end in itself and an important part of the construction of knowledge. Diaz-Strong, Luna-Duarte, Gómez, \& Meiners (2014) stated that only through collaborating for transformation "can we honestly question who we are at the backdrop (of forefront) of who others are in relation to us, in relation to how we perceive 
them and they us, and in relation to sustaining meaningful relationships" (p. 27). It is through relationship that we are fully able to develop our ideas because we begin to see ourselves, and others, in light of an expanding world-view. Establishing such relationships are an essential part of a participatory design research process.

Designing the initial intervention in this design project was a collaborative process that involves the synthesis of the research literature outlined previously, participant's backgrounds and identities, and the STEM content that is to be learned as proposed by the Next Generation Science Standards and Common Core State Standards. To guide and structure the planning for a design experiment Cobb and colleagues (2003) recommended framing a design experiment around "conjectured starting points, elements of a trajectory, and prospective endpoints" (p. 11). I see the conjectured starting points as what is known about participants from the relationships that have been established. It is important to have a clear understanding of the students' values and interest as they relate to STEM learning and peripherally, an understanding of their content knowledge. This background understanding, the views of multiple participants, and the conceptual framework feed into a proposed trajectory where we imagine how the current situation can be improved upon. Finally, I see the endpoints of the project as what we imagine that we can do in the timeframe given to the intervention. The challenge in this process is designing the intervention in a way that allows students to participate meaningfully and to see that their participation is leading to the generation of new ideas.

Engaging in the initial work of developing relationships, explicating values and interests, and designing the intervention lead up to the main event of conducting the design experiment. As the design experiment is enacted, it is be important to revise and 
adjust expectations of the researcher and the participants involvement. Such a revision is be important because this study needs to be practical and needs to affirm and strengthen the relationships of the participants. A particular challenge as a teacher/researcher during the iterative design process has been balancing competing responsibilities towards students and the school community, towards self, and towards the research community. This challenge brings to light important considerations of what practice-based research can look like and what the benefits are for students, teachers, and the research community.

Research context. Western Elementary School (a pseudonym) is located in a medium-sized city with approximately 80,000 residents. Western Elementary school is located on several ecological, social, and cultural boundaries. Ecologically, Western Elementary sits between the Forested Eastern Cascades and Foothills and the Northern Basin and Range Ecosystems. Thirty miles to the west receives an average of 80-100 inches of rainfall while 30 miles to the east receives less than 20 inches. This difference in rainfall amounts contributes to an enormous amount of biodiversity in a relatively small area.

Humans have inhabited this area for thousands of years. A few hours to the south, the evidence of human occupation dates to 14,000 years ago (Jenkins et al., 2013). During the 1820's the Northern Paiute lived in the area (Voegelin, 1955). After contact with European-American settlers, diseases, forced relocation, and war expelled them from their homeland. In 1872, the Northern Paiute signed a treaty with Ulysses S. Grant setting aside the 1.4 million acre Malhuer Indian Reservation. This land would have enabled the Northern Paiute to continue living their tradition lifestyle. Many bands of the 
Northern Paiute from the region moved to this reservation. However, several years of pressure from European-American settlers and involvement in the Bannock Indian War caused the government to terminate the reservation in 1879 and relocate the tribe to the Yakima Indian Reservation. During the march north, many Northern Paiute people died, and thus, many never again saw their homeland.

The following section describes the history of European-American settlement and the development of Central Oregon (Wikipedia contributors, 2019). European-American settlers continued to arrive in the region as suitable land to the west of the Cascades was no longer available (Wikipedia contributors, 2019). Though they found land, much of it was not suitable for farming and ranching due to the lack of water. In the early 1900s, settlers dug irrigation canals throughout the region. The water drawn from the region's rivers had an enormous impact on the health of these rivers. This is also the time that logging operations commenced. The area's first immigrants coming for employment in the logging industry were from the Scandinavian countries. Later logging immigrants came from Eastern European countries. There was considerable backlash regarding the Eastern European immigrants including the formation of a Klu Klux Klan group during the 1920s (Father Luke, the KKK, 2017). Progressive forces eventually suppressed this group, but many Eastern European immigrants felt compelled to Americanize their customs. From the early 1900s to the 1980s, the city's economy centered around logging, farming, and ranching. Over the course of these 80 years the areas rivers, forests, and grasslands where severely impacted by the resource intensive economy.

Western Elementary School was built during the early 1980s as an eastern outpost to a growing school district. It is brick building with 20 classrooms, a 
gym/cafeteria, a music room, a library located in the hub of the school, and a front office. Each classroom has one small window. Western Elementary School has a very large grassy field that is irrigated year-round from one of the adjacent canals. The school is surrounded by farm fields and abuts a sports field park with a large natural area. During the 1980s and 90s the school served a rural population.

In the 1990s the logging industry was no longer as profitable due to environmental regulation, and the town mill shut down. However, tourism and the housing market took its place as the economic driver of the region. During this time, the town was one of the fastest growing in the United States. Many farms and vacant lots around Western Elementary School turned into housing subdivisions. The housing prices in the eastern side of town were much more affordable than on the western side of town. Many working-class families moved to the more affordable area of town during this time. Then in 2006, the housing market collapsed and the town experienced massive unemployment. The collapse hit the working-class families the hardest. The $2^{\text {nd }}$ grade students who worked with me on this project were born during this time.

When I started working at Western Elementary in the 2015-16 school year, families reflected a growing economic diversity in the region. At this point, most families that had experienced economic hardship during the 2006 recession had recovered. However, Western Elementary was still a Title 1 school with $44 \%$ of students coming from economically disadvantaged households (Oregon Department of Education, 2019). Currently, the school is in danger of losing Title 1 status, as only $38 \%$ are considered economically disadvantaged. In addition to increasing local prosperity, population demographics have changed because of families moving in to the area. 
Whereas, before the housing boom and recession the school population was mainly rural children whose families had lengthy histories in the area, now there is a mixture of families, including families that have moved from more populated areas on the west coast, families that have moved to east Bend to find affordable house, and families from areas that have historically attended Western Elementary. Income earners for families are employed in a diversity of jobs including health care, home building, engineering, K12 education, and service industries.

In the 2016-17 school year, 590 students attended Western Elementary. The demographics for the student population were $86 \%$ White, $8 \%$ Hispanic/Latino, and $4 \%$ Asian (Oregon Department of Education, 2019). The lack of cultural diversity at Western Elementary, and in the city itself, is striking. Part of this lack of diversity is intentional. For example, the Northern Paiute who originally inhabited the area were forcibly relocated (Ruby, Brown, \& Collins, 2013). In addition, when Oregon was first founded, the Oregon constitution banned African American settlers (Taylor, 1982). In additional to intentional exclusion, diverse groups may have been further marginalized due to implicit bias. Implicit bias is when peoples' stereotypes and beliefs effect thoughts, actions, and decisions unconsciously. Historically the types of employment available in the region and intentional exclusionary practices attracted EuropeanAmerican people. Such a homogenous community had little experience with minority groups such as, African Americans, Latino/Hispanics, Asians, and Native Americans. I speculate that with little exposure to racially diverse groups of peoples, implicit biases may have created racial barriers the barred diverse groups of people from moving to the area. More recently, the growth of the housing industry in the 2000s created an 
affordable housing shortage that further exacerbated this situation. The demographics of Western Elementary are a product of explicit and implicit biases and economic forces that have created a homogenous European-American school population.

Though racially homogenous, there is a significant amount of socio-economic, political, and individual difference or within group diversity. For example, economically our school serves a very diverse group of families with $44 \%$ of students receiving free or reduced-price lunch during the 2016-17 school year. Additionally, 12\% of students are diagnosed with learning disabilities (Oregon Department of Education, 2019). One hidden problem that does not show up in the published data about our school is the students who have difficulty managing their behavior. Similar to national trends across our state, student behavior needs have increased while funding supports has decreased (Roemeling, 2018). In some classrooms, students' explosive and unsafe behavior necessitates clearing the room of students several times a week. Students coming from economically disadvantaged homes, having behavior needs, and having learning disabilities, may at times need additional supports to experience an equitable learning environment. Furthermore, the students from advantaged backgrounds may need additional supports to make a classroom more equitable for all students. Sometimes the advantaged students who do not recognize their own privilege have a hard time understanding what it might feel like not having those same privileges. For this reason, focusing on equity benefits all students because students learn how to create a community of learners that respect each other's differences. In my experience, politically, the area around Western Elementary has a mixture of competing political perspectives. Historically, the congressional and senate seats have been Republican. However, as 
families move to the area from major West Coast cities the region is starting to look more and more democratic in their political affiliations. Discussions on the day that our current president was elected showed clearly that the students at Western Elementary come from families with a wide array of political perspectives.

When I first began teaching at Western Elementary School in 2014, the district had just adopted a new reading curriculum. It was the second curriculum that had been adopted since high stakes testing and accountability measures were put in place 12 years ago. During the first round of adoptions, teachers were asked to follow the curriculum with fidelity. Many teachers who had significant experience teaching were told that they were no longer allowed to design their own units of instruction. This upset many teachers initially, but by the time I arrived at the district, it was accepted practice that everyone would follow the curriculum with fidelity. The previous principal and a teacher who changed careers from engineering were dissatisfied with the lack of a well-rounded curriculum at Western Elementary. They wanted students to learn science and engineering concepts through project-based learning. The idea was proposed to staff and the work of developing a STEM school was begun. Though Western Elementary is a designated STEM school, they do not receive additional money or professional development funds from this designation. The PTA holds several fundraisers that support the STEM mission including a school dance, a spaghetti night called STEMghetti, and a giving letter. The giving letter asks families to donate money and replaces the fundraising via the sales of cookie dough and wrapping paper.

Participant sampling and rationale. Purposive sampling was selected as the method for this study. Plano-Clark and Creswell (2010) described purposive sample as 
when researchers "intentionally select sites and individuals to learn about or understand the central phenomena" ( p. 254). The research site was selected because it is a selfdesignated STEM school with a unique profile of intersecting economic, social, and political boundaries in a developing rural region. The current milieu provides an important context to study E-STEM learning practices because of the challenges associated with implementing these practices during a time of evolving demographic and educational change. This change creates a certain amount of turbulence as teachers and students attempt to work together against the backdrop of standardized testing pressures, mandated curriculum, and inadequate resources in the classroom. Teachers and students working together to create more E-STEM learning experiences is a research context that needs further exploration. Describing the research context and detailing how a classroom teacher, in this case myself, and students manage this turbulence to create an equitable learning environment is an important outcome of this research study. A limitation of purposive sampling is that participants are not chosen randomly. This is a limitation because the sample may not be representative of a larger group from which generalizations can be made (Krathwohl, 2009). However, this is not a concern for my study because I am not seeking to make generalizations based on representativeness of a group. Rather, I am seeking to build theory within a specific context and for that reason, my sampling methods focused on finding a context and participants that lend themselves to the research question and the design of the study. In other words, I am studying my own practice with my students to gain better understanding of E-STEM learning practices. 
This study concentrates on the students and educators associated with a 2nd grade general education classroom during the last 10 weeks of the school year. During this time, I worked with students to learn about local landforms, plants, and pollinators. I designed the STEM units collaboratively with my students, our outdoor education partners, and the land we live in. I incorporated the land that surrounds us as a participant in curriculum design because this shared place gives us much to consider and is a starting point for learning. Furthermore, I designed these units to address NGSS and CCSS standards. I also designed the units in anticipation of student connections and experiences based on careful listening to students over the course of the year. As I enacted the unit with students, I adapted and adjusted the units to include students' emergent questions, interests, and learning needs. The goals of the units were that students: (a) develop a shared understanding of their local environment, and (b) be empowered to learn more about this environment in the future. The role that students played in the co-creation of these units was an important focus of the study because there is a limited research base detailing young students and teachers working collaboratively. Finally, how I positioned students had an impact on their developing identity and their willingness to identify with STEM disciplines (Barton \& Tan, 2010; Holland et al., 1998; Rahm \& Moore, 2016). Casting students as co-designers in their own learning was a deliberate move to boost their engagement in learning and subsequent positive identification with STEM learning experiences. Whereas in the aforementioned section of this paper, I described the participants, how they were chosen, and what transpired during the timeframe of the research project, in the following section of the paper, I describe the procedures enacted with the participants. 
Procedures. Participants in the research study described in the previous section will be involved in testing different equity-based STEM practices. These practices were an intervention to address student engagement in STEM disciplines. I describe these equity-based practices in the data analysis chapter; these come from the research base shared in the literature review. I embedded the teaching practices in several STEM units that have their starting points in investigating local landforms and understanding the relationships between the needs of plants and pollinators. These units included field experiences at the local city park behind the school, a National Volcanic Monument, and a meadow and waterfall site that has been a part of the studies throughout the year. An explicit outcome of the unit was that students saw themselves as an integral part of a supportive classroom community engaged in STEM disciplines to learn about their world.

A special consideration of this study was to minimize risk to students of being pressured to be a certain way or give certain feedback because the researcher is also their teacher. A large concern was that students in $2^{\text {nd }}$ grade may feel coerced to participate or may feel uncomfortable given the power dynamic between student and teacher. In applying for IRB approval, major revisions had to be undertaken to take this into consideration because of the students' age and the previously mentioned power dynamic. In general, students' experience of this research study was only slightly different from their experience of regular classroom life. This was critical because the teacher is also researcher and to change a student's experience of $2^{\text {nd }}$ grade to do research takes away their right to a $2^{\text {nd }}$ grade experience. Unfortunately, this means that students had less direct voice in the participatory design process and it may have limited the outcomes for 
participants. For example, because I could not do interviews or smaller discussion groups to gather data on students' perspective, I used observational notes after teaching to gather data. This means that students who may have had important things to say were not heard because I was unable to ask them. For this reason, outcomes for students were necessarily different than if their participation and voice was included more strongly. The upcoming section will detail the design of the study and explain how the design minimizes risk of coercion to students.

Informed consent. There were 24 students in the class who worked with me on this research study. All students participated in regular whole group classroom activities. I protected their anonymity by only taken notes and gathering work that did not include student's names. I obtained informed consent from students so that as the researcher, I could look at individual student's assignments. A third party invited all students to participate so that they do not feel coerced to join the study. The third party held all informed consent forms until after the study and school year was completed. This reassured students that whether or not they participated, it would not influence their interaction with me, the teacher. The third party chosen was our school librarian. She has weekly contact with all students and has developed a trusting relationship with students over several years. The librarian explained the research study to students and let students know which parts of the study did not require their consent and would be anonymous and which parts of the study required their consent and would be confidential. Informed consent forms were sent home with students and brought back to the librarian. Parents of students could call the third party with any questions about the 
study. The librarian kept the informed consent forms in a locked office space until then end of the school year, and then she gave them to me, the researcher.

Procedures used to collect data and design interventions. Given that all students in the classroom participated in the context of the research study, it was important that the teacher/researcher did not in any way negatively impact their learning outcomes. For this reason, data collection and designed interventions were carefully evaluated to be minimally disruptive to classroom routines. Furthermore, it was essential that the data collection not place an unreasonable burden on the teacher/researcher. Such a burden would have impacted the teacher/researcher negatively and then the teacher/researcher could not do the job of taking care of the emotional, social, and academic needs of the students. In other words, that data collection needed to work for both students and the teacher/researcher within the constraints of regular classroom life. Multiple data collection methods met these criteria and were used to help the teacher/researcher and students investigate the previously mentioned research questions. These collection methods included participant observation, collecting artifacts from whole group discussions, and gathering student work samples. After data collection was completed, I analyzed the data within hours and used the results to design subsequent interventions planned for the subsequent days. In the next paragraphs, I briefly describe data collection methods and how interventions where designed.

Participant observation was one of the most important ways to collect data for this type of a study. It is an important and non-invasive part of a teacher's everyday routine. During regular classroom life, observational data is both informal and implicit. However, during this research project, I formalized data collection methods to develop a better 
understanding of my observations and how I was using these observations, to plan future learning events. Teachers rely on establishing strong relationships with students and use these relationships to make sense of observations. Such an intuitive and relational perspective helps teachers fine tune observations and inferences to specific student's profiles. Later in Chapter 3, I discuss the importance of teacher positionality in making sure that an intuitive and relational perspective is balanced within a larger context. The synthesis of an intuitive and relational perspective as well as an understanding of the larger context helps to draw out valid actions regarding improving teaching, and valid claims regarding the research question. Another reason that participant observation was important for this study was that students in $2^{\text {nd }}$ grade often have difficulty expressing abstract concepts that might arise when investigating the research questions. However, students are very good at communicating implicitly through their actions and with words. Words along with actions observed and interpreted by the teacher/researcher through participant observation are one foundation of the research study.

Another data source includes artifacts from whole group discussions. In the research classroom, it is a common practice to write down what students are saying on chart paper when discussing a topic or learning new content. Normally, this practice includes writing down the students name next to their comment or question so that the teacher can refer back to student input. However, to preserve anonymity and include all students, I did not record names during this project. The practice of recording student thinking aligns closely with the dual research goals of investigating the research questions and improving teaching and learning. Recording students' thinking allows students to share their thoughts and questions publicly. This type of engagement is an 
indicator on the efficacy or lack of efficacy of an intervention. For example, if students have nothing to say after a project, it is a good indicator that the project did not increase engagement. Whereas, if students have much to say and offer relevant questions or comments to further group discussion, it is an indicator that the project was successful in engaging students. The practice of recording student thinking also served the purpose of increasing engagement and augmenting identities because students saw that their thoughts and ideas were valued by their classmates and the teacher. Instead of just learning for a grade, students were learning to help build the classroom community or make sense of a particular phenomenon. Furthermore, their publicly shared questions and ideas had an impact on the direction of future learning as I folded their thoughts and ideas into the curriculum design.

An important consideration was that not all students feel comfortable sharing their thoughts and feelings publicly. For this reason, it was important to have other avenues for students to share. Individual and small group assignments provide such an opportunity. These assignments can be directly related to the research question or assignments related to content that can be used as indicators of engagement. Assignments that are directly related to receiving feedback on the research questions and/or designed interventions were anonymous, while regular classroom assignments with student names were only included from students with signed consent forms. At times, it was appropriate for another student to write down what a student wants to say. This was an important consideration because some students in $2^{\text {nd }}$ grade have difficulty writing. Scribing for a student that is still learning to write was an important way to include that student's thoughts in the project. Normally a teacher would scribe for the 
student; however, to protect anonymity it was more appropriate to have another student be the scribe.

As stated earlier, I used three types of data sources-participant observation, discussion artifacts, and student work — to design interventions that increased engagement for all students. In participatory research, a common practice is to have participants engage in analyzing data and drawing conclusions. Originally, it was my hope that there would be a meaningful way to do this with $2^{\text {nd }}$ grade students. However, in this case, the responsibility for students learning the academic content for $2^{\text {nd }}$ grade did not allow additional time to focus on this important phase of participatory research. Doing analysis and drawing conclusions outside of regularly scheduled class times was also not an option because exposing students to such a heightened level of involvement could expose them to an increased risk of feeling coercion. For these reasons, in my role of teacher/researcher, I carried out data analysis and intervention design. In the analysis, it is important to look at indications in the data that appear to point to what is working and for whom, and what is not working and for whom. It is then the teacher/researchers' job to think about the multiple layers of social, academic, and emotional considerations in coming up with future interventions.

Maintaining data. Consent forms were stored in the librarian's locked filing cabinet until the end of the school year. Data and records from all other phases of the study were stored in the researcher's home in a file cabinet. Electronic records were stored on a flash drive in a Dropbox account, and on a password protected researcher's computer. These data will be stored for a minimum of three years after the completion of the project. 
Instruments and measures. Developing instruments and measures that help the researcher and participants gain an understanding of the research questions is a context specific process that needs to be carefully thought through and adjusted throughout the research process. Maxwell (2013) described the relationship between research questions and data gathering techniques:

The development of good interview questions (and observational strategies) requires creativity and insight, rather than a mechanical conversion of the research questions into an interview guide or observational schedule, and depends fundamentally on your understanding of the context of the research (including your participants' definitions of this) and how the interview questions and observational strategies will work in practice. (p. 101)

An important consideration in developing the instruments used in the research project was how data collection works in tandem with teaching. As previously mentioned, the IRB committee was very clear that this study carried out by a teacher of young children needed to be minimally disruptive. Common research practices such as focus group interviews, video and audio recordings, and individual interviews would not fit the criteria of being minimally disruptive; in this instance, these might be an artificial fit to the needs of the students. One can also imagine that having a teacher take observational notes while teaching would not be plausible. Teachers are always observing, yet they very rarely have time to write down notes while in the moment. This is especially true during STEM lessons where students many times work in small groups with hands on projects. The following instruments were chosen because they are minimally disruptive and practical for a teacher/researcher in the classroom setting. 
Table 3.2

Instruments Selected and Constructs Measured

\begin{tabular}{|c|c|c|c|}
\hline Instrument & Who & Purpose & $\begin{array}{c}\text { Time } \\
\text { administered }\end{array}$ \\
\hline \multicolumn{4}{|l|}{$\begin{array}{l}\text { Pre- and post- } \\
\text { Intervention }\end{array}$} \\
\hline $\begin{array}{l}\text { Teacher Reflection } \\
\text { Notes }\end{array}$ & $\begin{array}{l}\text { Teacher uses } \\
\text { participant } \\
\text { observation notes to } \\
\text { plan future } \\
\text { interventions and } \\
\text { reflect on past } \\
\text { interventions }\end{array}$ & $\begin{array}{l}\text { To gain an } \\
\text { understanding of the } \\
\text { efficacy of a STEM } \\
\text { teaching practice }\end{array}$ & $\begin{array}{l}\text { 4-5 times per } \\
\text { week from } \\
\text { March } 23 \text { rd to } \\
\text { June } 16^{\text {th, }} 2017\end{array}$ \\
\hline \multicolumn{4}{|l|}{ During } \\
\hline $\begin{array}{l}\text { Participant } \\
\text { Observation }\end{array}$ & Entire class & $\begin{array}{l}\text { To observe } \\
\text { interventions in the } \\
\text { classroom and how } \\
\text { students respond. }\end{array}$ & $\begin{array}{l}4-5 \text { times per } \\
\text { week between } \\
\text { March } 23 \text { rd to } \\
\text { June } 16^{\text {th }}, 2017\end{array}$ \\
\hline Journal Prompts & Entire class & $\begin{array}{l}\text { To gain an } \\
\text { understanding of } \\
\text { student experiences } \\
\text { with STEM teaching } \\
\text { and learning } \\
\text { environments as it } \\
\text { relates to their } \\
\text { engagement. }\end{array}$ & $\begin{array}{l}\text { Once every } 2 \\
\text { weeks } \\
\text { March } 23 \text { rd to } \\
\text { June } 16^{\text {th }}, 2017\end{array}$ \\
\hline Discussion Notes & Entire Class & $\begin{array}{l}\text { To gain an } \\
\text { understanding of } \\
\text { student experiences } \\
\text { with STEM teaching } \\
\text { and learning } \\
\text { environments as it } \\
\text { relates to their } \\
\text { engagement. }\end{array}$ & $\begin{array}{l}\text { Once every } \\
\text { week March } 23^{\text {rd }} \\
\text { to June } 16^{\text {th }} \text {, } \\
2017\end{array}$ \\
\hline
\end{tabular}

Lesson plan and notes form. I used the Lesson Plan and Notes Form to plan

lessons and then record observation notes (see Appendix C). In the left column, I 
described the intended learning sequence. This was important data because the intended learning sequence was planned using previous data collected. It was also important because it showed what had been planned which could then be compared to what actually happened. In the observation column (right side), I wrote notes about what actually occurred in the classroom both in regards to our intended plan and what students and teachers said and did. Because I was participating in the lessons with students, I had to keep note taking to a minimum during the lesson so as to be fully present. This allowed me to focus on engaging participants and observing their thoughts and reactions. However, shortly after the lesson, I wrote detailed notes of relevant features of the classroom occurrences.

\section{Discussions and journal prompts intended to engage students in reflecting on}

classroom experiences. Within the limited time prescribed in the research setting (classroom), and the developing ability of $2^{\text {nd }}$ graders to give consistently reliable information about abstract concepts on aspects relating to the research questions, the discussions and journal prompts were often directly related to content. However, the way in which students respond to content can be seen as an important indicator of engagement. I took discussion notes as students participate in whole class discussions about a topic. Then, I wrote student ideas on a flip chart. Because discussion notes are a public record shared by all participants, students built on other's ideas as well as internalized some of these ideas. In this way, the discussion notes were generative in nature. Journal prompts were similar but more individual. Students responded to a topic after learning or discussing a topic. The journal prompts were an important indicator of what students were able to do independently. However, the journal prompts lack access 
for all students because some students have difficulty writing. I accommodated for this by having other students scribe for those students.

Teacher reflection/researcher analysis. I used the Data Analysis Form (see Appendix D) was used to analyze the previously described Lesson Plans and Notes, discussion notes, and journal prompts. The left most column is descriptive in nature, highlighting the salient aspects of the lesson that pertain to the research questions, while the middle column is a place to write down emerging questions or themes. In the right column, I responded to the middle and left columns with a discussion of trends, patterns, and questions. To protect the anonymity of all participants, I used no names. Instead, I used descriptors such as a student, several students, or a group of students to connote the number of students.

I designed each of the different instruments to collect data on how a teacher understands the way in which STEM teaching practices engage students. Given that the teacher collected and analyzed all data, it was important to note that all data collected went through the lens of the teacher and therefore is a teacher's perspective on students' experience. I adjusted research instruments throughout the research process to support a teacher/researcher gathering data while teaching. An important consideration in using these tools is to disrupt the learning environment minimally. A key consideration in this goal is to find a balance between the responsibilities of teaching and researching. In the following positionality section of the paper, I discuss finding this balance.

The researcher's positionality. Positionality is the stance or positioning of the researcher in relation to the context of the study, which includes the community, the organization or the participant group" (Coghlan \& Brydon-Miller, 2014) This research 
project took place in an organization that is part of the national education system and an integral part of a community. The participants in the study were situated within a national education organization and a local community. To make matters even more complex the teacher/researcher was in multiple educational organizations including the district were the research project was taking place and the university that was support this project. Teaching and research are two inherently complex undertakings that share the goal of improving the lives of others. This shared goal may make it seem easy to be both teacher and researcher. However, as action research calls us to do, there are many points of tension that must be negotiated because of the multiple overlapping sphere of influence experiences by the participants.

Similarly, the role of student and teacher may seem on their surface as compatible roles. Student and teacher are socially constructed roles that most everyone in society has had experience with and has developed assumptions about. However, when one digs deeper into whose voice is given privilege in the classroom and the resultant inequities that this privileging sustains, it becomes apparent that there is more here to explore. Furthermore, who the researcher/teacher and students are and how they are positioned by societal influences complicate matters even more. It is here, in this overflowing bounty of complexity, where the attributes of qualitative research are able to flourish. There will never be another study in the same setting, at the same time, conducted with the same people, and done in the same way. For this reason, this study has a unique profile that will shed light on one particular context. In the same way that understanding deeply the humanity of one person allows us to understand all humanity but does not allow us to understand every person; thus, this study could allow the researcher and reader to 
understand important aspects of classrooms but will not allow us to understand all classrooms. In the following paragraphs, I attempt to describe how the main actors (researcher, teacher, and students) were in play during the duration of this project to create a unique study that could have implications for all classrooms.

Understanding my own journey into teaching and how being part of the teaching profession has influenced me is an important consideration when thinking about my perception of students. As a White male coming from a middle-class background, I have come to realize that much of my success can be attributed to the cultural capital that has been passed down to me (Sullivan, 2001). The norms and expectations of society have given me opportunities and second chances that many others have not received. As a student in a K-12 setting, I was always able to follow norms and meet expectations with relative ease. I do not remember having problems with learning in school. Learning and academic success were valued by my family and I was well supported. However, I had difficulty fitting in socially at school. My family immigrated from Germany shortly before I was born and we stayed relatively separate from American culture. The discord of growing up in two cultures was challenging and many times; it left me feeling isolated from both cultures. Being bi-cultural and bi-lingual helped me understand the isolating effects that norms and expectations can have and that norms and expectations are relative. I chose teaching because I wanted to help students that similar to me did not feel that they fit in. When I made this choice, being a White male made it easy to move from feeling alienated, to being part of mainstream society. As a teacher who is paid by tax payer dollars, society expects me to hold students accountable to behavioral norms and academic expectations. These norms and expectations can at times have a marginalizing 
effect on students. On the other hand, students and families have their own and at times divergent views of what norms and expectations they have for education. In my view, the challenge of teaching is standing at these crossroads between society and students. It calls for finding a way to negotiate the tensions of differing norms and expectations.

Managing this tension led me to develop an intuitive and relational style of teaching that keeps in mind the broader societal context. Developing strong relationships with students and understanding their social, academic, and emotional aspects occurs throughout the year as I listen to students, watch how they interact with their classmates and myself and observe how they respond to classroom activities. How I see each student is subjective and in a constant state of flux as I learn more about each student and as they grow and develop. Knowing that my own understanding of students will never match who they are is important because it acknowledges the uniqueness and possibility of each student. However, just focusing on the student in my classroom would not be enough to prepare students for the world we live in. Students will need to get jobs and live productive lives in a society whose historical power structures marginalized groups of people and greatly damaged our environment. To prepare students for their future I have worked at reimagining a curriculum that teaches student the standards they need to know, the societal context we live in, and creates a classroom community built on trusting relationships that seeks to support all students. Just as, my understanding of students is on constant revision my understanding of curriculum and its goals needs to be in constant revision as I change to a developing understanding of my students and the world in which they live. 
Several years ago, I started the journey of developing myself as a researcher. I felt comfortable enough in my responsibilities to the teaching profession and to my students to take on the additional role of researcher. In retrospect, this may have been a naive assumption based on a lack of understanding of what research entails. However, I think it is important that we as teachers and/or researchers broaden the view of research to include a more applicable approach—one focused on practice research. For example, much research in classrooms is carried about by teams of researchers the work for relatively small amount of time in a classroom and spend a large time theorizing about what happened during this small amount of time. This is nice, and it gives of an important window into what is possible and the meaning behind what is happening. However, it does a little to change classroom practice. Initially, I assumed that doing research in my classroom would follow a traditional path. What I quickly learned is that when you weigh the responsibilities of a teacher, to society and to students, it is quite difficult to include the responsibilities of a researcher. It is nearly impossible to gather data on my own teaching and students while also giving $100 \%$ of my attention to teaching. For this reason, I had to change my methodology to match more closely the realities of classroom life. For example, I originally wanted to interview students before, after, and during the classroom interventions. However, in the IRB process it was clear that such interviews could have a negative effect on how students feel in my classroom. In this case, as in several others, my role as a teacher kept me from fulfilling my role as a researcher as I had envisioned. I have mixed feeling about how my role was limited by the IRB process. It forced me to change my methodology to match what I do every day in the classroom, to teach, observe, and reflect. However, I worry that the research 
community will not see this as research because the students did not get to participate in the course of the research in meaningful ways. On the other hand, the methodology enacted improved my student's experience of learning and my own understanding of my students and teaching. In many ways, this research project helped develop me into the teacher that I am today.

One of the challenges of this project has been processing the different ways that teachers are positioned in the research world and researchers are positioned in the teaching world. In the research articles I read as part of my literature review, I did not find examples of researchers who are also full-time classroom teachers. Sometimes, a researcher partners with a teacher, but that is not the same. Additionally, I have not found any fiscal support for teachers doing research. My school district and the institution I am working with to attain this degree do not offer grants, work release, or paid sabbatical to pursue research. However, there are many examples of researchers working in classrooms to gain information. Implicitly, this says to me that teachers are useful in the research world as subjects and possibly partners but cannot do valuable research on their own. On the other hand, it is my experience that researchers are viewed as out of touch. Research recommendations are stacked onto a teacher's ever-growing list of things to do while support in the way of time and professional development are continually lacking. As a teacher working on a dissertation, I have found that the educational community generally views it as a nice project but there is little fiscal support or interest. Similar, to my experiences growing up bicultural, I find myself on the margins. 
Data collection and analysis. Maxwell (2013) advocated for a continuous analysis of data starting immediately after the first data is collected. His rationale is that such a continuous level of data analysis will inform the study through helping shape the researchers thinking during the study.

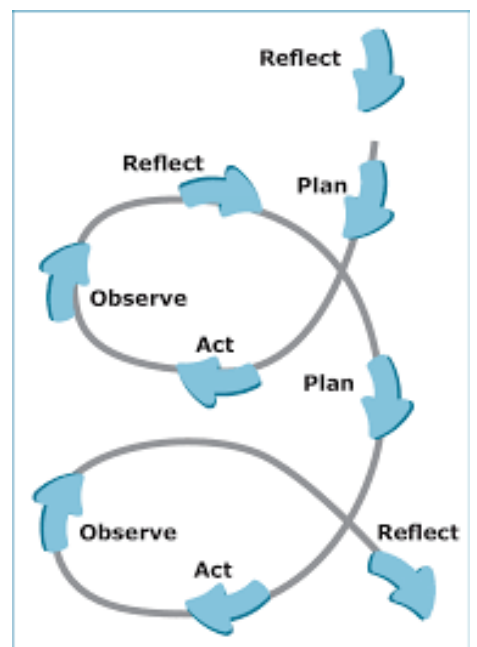

Figure 3.1 This model of action research shows how the action research cycles build on each other. Reprinted from Collaborative Action Research Endeavor (CARE) for Quality, by L. Willox, (retrieved from https://careforquality.weebly.com/background.html)

In action research, such a continuous analysis (see figure 3.1) is essential to inform the design process and engage participants in meaningful reflection. Kemmis and McTaggard (1988) described the data analysis process as "plan, act, observe, and reflect." This process closely aligns with the work that teachers do on a daily basis. The difference in this research project was that the teacher highlighted students concerns as much as possible. Furthermore, I wrote memos and reflection notes to highlight developing understanding. Such a data analysis informed the design process of curricular interventions after which I reflected on the entire data set to undergo a thorough retrospective analysis as called for be Cobb et al. (2003). In the ideal situation, students 
would have been involved in each step of this process. However, due to IRB constraints that highlight the need to balance responsibilities of the research project and risk to students, students were only involved in traditional classroom activities. After the initial data gathering and intervention cycles, I used grounded theory to look for themes (Strauss \& Corbin, 1990). Creswell (2013) described the goal of grounded theory as developing theoretical propositions. Creswell's goal of developing theoretical propositions corresponds to my goal of developing an understanding of why the designed interventions worked or did not work.

Table 3.3

Summary of Research Questions, Instruments, and Data Analysis

\begin{tabular}{|c|c|c|}
\hline Research Question & Instruments & Data analysis \\
\hline $\begin{array}{l}\text { How do students and } \\
\text { teachers negotiate } \\
\text { equity-based STEM } \\
\text { teaching practices? }\end{array}$ & $\begin{array}{c}\text { Journal entries } \\
\text { Participant Observation } \\
\text { Discussion Notes }\end{array}$ & $\begin{array}{c}\text { Journal entries } \\
\text { Participant Observation } \\
\text { Discussion Notes }\end{array}$ \\
\hline $\begin{array}{l}\text { How do different } \\
\text { enactments of STEM } \\
\text { teaching practices } \\
\text { influence student and } \\
\text { teacher engagement? }\end{array}$ & $\begin{array}{c}\text { Action research cycle } \\
\text { Open coding } \\
\text { Descriptive report }\end{array}$ & $\begin{array}{l}\text { Action research cycle } \\
\text { Open coding } \\
\text { Descriptive report }\end{array}$ \\
\hline
\end{tabular}

During the initial phases of the design process focused on research question 1 and 2 (see Figures 3.1 and 3.2), I began analyzing data using informal processes such as close reading and reflection and writing memos to develop an understanding of the data. Then, I used open coding (Strauss \& Corbin, 1990) to categorize data. I carefully analyzed the text to develop categories. Once I developed these categories, I generated and analyzed 
descriptions to suggest theories that may explain what happened during the research project.

Another way to understand the action research methodology is to use the lens of NGSS science practices. This may be an especially productive lens in doing participatory action research in E-STEM learning environments because it mirrors the knowledge creation processes that students use in their day-to-day E-STEM learning experiences. McNeill, Katsh-Singer, \& Pelletier (2015) have taken the eight science and engineering practices described in NGSS standards and grouped them into categories so teachers and researchers can see how the different practices facilitate knowledge creation processes (see figure 3.2).

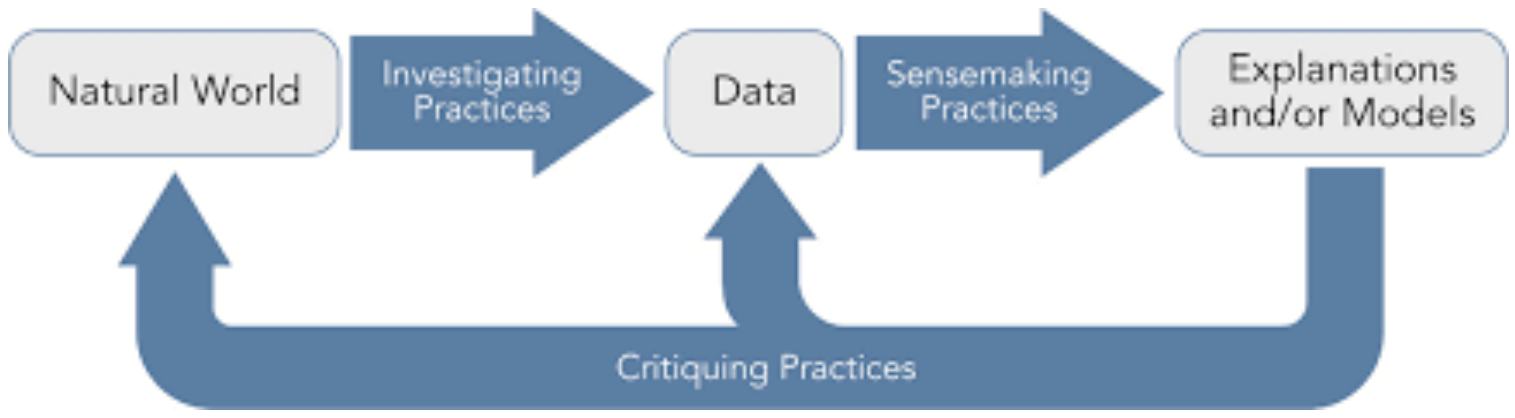

Figure 3.2 This figure shows the NGSS knowledge creation processes with practices in three categories including investigating, sensemaking, and critiquing practices.

In figure 3.2 the practices are grouped into three categories that are used to make sense of the natural world. These categories are investigating practices, sensemaking practices, and critiquing practices. I will describe how these three categories in the NGSS knowledge creation process helped define the action research cycle that I described in the previous paragraphs. The natural world, in my case, are the occurrences that happened in the physical space of my classroom. Whereas, investigating practices in my classroom 
gathered data about classroom occurrences/natural world. Investigating practices included classroom observations and the creation and gathering of student work samples including journal entries and discussion notes. This data was then analyzed using sensemaking practices. In the action research cycle (see figure 3.1) this is described as reflecting, while in the NGSS knowledge creation process this is described as sensemaking practice (see figure 3.2). Sensemaking/reflecting practices in my research included open coding and writing descriptive reports. These sensemaking practices help develop a model or explanation of how E-STEM teaching practices work in my classroom, which then went into the planning of following E-STEM learning experiences. In the NGSS process planning facilitates a critique of my developing explanation of the classroom/natural world and of my data. For example, if I think that SEL learning experiences will help students participate in E-STEM activities then I can plan a SEL experience as a lead-in to a STEM experience and see if this idea actually does increase participation. Gathering data and then engaging in reflection/analysis/sensemaking practices helps me further develop my explanation or model of how E-STEM learning experiences are developed. Using both the continuous action research cycle and the NGSS knowledge creation process helped provide a structure to the participatory action research process that was both flexible and supportive. It would be interesting to see how this process could engage older students more deeply in participatory action research experiences in E-STEM classrooms.

\section{Countering Current Educational and Research Trends}

Research carried out in learning environments for young students have many times treated students as objects to be studied. The current educational climate with high 
stakes testing gaining prominence and students and teachers under increasing pressures has a similar marginalizing effect. This research project emphasized means to counteract this trend by centering the research questions and methodology on strengthening student and teacher voice in working together to envision alternative educational structures in STEM learning environments in order to promote flourishing classroom environments. Balancing the competing responsibilities of teaching, student learning, and research has altered this project to be much more researcher centered in its approach than I first hoped. However, the guiding light of this projects was the students' and I working together to create a more equitable learning environment. Though the research process may have been more researcher centered, the student experience in the classroom was very much focused on their voice and perspective. 


\section{Chapter 4: Data Analysis}

Students participate in unique educational experiences when attending an elementary school with a STEM focus. All students at Western Elementary engage with a broad curriculum on a daily basis that emphasizes integrated STEM learning experiences. Though the importance of STEM education is becoming more and more critical with the increasing demands of worldwide economic and environmental issues, Blank (2013) found that science learning in K-2 classrooms only happens on a daily basis for $20 \%$ of students. Some argued that this lack of science instruction in the primary years contributes to the inequity in subsequent science achievement (Morgan, Farkas, Hillemeir \& Maczuga, 2016). At Western Elementary, 100\% of students receive daily science instruction; however, their engaged participation in this instruction is not necessarily equitably distributed. Equitable learning experiences would give all students different supports to access similarly high levels of engagement. However, in many learning experiences students do not get the support they need and therefore have difficulty participating. This variation of participation creates a situation where some students are benefiting more than others are from daily STEM instruction. There is an extensive research base, as described in Chapter 2, regarding equity-based STEM teaching practices. The existing research indicates that equity-based STEM teaching practices may create more equitable classrooms with a broader level of participation. However, few research studies have been published by practicing teachers who are implementing equity-based teaching approaches. Such practice-based research can shed light on the different ways that equity-based STEM teaching practices may be used in classroom settings. The goal of this ten-week long study was to engage students in the 
process of implementing equity-based STEM teaching practices so that learning engagement is more equitably distributed. I explored two questions through the subsequent data analysis:

1. How do students and teachers negotiate equity-based STEM teaching practices?

2. How do different enactments of STEM teaching practices influence student and teacher engagement?

I conducted this participatory action research project over the course of 10 weeks from beginning April to the end of the school year in the $3^{\text {rd }}$ week of June. The following section presents an overview of the STEM learning experiences during the research project. In subsequent sections of this chapter, I describe classrooms experiences as they relate to themes that emerged in the data analysis.

\section{STEM Learning Experiences in a Second Grade Class during the Research Project}

This research project takes place in a second-grade class of 24 students where I was the lead teacher. At the time of this research project, I had been teaching at this STEM elementary school for two years. The school is located on the outskirts of a small but growing city in the western states and draws students from both rural and urban areas. Though the school has limited diversity in terms of cultural variability, there is, however, a large amount of socioeconomic diversity. The school is one of the older buildings in the district. When the district built the school, it was designed with only one small window in each classroom. One door leads to the hallway and the rest of the school, while another door on the opposite side of the classroom leads outside to the playground. The classroom layout includes five tables with cubbies underneath the tabletop for students to store their supplies. Each of these tables seats four to six children. There are 
several tables along the back wall where children access the supplies. At the front of the classroom, there is a whiteboard and a large rug that serve as a meeting area. An easel with chart paper leans against the whiteboard. To the right of the meeting area, are bookcases with a classroom library. The classroom is quiet in the mornings as light shines in the lone window. At 9:00 am, when the bell rings, students come into the classroom and the action begins.

This research project collected data regarding STEM-based teaching and learning between April 1st and June $21^{\text {st }}$. Before this time, our grade-level team planned four learning experiences that focused on several different content areas recommended by the Next Generation Science Standards (NGSS Lead States, 2013). Our grade level team consisted of four White middle-aged women and myself. One of the team members was close to retirement while the other team members had been in the teaching profession for less than five years. All team members had been part of the local community for most of their lives. In designing these learning experiences our team used a combination of resources including commercially available engineering and reading curriculums, local outdoor education partners, and our own knowledge of the local environment. Though our grade level team had the experience and willingness to plan units together, our school, being similar to schools across the nation, did not receive adequate time to plan high-quality learning experiences (Darling-Hammond, Burns, Campbell, \& Hammerness, 2017). This was not because the administration did not value the learning experiences, but rather because there was not enough money to release teacher from other duties so they could plan together. Consequentially, the design of these units was ad hoc and, as a result, there was a wide variety of learning experiences between our classrooms. Due to 
the nature of the implemented research project, there were several key features in my classroom that emerged as the students and I worked together to implement equity-based STEM teaching practices. Though similar practices may have been used in other classrooms, there was little time available to work as a team and critically discuss how equity was being supported during science instruction. Rather, most conversations focused on the immediate concern of what we would teach, and not on how we would teach it. The differences in instruction included (a) integrating student interest and questions in everyday teaching and learning, (b) an increased focus on social and emotional learning for all learners, (c) the application of the engineering design process in solving local problems. In the following table, I give an overview of the units that students participated in and the NGSS recommendation focus of each unit.

Table 4.1

STEM Learning Experiences and NGSS Focus

\begin{tabular}{|c|c|c|}
\hline $\begin{array}{c}\text { Learning Experience and } \\
\text { Duration }\end{array}$ & NGSS Focus & Activities \\
\hline $\begin{array}{l}\text { Designing a video game } \\
2 \text { weeks, } 1 \text { hour per day }\end{array}$ & Engineering Design & $\begin{array}{l}\text { Design a video game } \\
\text { using Scratch Jr. Coding } \\
\text { App to meet certain } \\
\text { design specifications. }\end{array}$ \\
\hline $\begin{array}{l}\text { Local Landforms and } \\
\text { Erosion. } \\
6 \text { weeks, on hour per day }\end{array}$ & $\begin{array}{l}\text { Earth's Place in the Universe } \\
\text { Earth's Systems }\end{array}$ & $\begin{array}{l}\text { Develop a model for } \\
\text { how local landforms } \\
\text { where created and } \\
\text { engineer a solution to } \\
\text { limit erosion. }\end{array}$ \\
\hline $\begin{array}{l}\text { STEM Week. } \\
1 \text { week } 2 \text { hours per day }\end{array}$ & Engineering Design & $\begin{array}{l}\text { Design solutions that } \\
\text { limit the amount of } \\
\text { waste used in a school. }\end{array}$ \\
\hline $\begin{array}{l}\text { Plants and Pollinators. } \\
2 \text { weeks } 1 \text { hour per days, } 6 \\
\text { weeks } 15 \text { minutes per day }\end{array}$ & $\begin{array}{l}\text { Ecosystems: Interactions, } \\
\text { Energy, and Dynamics }\end{array}$ & $\begin{array}{l}\text { Design an experiment } \\
\text { that tests the needs of } \\
\text { plants and designs a }\end{array}$ \\
\hline
\end{tabular}


solution that moves

pollen.

During these learning experiences, it was important not to rush and put students at risk of experiencing stress due to the research project. For this reason, I collected data in a way that was minimally disruptive to students. Employing participant observation as a methodology, I gathered data throughout teaching and recorded my observations immediately after the teaching day. I also collected student work and notes from classroom discussions as anonymous entities. As everyday field notes, I used these data when redesigning subsequent learning experiences to create a more equitable learning experience for all students.

\section{Social-Emotional Learning}

One theme that emerged during the course of this research project is that many second-grade students were concerned with social relationships and emotional wellbeing. In this section, I describe the data and subsequent SEL interventions that led to an observed increase in student engagement. When I looked at initial data, I conjectured that broadening the scope of STEM learning experiences to include students' concerns with social relationships and emotional well-being would be an important component for increasing the equitable distribution of engagement in STEM learning activities. As described in Chapter 2 in delineating relevant background literature, social and emotional learning is an important component of academic engagement (Frey et al., 2019). Sevenand eight-year-old students are psychologically at a social developmental stage where they crave responsibility and independence and are concerned with others' socially relevant reactions towards them (Durlak, 2015; Wood, 2007). Additionally, they are at 
an emotional developmental stage where they have a hard time listening to directions from adults and thus become easily distracted (Durlak, 2015; Wood, 2007). Due to students' heightened awareness of others reactions towards them and their propensity to become easily distracted, students may need additional instruction and support in problem-solving activities when working on STEM learning experiences. The qualitative data from this project indicated that students that were experiencing difficulty engaging in STEM tasks due to a pressing social or emotional concern where more apt to participate when STEM learning experiences were scaffolded with SEL experiences. For this reason, providing E-STEM learning opportunities for students went hand in hand with creating an equitable classroom community. Such a classroom community had a supportive social fabric and was made up of community members that had developed their collective skills of social problem solving. This community capacity supported their engagement in the challenges presented by collaborative STEM learning.

Developing relationships before the project begins. The need for an increased level of support in the social and emotional domain was especially apparent in January of 2016. This was three months before the beginning of the research project. However, I am including this description because it provides relevant context for the research project. Following is a description of the classroom situation and subsequent interventions that occurred before the research began. This is relevant because throughout the research project students were engaged in daily routines and used language that I helped to establish during these earlier interventions.

At this point, the year had progressed enough that students were familiar with each other but simmering friendship issues were starting to bubble up. In general, second 
grade students have a hard time understanding the underlying issues of social problems (Durlak, 2015; Wood, 2007). They tend to point towards direct experiences with classmates that may have caused a disruption. However, as I addressed these direct experiences with students, new situations would quickly come up. The ongoing need for support with problem solving made me think that we needed to change the entire social climate of the classroom to be more empathetic. My idea was that an underlying network of social connection and empathy would support students when problems arose. In addition to a general social malaise, we, in the classroom, were having significant difficulty integrating a particular student on the autism spectrum. This student's one-onone aide had to take him out of the classroom frequently because of disruptive behavior, while the rest of the students were mostly unsure of how to interact with this student.

A rising tide raises all ducks. To create a positive change in classroom climate, a parent, the life-skills teacher, and I planned several weeks' worth of instruction that would occur during our scheduled STEM learning time. The focus of this instructional plan was developing social cohesiveness by augmenting social and emotional skills. In designing these activities, I worked with a parent of one of my students with autism. This parent was earning her master's degree in education and wanted to collaborate with me on an action research project. She wanted to learn more about how creating an inclusive classroom impacts students' perception of unique students. I also enlisted the help of the life-skills teacher who was a case manager for our student with autism. We planned several different activities that we thought would engage students in thinking about concepts such as inclusivity, being different while being part of a group, and how to support others. 
We called the theme "a rising tide raises all ducks." The idea behind this theme is that when students engage in pro-social behavior it helps the entire group. As a model of this phenomenon, students decorated store-bought rubber ducks to display unique characteristics of their personality. For example, a student decorated one duck with a sparkly cape, unicorn horn, and rainbow colors. Another student decorated a duck as a Pokemon. Though I asked students to design their ducks to show certain characteristics, they tended to just enjoy the decoration part and then give meaning to those decorations after the fact. Then, we added these ducks to a 10-gallon aquarium. Initially, the water level was only an inch or two. Then, I worked with students to come up with pro-social actions that they felt would benefit each other in the class. I wrote their suggested actions on cups. The examples included helping others, being a good listener, and waiting patiently. When students did something positive and someone else recognized this, they added a cup of water to the aquarium using a cup labeled with the prosocial behavior. The goal was to add enough cups of water to raise the ducks high enough so they could see over the lip of the aquarium.

Give someone a boost. In addition to this duck activity, we planned several more interventions to help students gain confidence in challenging social situations. The interventions included inviting an autism specialist to talk with students, practicing problem-solving skills, and reading and discussing many different books about the tension of being unique as well as being a part of a group. For us, collaborating with the autism specialist was especially powerful. She brought a level of expertise and passion for the topic that students were enthusiastic about. We also frequently worked as a class to act out and solve social problems using our ducks. This routine would include all 
students coming and sitting around our pond (a blue piece of paper) and adding their uniquely designed rubber ducks to the pond. Then we would act out a social problem using volunteers' ducks. This problem came from a situation that students brought to our collective attention. In a later part of this chapter, I describe the research project, and I provide an example where we used this routine to help students participate in small group work. This routine as a projective technique addressed students' concerns in an indirect way and allowed a certain level of detachment that seemed important for problem solving. The resulting detachment may be important for second-graders because when confronted directly with a situation, it is easy for them to become either defensive or feel that they are in trouble. Once I explained the situation, the students would act out different legitimate solutions. Reading and discussing books or images focused on social and emotional learning was also an important instructional intervention. Though school districts commonly see the need for increased support for social and emotional learning, our school district does not have the resources to purchase materials or give extra planning time to teachers to make social and emotional learning a core part of their classroom instruction. Teachers who see the importance of social and emotional learning must invest additional time and energy into procuring their own materials and designing their own instruction. The materials I choose specifically to address lagging skills of communication and/or classroom climate issues. One discussion that had a lasting impact was the equity versus equality poster. I drew a picture of three different-sized students trying to look over a fence on chart paper and shared it with students. We discussed if this situation was fair and how it could be fairer. A phrase that came out of this discussion was giving someone a boost. Students were referring to the boxes used to 
boost the smaller children up so they could see over the fence. This phrase was subsequently used by students to describe helping someone that needed additional support to access learning or social situations. It seemed to help normalize the need for additional support.

The time invested in developing social cohesiveness and problem-solving skills seemed to create a more positive classroom climate. Though social problems and challenging situations still occurred there was now a shared understanding of a common context along with a common language - a common ground that we developed to support students in working together to solve problems that might occur during our STEM activities. It is also important to remember that problem solving is generally not a solo activity. The experiences I describe in the following section of writing refer back several times to this initial phase of developing relationships as it continued to be relevant and referred to throughout the remainder of the year.

Social-emotional learning during the research project. The following sections describe pivotal learning experiences that occurred during the course of the research project regarding social and emotional learning. I selected these experiences when reflecting on the data during data analysis. I selected them because they appeared significant in bringing about changes in the students' and teacher's understanding or skills regarding social and emotional learning.

Sometimes group work seems impossible. Teaching specific skills for group work was one teaching practice that came up several times before the research project began and then again throughout the research project. Interventions to address concerns with group work were ongoing both before and during the project. Some teachers and 
curriculum writers may assume that primary school age students are able to work with each other in small groups. However, working cooperatively is a challenging skill for many primary age students. There are moments when the wheels come off and the class seems unhinged when I swear to myself, "never again." Students are upset, I am upset, and learning seems to halt. My largest concern is that without appropriate support, such as teaching specific group skills and practicing listening and empathy, group work can risk further marginalizing students who are already on the margins. During the course of this study, it was clear to me based on everyday field notes regarding student's behavior, which we would need to work on developing skills pertinent to group work and further develop the underlying skill of listening with empathy. Thus, when designing learning experiences for this group of students it was important to create as many opportunities as possible for students to hear from their peers about their experiences while working in a group. Furthermore, it was important for students to be empowered to come up with their own solutions to the problems we encountered. In the following is a description of a series of lessons in which I describe students working in groups and how we worked together to improve the experience and engagement level of all students.

Reflecting on past experiences with collaboration. One morning during the first week of the research project in early April, we had a read aloud about teamwork and soccer during our reading block. This read aloud was part of our reading curriculum. As we read Soccer Friends, many students shared experiences about working in groups. Examples include playing soccer on a team led by a coach, arguing with siblings about what to watch on the television, and building a fort with friends. These experiences were sometimes positive and other times not so positive. Knowing that students had various 
experiences with collaboration, I thought it seemed relevant to ask students how they learned to work together. The idea was that if we better understood how we learned to work together it would help us understand why we sometimes have difficulty working together. I prompted students to write about how they learned to collaborate. In reflection on their notes, it was apparent that I was asking students to reflect on their own experiences. Research has shown that reflection is an important skill that can lead to greater levels of empathy (Zins, Bloodworth, Weissberg, \& Walberg, 2007). After working for 15 minutes, I asked students to bring their pieces of writing to sharing circle; I invited them to volunteer by raising their hand. Students shared a mixture of experiences. For example, one student shared that in their family, parents yell at the kids if they are not working together. Another student shared that his family had recently divorced and his brother was always mean to him. This prompted several other students to share experiences about divorce or mean siblings. There were also positive experiences with collaboration. A student shared about a sports coach that helped them work as a team. This student shared that the coach would encourage them to do their best. Another student shared how a parent that was always patient used a calm voice when things did not go well.

In the notes about this conversation, I find collaboration is a risky proposition for many students. When we ask students to collaborate, we are asking them to work with other students who may treat them in ways that trigger past experiences. This is especially true when working with students who may have experienced various types of trauma in their childhood. Teachers might assume that students are disengaging from collaborative group work because they do not care about the work or are unmotivated. 
However, after listening to students, it was clear that another important consideration is students' past negative experiences and making sure that they feel safe to work with other students. Based on previous observations of students working together it seemed that we needed to work on group work skills. However, now it appeared that an important additional component was that we needed to make sure students feel safe in what can otherwise be a chaotic situation. For this reason, in addition to teaching group work skills, I decided that students needed additional experiences in developing their willingness to listen to and empathize with another students' point of view. Listening and empathizing with others are underlying practices that would help students develop caring relationships with other students in the class, but they are also developing caring relationships in other parts of their lives. The ultimate goal is not only to develop students' skills at participating in group work, but also to develop caring citizens who are able to empathize with people and situations in an increasingly technologically connected but emotionally disconnected world.

Sometimes a few of us need the help of everyone. During the 2nd week of April, we were working on an engineering task that was part of a professionally designed curriculum. Students would be designing a video game using a programming app named Scratch Jr (https://www.scratchjr.org/). This app was designed through a collaboration with DevTech Research Group at Tufts University (https://sites.tufts.edu/devtech/), the Lifelong Kindergarten Group at MIT Media Lab (https://www.media.mit.edu/groups/lifelong-kindergarten/overview/), and the Playful Invention Company 
(http://www.playfulinvention.com/?doing_wp_cron=1561993231.352719068527221679

6875). Before designing the video game project on their iPads, students were learning skills through smaller challenges. On April 8, we designed a scorekeeper game with Scratch Jr. that would help students understand how to create code that would keep scores based on when a soccer ball was reaching a specific target. One of the main skills that this project required was working with a small group of three students and sharing an iPad to create a code that would meet certain design specifications. During this particular learning activity, most of my time was taken up solving conflicts that arose from difficulties with students working together in sharing an iPad. For this reason, once the main part of the learning activity was concluded, I decided to ask students to reflect on this particular learning activity and give feedback on how they thought cooperating with group members went. Following are notes from this discussion. The names used in the field notes are fictitious.

Field note Frank Heimerdinger, April 11, 2017, 1:35 pm

Teacher-How did it go today, cooperating with your group?

Allison-Great, because me and my partner were getting along well and almost completed our work

Baily-It went pretty well but somebody was messing around.

Catherine-Went terrible because we didn't get much work done because we were just trying to get the characters right.

Danny-It went bad because somebody would not let me use the iPad.

Evelyn-It went well, first, we had a problem, then we fixed it because another group helped us fix it. 
Feneca-I got sad because I barely didn't even get a turn.

Gabe-It went bad because somebody in my group wasn't listening to direction. Heather-We worked together well the first time, one person in my group was

\section{being selfish.}

Based on these notes, it seemed there was a mix of positive and negative experiences as students worked together. Phrases that point to positive group experiences include we fixed it, getting along well, completed our work, and went pretty well. Whereas phrases that indicate a challenging group experience were as follows: messing around, didn't even get a turn, didn't get much work done and wasn't listening to directions. Furthermore, students seem to be very aware of group dynamics. This seemed to indicate that students care about how well their group works together. Though students may care about how well they work together, they needed a significant amount of support to solve problems. This was evident because of the intensive amount of support that I had to provide regarding cooperation skills while students were working. For example, when students were working on designing the scorekeeper app, one group had a disagreement about who could be in charge of adding components to the program. Danny wanted to add components while the others in the group did not want this. Danny felt like he was getting treated unfairly and left the group; he hid underneath a table and started crying loudly. The crying was loud enough that it was disrupting other groups. This required $100 \%$ of my attention. While I was working with Danny, Baily's group became loud and disruptive. I later found out that they were taking pictures of each other and distorting the pictures using a camera feature. These compounding issues left me 
little time to support students with the actual work of programming the video game app and left me feeling overwhelmed.

Based on data collected during this learning experience, it was clear that not all students were receiving the support they needed to participate fully in the lesson. Such a lack of support created an inequitable situation in our classroom. To increase equitable participation, I analyzed the data that I collected the previous day. One piece of information that stood out from the data is that students had difficulty sharing the iPad as a physical object. It also seemed that students had a hard time listening to each other. This may have been because of the excitement of the project, but it may also have been because we had not established protocols for sharing the iPad. Based on my experience with $2^{\text {nd }}$ graders, I was confident that they could come up with a solution to sharing the iPad. As described in the previous section, I wanted to create contexts that would empower students as problem solvers when working together and sharing the iPad seemed like a great opportunity for this. On the other hand, coming up with ways to practice listening seemed like an area where some of my teaching experience would be helpful. The following is a description of a series of lessons that show how we started this plan but then also adjusted it according to what happened in the classroom. The end result was students were participating in a series of lessons that helped them problem solve group work problems and practice listening in the context of a design project.

During the next lesson, I asked students to come up with a plan for the starting screen for their video game. The starting screen would have a character as a protagonist, an obstacle, and a target that the character would reach. Knowing that students had difficulty listening to each other the previous day, we practiced listening and re-voicing 
the design criteria. In addition, I introduced a protocol that would help them practice listening to each other's ideas. During this portion of the lesson, as a part of the protocol, I intentionally slowed down the pace of talking so that students could practice what it feels like to be a listener. After we invested several minutes of time learning and reviewing the design criteria, I explained another new protocol: Share the Pen. During this protocol, the student with the pen is in charge of writing down somebody else's idea. If someone has an idea he or she wants to share, he or she has to tell it to the person with the pen. If the person with the pen wants to share an idea, he or she hasto pass the pen to another person. I designed the Share the Pen protocol to require that students depend on each other to get their ideas included in the project. My hope was that using this protocol in conjunction with the task of designing the starting screen to the video game would help support students' ability to work together.

As students started working, there was a quiet hum to the class. My initial impression was that students were working well together. Compared to the previous lesson, this time only two out of eight groups had social/behavioral issues, and I was able to listen to students' conversations and help with content-support where needed. However, in so doing it became apparent that even though there were no major disruptions in the class, several students were not using the pen or talking. It appeared that these students were not engaged in the activity as they sat physically away from the group of students and did not interact with the group at the same level as others. Based on my observations, it was unclear if others were not including these students or if they were struggling to find a way to include themselves. Accordingly, I decided to focus the next lesson on supporting students who were having difficulty initiating a turn. 
During the following day, on April 11th, instead of starting with the next computer programming lesson we met at the carpet in a sharing circle with our rubber duckies. We made the ducks previously as part of our midyear community building intervention. I set up the situation with two ducks working and the one duck not participating. Students then acted out different ways to solve the problem from the different ducks' perspectives. One strategy that a student shared was that the duck not participating could ask for a turn. Then, we acted out this scenario with the ducks, and I prompted students to think about what the working ducks should do when another duck asked to participate. After we practiced this for several turns, I prompted students to think about what the working ducks could do to give the duck waiting to participate a boost. Using the word boost connected to our previous experience, several months before, with the equity versus equality discussion. A student suggested the working ducks invite the duck waiting to participate to have a turn. We then, in turn, acted this out in several different ways. During this activity, the teacher's role was providing a discussion structure with appropriate prompts to facilitate discussion about an issue that impacted classroom participation. The students' role was to come up with solutions to the problem and practicing different iterations of this solution. Students seemed to enjoy this activity. They focused their attention on what classmates did and behavior supports, such as, reminding students to look at the speaker and not have side conversations, were minimal. Perhaps the best indicator of engagement was laughter when students acted out the skits. Student attempts at humor and appreciation for humor showed that they were trying to make these delicate conversations their own. 
As we started working on the next programming challenge, I focused my observations on the two groups that struggled with equitable participation the previous day. One of the groups was comprised of three boys who were close friends. Though they were friends, their group dynamic was a daily roller coaster. One of the student's parents had recently separated and he was prone to loud bouts of inconsolable crying that lasted more than ten minutes at a time. The other group was comprised of two girls who had a contentious friendship, and a third girl who was very even keeled. Both of these groups came up with a plan for sharing the iPad on their own. The group of boys decided to use the timer and switch the iPad "driver" after every 10 minutes. The group of three girls decided to modify the "Share the Pen" protocol; they had the student with the idea tell the iPad "driver" what to do. The rule that was important for creating sharing is that the person with the idea could not create his or her own idea on the iPad. Both of the groups had much-improved participation and were able to make progress on the project. There were no students who seemed to be sitting apart from their group. Conversations and body language seemed reciprocal. At the end of the lesson, I checked in with both groups privately. Group members shared that they thought their learning experience was positive

The notes about this learning experience point out that for some students to engage in collaborative learning tasks they require additional supports. The engineering task of designing an iPad game using a programming app was part of a professionally designed curriculum. If I had taught the curriculum the way it was written, many students in the class would have had difficulty fully participating in the learning experiences. There may be times when teachers think to themselves about some students 
that "these kids just can't do group work." However, this research process and the student's candid participation helped me to see that they can be successful with group work when they have the available support they need. In this classroom, the students played an important role because the students indicated that they needed support through their behavior and their voiced concerns. Furthermore, they were willing to practice skills and come up with their solutions to the problems posed. My role as a teacher was providing a structure that created a concerted focus that eventually helped students internalize skills necessary to solve problems. However, this aspect of teaching is many times overlooked in a professionally designed curriculum, leaving many teachers (and their students) with limited resources to support group work.

Stop the discord before it spreads. One of the more challenging aspects of group work was being able to help students solve a group dynamic problem in the moment. When small groups are working on engineering or science projects the classroom is a busy place. Students are talking, moving around the classroom, supplies are out, and there is a general feeling of controlled chaos. Some students and teachers thrive in this type of environment. However, many students (and teachers) may become overstimulated. In the past, I have had an especially hard time when a group devolves into bickering and arguing. Here my role as a teacher in charge of learning and my role as a caring human being are in conflict. I have thought to myself, "I should be helping kids with learning, why are these kids arguing again." The premise of this research project along with my students helped me see that my own awareness of social and emotional learning is equally important to my focus on academic learning and not in conflict with academic learning. This helps me engage with students when they are 
having an issue. One theme that came up during the research project is that providing specific scaffolding for students whose small group is experiencing conflict can be a very effective tool for supporting social and emotional skills; it is equally important to the academic work that students are doing.

One example that illustrates both the seemingly trivial nature of students' problems and the importance of working with them to solve those interpersonal conflicts occurred several weeks later in May, towards the end of the school year, as students were designing a solution to minimize the amount of cafeteria waste our school produces. We worked together to come up with the idea of designing a reusable snack container made from recycled items. I asked students to use the engineering design process to design their snack container to meet certain design criteria. When the students started the process of designing their own snack containers, I selected groups of three students based on similarities in their design. After that, I tasked students with combining designs and coming up with a final prototype that they would build. Knowing that combining ideas can be difficult for students we used a protocol where students first had to listen to everyone's idea and then re-voice important features. Then students would use features that worked well together in their final design. Student engagement was high during the listening and re-voicing phase of the process as evidenced by reciprocal turn taking, attentive listening, and students' conversations being on task. The repeated practice of listening and re-voicing seemed to be improving their skills in collaborative work. Combining ideas was also going well for most groups. I was able to check in with each of the eight groups, listen to their ideas, and provide probes to further their thinking. However, one group became stuck. I noticed that students in this group were no longer 
sitting close to each other, and the voice level had become elevated. I went over to this group and asked what was going on. I learned that there was a disagreement about whether or not to add a sticker to the design. This group had taken a $12 \mathrm{oz}$. Gatorade bottle and cut three sides of a 2" by 1" rectangle out of it. The fourth side of the rectangle was still attached and acted as a hinge to the door. One student wanted the door to have a sticker on it. This seemingly trivial part of the design was a big deal for this group of students. Furthermore, such a need to decorate everyday cultural artifacts may be a shared aspect of being human as described by researchers in ethnomathematics (Mukhopadhyay, 2009). My hunch was that it had more to do with an exercise in creativity and feeling the need to be included, than the actual sticker. In these types of situations, it was easy to try to solve the problem for students. However, based on previous experiences during this research project, I wanted to make sure that students had an opportunity to practice listening and empathizing with others while in the controlled chaos of an engineering project. If my hunch about students needing control and inclusion was correct, then listening and empathizing might help with their underlying problem. Students around the classroom continue to work, talk, and move around while I asked each member of the group to slow down and share their thoughts about the sticker. After each student had a chance to share, I asked the other students in the group to revoice what they had heard. This process, albeit slow, was important because I wanted to make sure that each student had an opportunity to be heard. Additionally, this process would give students needed time to participate in known routines and thus become more emotionally regulated. Once we had gone through this process, I reminded them that "Now that you have all listened to each other you are ready to come up with a solution. 
Please raise your hand when you have come up with an idea that you can all agree on." As I walked away, students in this group started talking and eventually, they came up with a compromise.

In reflecting on these field notes, I saw that providing scaffolding to move the group out of a challenging situation was important. Once we enacted the routine of listening and re-voicing to understand the problem, it was just as important to walk away and let them sort out the problem. Scaffolding student problem solving in this situation gave this group of children the support they needed to solve their own problems without taking away from the challenge of actually solving the problem.

Social and emotional learning on par with academic learning. Research on children's learning is finding that social and emotional learning is critical to the success of students in school and life (Frey et al., 2019; Zins et al., 2007.) Furthermore, a teacher's social and emotional characteristics and competencies have been shown to be an important contributor to a classroom climate that promotes academic learning (Jones, Bouffard, \& Weissbourd, 2013). This action research project helped me see how I may at times privilege academic goals over social and emotional learning In this case, it indicates that listening to students concerns and responding to them augmented students' ability to engage in complex tasks when working in small groups on STEM-related projects. Students played a pivotal instrumental role in this process because their concerns changed the course of how I taught the curriculum. In the three incidents described previously, I attempted to articulate the need to listen to students concerns based on their experiences with collaboration, the need to engage the entire class in supporting the development of group work skills, and the need for the teacher to be able 
to support on an as-needed basis. The planned curriculum did not anticipate the three events in our learning year. Rather, the planned curriculum focused on standards-based content. As a teacher who has a bias towards academic learning, I initially planned to teach to the standards. However, in implementing the planned curriculum and observing students it was clear that there was a need to invest more time in social and emotional learning. Listening to students and changing the course of the curriculum to foreground their concerns were instrumental in bringing about a change in the flourishing of the classroom.

As we plotted our course into uncharted waters of social and emotional learning it was helpful to use research-based practices (Frey et al., 2019). Students and I found that emphasizing listening and foregrounding empathy provided important scaffolding to help the class become a better place for cooperative learning. The research findings from this project may indicate that including these aspects in our pedagogy helped students engage in complex group work. Giving these additional supports gave more students opportunities to participate and allowed them to feel successful about their work. In the course of completing their projects, they engaged in academic work that moved them towards mastery of standards. Furthermore, the research findings and analysis changed my own perception of which types of curriculum and teaching have value in the classroom. I now see the importance of focusing on social and emotional learning in tandem with the academic.

\section{Students' Interests and Questions Leading Instruction}

At West Elementary, teachers ask students to participate in learning activities as a part of the district-adopted curriculums. Sometimes these learning experiences connect 
with students' backgrounds and interests, while other times they do not. Curriculum designers need to design a curriculum that will be engaging for thousands of students at different geographical and cultural locations. It would be very difficult to design a curriculum that equally engages all students because they have different experiences and interests. Students' funds of knowledge have been described as an important starting point for curriculum development (González et al., 2006.) Teachers who know their students' backgrounds and interests can create or adapt learning experiences that connect with their students' funds of knowledge. Furthermore, the curriculum can be designed to elicit students' questions that will deepen a teacher's understanding of students' funds of knowledge and give students a sense of control and agency for their own learning that increases their engagement. I found that these teaching and curriculum design practices, when built on throughout a school year, helped create engaged learners who eagerly participate in learning experiences that meet NGSS standards and incorporate their own questions and interest.

Throughout the school year, students were engaged in learning experiences that attempt to localize science learning and build on student questions. In the fall, for example, students worked as biologists investigating ground squirrel populations in two different ecosystems. During the winter, students designed their own "kitchen" experiments regarding changes in states of matter, and whether the changes were reversible or not. In each of these learning experiences, students' questions and interests were instrumental in shaping the course of the curriculum. In the following section, I address how I sustained and built upon this type of student engagement during the course of the research project from April to June as we learned about the geologic processes that 
shaped the local landscape. A theme I developed from the data was the importance of teachers' willingness to adapt curriculum or change plans. Student interest and questions seemed to increase when the teacher adapted or designed curriculum to incorporate students' questions and interests.

Exploring our backyard through the lens of NGSS. As discussed in Chapter 2, Next Generation Science Standards (NGSS) presents an important opportunity to reimagine STEM learning in ways that draw on students' innate curiosity and expertise. In support of teachers' ability to use students' questions and interests as an aspect of curriculum design is the teaching practice of exploring scientific phenomena that are locally situated or place based as launching points for legitimate learning. We selected the place-based scientific phenomenon to be familiar and observable to students, and yet, contain nuanced and complex scientific knowledge. In the following paragraphs, I describe a science unit that our $2^{\text {nd }}$-grade team designed for students that focused on the geologic processes that formed our local landforms.

Based on my observations throughout the year, the students had a great deal of familiarity with many of the geologic features in our area. Many students play amongst the volcanic rocks and ridges that proliferate throughout our urban and rural landscape. Furthermore, many students spend time in the rivers, lakes, and mountains in our area. Yet, they have only a developing understanding of the geologic processes that created these volcanic features. Focusing our learning on helping students see the scientific in the everyday ensures that they have a learning experience that connects the rich base of scientific knowledge with their own everyday experiences and practices. Furthermore, these everyday experiences provide a deep well for rich questions and authentic interest. 


\section{NGSS performance expectations and local landforms provide a framework.}

West Elementary is located in an area in the western states that has a rich geologic history. Within a 30-mile radius, there are hundreds of different volcanic features. These features include shield volcanoes, cinder cones, lava tubes, stratovolcanoes, lava flows, and tumuli. Rivers and lakes are formed from the snowmelt from these features. Geologic processes created deep canyons and flat meadows, and provide irrigation water to many of the families that attend West Elementary. The ground we live on, the dirt students play in, and the water that gives life to local farms are products of the geologic features of our region. From listening to students and collecting information about student thinking, I found that students very rarely have a developed understanding of the attributes of geologic features and their formation. On the other hand, I found that they have a rich knowledge of the observable properties from direct experiences that lead to insightful questions and lasting interest.

The NGSS standards provide several performance expectations that help students to develop answers to questions regarding how land changes and what causes it to change (NGSS Lead States, 2013). Additionally, the NGSS standards help students to see the importance that bodies of water and snowmelt play in the earth's change processes. A final consideration of the NGSS standards is learning about how these changes in landforms impact humans and designing a project that limits the impacts of erosion. Over several years, the $2^{\text {nd }}$-grade team of teachers worked together to plan a unit that starts with students' questions and builds into a study of our local landforms and how they were created. The unit that we designed is not set in stone. Rather, every year as we teach this unit and engage in learning with the students, the topics and their questions and 
explorations change slightly to adjust for students' authentic questions and interests.

During this research project, our exploration began with rocks that we collected on tumuli at the natural area at the park behind our school.

Phenomena light the spark. On a sunny spring day, we headed out to the park behind our school to find a rock. Finding a rock is a simple and intuitive activity that students seem to do often. In fact, students had been bringing in rocks from recess all year long to share with the class. This was one of the reasons that I chose this activity. The other reason is that from previous research I knew that a rock that students find in our park has a rich geologic history—one connected to scientific knowledge that we can explore in an NGSS-aligned learning experience. Our school, the park, and most of the area where students live sit on an ancient lava flow. This lava flow is more than 40,000 years old and traveled over 45 miles from a still active shield volcano to our south. As the lava flow traveled, it created many volcanic features including rootless shield volcanoes, lava tubes, and tumulus (see figure 4.1). 


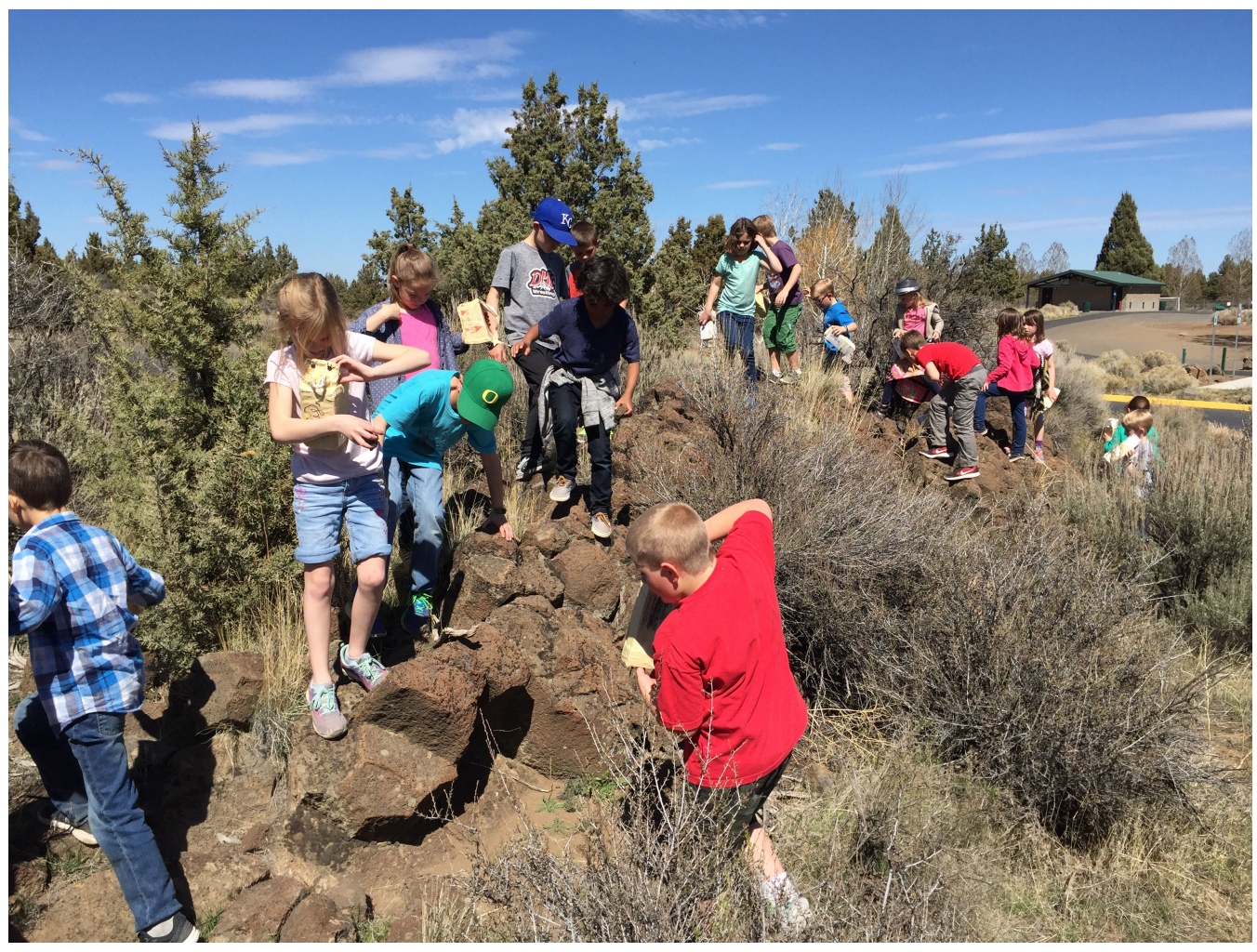

Figure 4.1 Students collecting rocks from a volcanic features that we later learned are called Tumulus.

These different geologic features were created through different processes that have to do with how lava flows and cools at different rates. A rootless shield volcano is a small shield volcano that erupts out of a lava tube. Lava tubes are conduits for hot lava that course through older cooled lava. Tumuli are areas where blisters have burst out of cooling lava, creating a small rocky mound. As students were finding a rock, unbeknownst to them, they were picking out their own personal phenomena to study. In this case, the phenomenon that would spark their interest and questions was the geologic processes that created the rock they found.

Questions lead the way. Once back in the classroom we launched into our study as students recorded their observations and generated questions regarding each of their 
rocks in their science journal. Students were eager to get started as evidenced by their energetic yet purposeful work. Students drew pictures, added labels, and wrote questions about their rocks. I included these questions in a Table 4.2. Students engaged in the practice of making observations and asking questions from the beginning of the school year when we started our exploration of habitat diversity by studying Rabbitbrush. Rabbitbrush (scientific name: Chrysothamnus viscidifloru ${ }^{1}$ ) is a fall flowering bush that is a critical food source and home for many different insects. Student questions developed in their initial study of Rabbitbrush became the basis for future learning. This routine of students making observations, asking questions, and then the class working on studying them as a collective, was re-enacted many times with many different topics and across different content areas. It may be that this repeated exposure and understanding that their questions would have power in deciding what students learned and may have led to this initial engagement in studying rocks.

While students worked, I circulated through the classroom gathering data on their observations and questions. This is an important stage of the teaching process because having this information helps me funnel the subsequent classroom discussion towards productive questions. Following is a chart that shows the different types of questions that students had. During data analysis, I organized the questions into categories similar to what I did in the moment while circulating through the class.

\footnotetext{
${ }^{1}$ https://plants.usda.gov/plantguide/pdf/pg_chvi8.pdf
} 
Table 4.2

Student's Questions Sorted into Categories for Instruction Further study High-interest tangents

We can talk about that later

Why is there orange stuff on the rock?
How did the holes get made?
How come there are crystals on the rocks?

Do spiders live in the rock? How was the rock made?

Did dinosaurs make the Where did the rock come rock? from?

Is this a lava rock?

Why is my rock pointy?

I found these categories helpful because they guided which questions we would highlight in whole class discussions. As the teacher, I am able to steer their learning towards questions that I know will lead to further and deeper learning about the NGSS topic of focus. However, it is important to note, that sometimes it is worth it to take a risk and follow students' questions to their undetermined conclusion. This is the case in the following scenario where we learned about crystal formation in volcanic rocks. Though initially I was skeptical about following this line of questioning, I found that this high-interest topic was a great way to engage students in developing an understanding of rock formation, the mineral content of lava, and the sources of lava. We built upon this important learning as we studied more about the geologic processes that shaped our local landforms. 
Detours provide unexpected depth. Several students were highly interested in the small crystals that they found in the rocks. For this reason, we began our learning with the question, How come there are crystals in rocks? Before starting an investigation of this topic, I had to learn more about why there are crystals in the rocks we found. I never noticed the crystals, and though I had some ideas about how they formed, I was still unsure. I checked out several books from our school library. Our librarian has amassed a large collection of books on science-related topics for us. In reading these books, I found out that the crystals come from silica minerals in the lava. As the lava cools, the silica minerals crystallize in different ways. Different types of lava have different amounts of silica in them and this makes different types of rocks. Three types of rocks in our area are obsidian, scoria, and pumice. In obsidian, the high silica content of the lava crystallizes slowly to make this glass-like rock. The same type of lava makes pumice, but pumice occurs when that particular lava violently explodes from volcanoes and crystalizes quickly as it cools in the air. This quick cooling traps many air bubbles in the rock making this a very light rock. Scoria, on the other hand, is a different type of more viscous lava and has lower silica content. This type of runny lava cools moderately quickly and has some air bubbles and the small crystals that the students observed.

An instructional routine we used to begin this investigation is an OWL chart. An OWL chart is a chart that includes observations, wonderings, and ways to learn about those wonderings. I learned this instructional routine from colleagues several years ago and use it frequently. It is interesting to note that this instructional routine is hard to trace back to one source, rather it has been adopted by the teaching profession and occurs in diverse settings in diverse ways. We used this instructional routine several times 
previously, so students had familiarity with the process. This is a high leverage instructional routine that engages students in several NGSS practices including practice 3 , designing and carrying out investigations and practice 1, asking questions and defining problems (NGSS Lead States, 2013).

Students were given scoria, pumice, and obsidian to make observations. I did not tell them the names of the rock and helped them to set up a journal page with three rows labeled rock 1, rock 2 , and rock 3 .

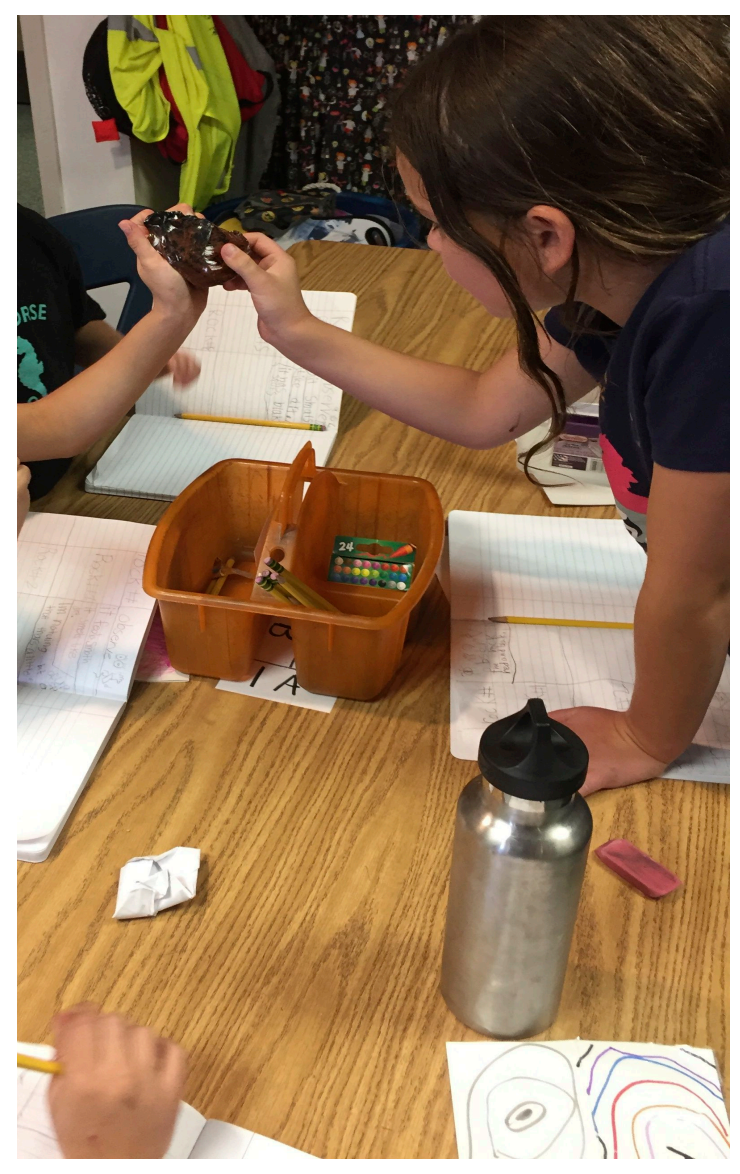

Figure 4.2 This group of students is observing the features of one of our rock samples and recording what they find in their science notebooks. 
The three types of rocks students were studying are commonly found in our local area and many students have previous experience in collecting and playing with them. I provided the rocks to students knowing that they would see different ways that silica crystallized (see figure 4.2). One exciting thing that happened during this observation is that students came up with ways to test the rocks. For example, one group of students devised the float test. This student took a cup of water and dropped their rocks into it to see if they float or not. This led to the observation that pumice floats while scoria and Obsidian do not. This test very closely mimics what I have observed my own children do when we go to local area lakes that have pumice around. It may be that previous experiences with the materials being studied helped students think of which properties to test and how to test them. In this particular instance, I stopped the class and we discussed how we had come up with a test similar to what scientists do. I asked students to continue thinking about tests that we could do to compare the properties of rocks further as they recorded their observations in their journal.

The following day, we had a class meeting. We added observations, questions, and ways we could learn to our OWL chart (see Table 4.3).

Table 4.3

OWL Chart for Three Different Types of Rocks

\begin{tabular}{lll}
\hline Observation & Wonder & Learn \\
\hline $\begin{array}{l}\text { There are three different } \\
\text { types of rocks }\end{array}$ & $\begin{array}{l}\text { What are the names of the } \\
\text { rocks? }\end{array}$ & $\begin{array}{l}\text { Ask an expert or read a } \\
\text { book }\end{array}$ \\
Rocks 1 and 2 have crystals & $\begin{array}{l}\text { How are the crystals } \\
\text { formed? }\end{array}$ & $\begin{array}{l}\text { Ask an expert or read a } \\
\text { book }\end{array}$
\end{tabular}


Rock 1 Floats but the others do not.

The obsidian is black and shiny.

Rock 1 and 2 have holes in them?

Rock 3 has sharp edges?
Why does rock 1 float?

Why is the obsidian so black and shiny?

Why do rock 1 and 2 have holes?

Why are the edges so sharp?
Break open the rocks to see what the insides look like Ask an expert or read a book

Ask an expert or read a book

Ask an expert or read a book

During this discussion while we made the OWL chart, we talked at length about how we could learn more about the questions we had. Students had unrealistic ideas about bringing different types of lava into the classroom or going to visit an active volcano. During this part of the conversation, we talked about how scientists in labs could bring in lava or go to an active volcano to learn about the different questions they have. However, we had to work within the constraints of what we could do on a school day. For this reason, as we completed the chart, students saw that our next step would be to obtain more information about the rocks we were studying by asking an expert or reading a book. NGSS practice 8 provides guidelines for students to obtain and evaluate information answering a scientific question through reading a text (NGSS lead States, 2013). Using the collection of geology books at our school library and books borrowed from our county library we dove into reading texts to answer some of the questions we had. At this point, the learning trajectory became an authentic reading lesson about how to obtain and understand information from a nonfiction text. This series of lessons included how to use nonfiction text features such as headings, glossary, and illustrations. Many of the texts had new vocabulary so we also had to work on how to use context 
clues to understand unfamiliar words. The initial question of how do crystals form in rocks had now become a study of the geologic process $=$ the formation of volcanic rocks and of our local volcanoes. In the process of these explorations, students engaged in several of the NGSS practices including designing and carrying out investigations, asking questions and defining problems, and obtaining and evaluating information. Though initially the observations about rocks containing crystals seemed tangential, it ended up that this high-interest question supported students in engaging in several important NGSS practices. Furthermore, as we went deeper into this question it connected to the overall understanding of how different geologic processes create our local landscape. Due to the nature of the questions students explored, there was an overreliance on text to answer the question. One weakness of relying on text to answer a scientific question may be that not all students are able to apply their background knowledge to a question, and students may only develop a partial understanding of a phenomenon. Knowing the importance of bringing science to life, our grade level team had previously scheduled a field trip to a local visitor center at a volcanic national monument.

Bringing text to life: Field trip. On a sunny spring day our class and several parent volunteers loaded onto a school bus and drove to a volcanic national monument a short distance from our school. Our grade level team and the education director at the national monument collaborated previously to design learning experiences to help students further their understanding of the geologic processes that contributed to the formation of some of our local landforms. We designed these learning experiences to connect directly to what students were experiencing or reading about in the classroom but 
also added newer models, explanations of processes with appropriate examples that we hoped would deepen understanding. This specific knowledge could then help students understand how geologic processes formed other locations. Finally, experts including retired teachers or scientists led the learning experiences at the national monument. These experts gave students important insights with other adults who cared passionately about the same topic that our students were interested in. A key aspect of the field trip was also developing relationships with experts who embody what it means to be both a scientist and a person invested in establishing a relationship with the broader community to help members of this community learn about science. As students unloaded the bus at the volcanic monument, I was excited about the learning experiences we planned that would help students connect their science learning to caring and knowledgeable people, an engaging location, and authentic ways of doing science. 


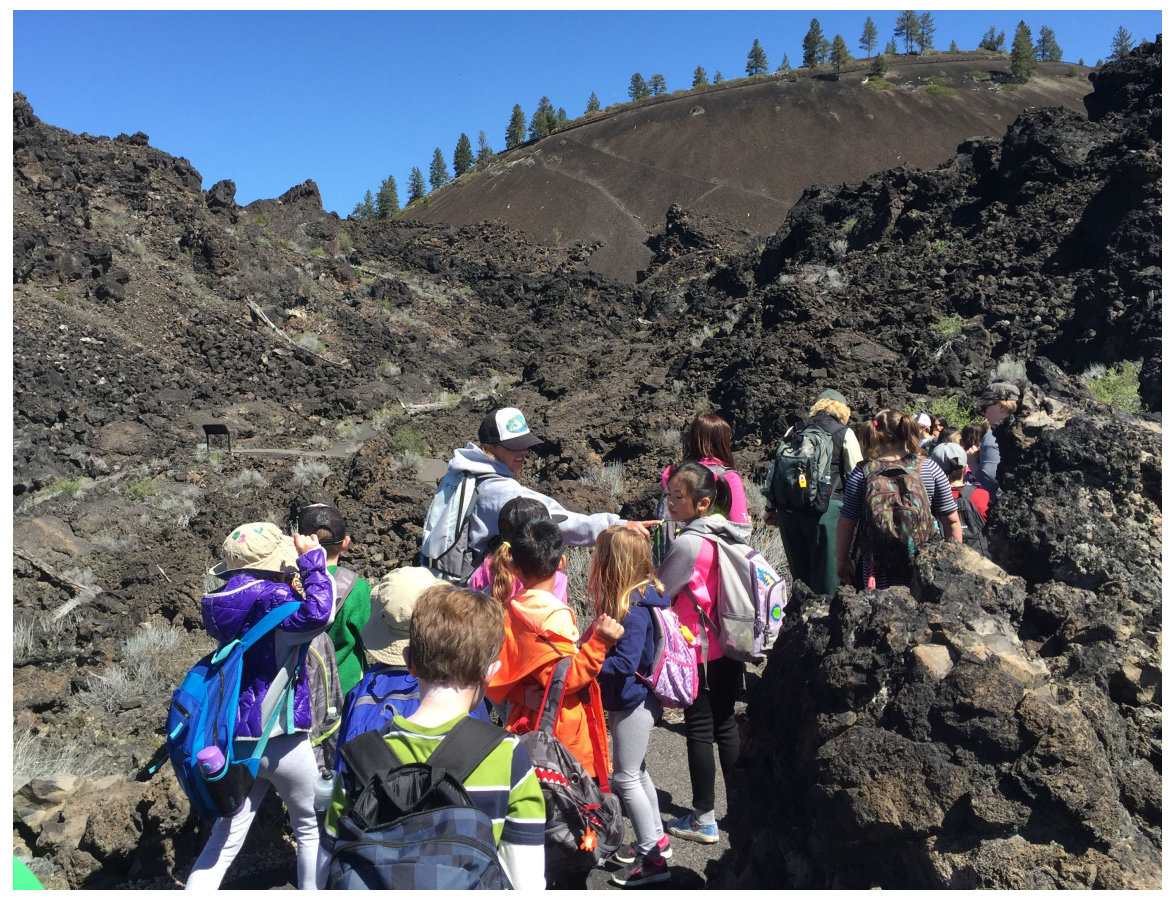

Figure 4.3. Students, parents, and volunteers hiking up the lava flow to view the vent on the cinder cone where the lava flow came from.

During the field trip, students had the opportunity to participate in activities that engaged them in authentic ways of doing science related to the NGSS science practices (NGSS Lead States, 2013). Practices that students participated included practice 2 developing and using models, practice 3 planning and carrying out investigations, and practice 8 obtaining, evaluating, and communicating information. One important model that students explored at the national monument was that of tectonic plates. Students used graham crackers and frosting to model tectonic plates floating on magma. Then, they pushed the crackers together or pulled them apart to show different ways that plate movement creates landforms. We also introduced students to specific processes that scientists use to plan and carry out investigations. A retired geologist showed students how to use the features of a rock and a dichotomous key to classify different types of 
rock. This is similar to the observations we did in the classroom but used more formal scientific processes. Students also had the opportunity to hike across a lava field and peer into the side vent that created the lava flow (see figure 4.3). During this hike, students learned about different types of lava, the silica content of the lava, and the ways lava created different volcanic features. Whereas students had read about silica in lava, now they had the benefit of listening to an expert who explained and showed how different lava types created the different crystal structures in volcanic rocks. This particular piece of information was especially relevant for students because we explored this question previously. Now, we were receiving confirmation of what we had learned.

There were several challenges that created barriers for some students to participate and engage in these learning experiences. One of the challenges was when volunteers were explaining a topic or asking students questions. Several students would look around or talk to their peers while the volunteer was trying to get their attention. This was especially problematic for four students. There are several possible explanations. One may be that students and volunteers had not developed enough rapport with each other to create a solid back and forth communication loop. Certain aspects of communication such as volunteers knowing how to get students attention and students feeling the need to listen can take time to develop for $2^{\text {nd }}$ graders. For example, at the beginning of the year, it took us several weeks before such a communication loop was established. Also, students may have different home experiences about what it means when you go outside. Many families in our region recreate outside. It may be that running, jumping, and exploring away from adult supervision is more common for students than having guided experiences doing science. A final consideration is that 
students may have been overwhelmed by the added stimulation of being at a new location. There were obviously many exciting and interesting things to experience. These challenges were important considerations to think about as teachers plan field trips. In retrospect, there are certain parts of the field trip I would adjust in the future to help support students who had difficulty engaging in the ways we were asking them to participate. For example, I would add a better balance between guided and unguided experiences. The unguided experiences may be important to include because they allow students to explore an area in informal ways that they may have experience with recreating with their families earlier. Such outdoor play has important elements of learning that we may have overlooked in our initial field trip design. Furthermore, it would be important to take into consideration the difficulty of communicating with "strangers" - the volunteers at the center-for $2^{\text {nd }}$ graders on a field trip. We asked volunteers and students to share information without having time to build rapport. During this field trip, we moved through four or five different stations with a different volunteer each time. It may be easier for students to develop such rapport if they have the same volunteer the entire time or if the teacher leads the field trip. Recognizing the challenges of the field trips is important because they show where we can make future improvements.

Moody Park: Service learning and exploration. Several weeks later in late May, during our annual STEM week, our school planned a day of service. As a result, each grade level in the school was going to a different park to pick up trash. The $2^{\text {nd }}$-grade team was heading to Moody Park. Moody Park is several acres of land that includes a large grassy area with trees and picnic tables, a paved walking path, and a playground for 
children. A volcanic ridge behind the manicured area of Moody Park has a trail that people use for walking their dogs. The trail goes steeply up a rough slope and then follows an old service road. During the initial part of the field trip, we picked up trash as planned. However, the manicured part of the park did not have a lot of trash. As we moved further afield, we noticed that the unmanicured parts of the park had more trash. Students were excited to head up the ridge to look for more trash. As we hiked up the ridge, several students started collecting rocks as well. Soon many students switched from looking for trash to looking for interesting rocks to collect. This seemed like a great opportunity to apply the science we had been learning to a new location. I found a discarded fast food cup and had students place different types of rocks into our impromptu container for later study. This unplanned interest ended up adding a learning component to our day of service. Hiking around, exploring, and picking up interesting rocks may be much more in line with students' everyday experience than what we had planned on our field trip to the volcanic monument. As we drove back to our school, I was thinking about how to expand on this student interest to engage them in science learning.

Is Moody Ridge volcanic? The following day after the service at the Moody, we began an investigation into students' questions regarding if volcanic activity formed Moody Ridge. Whereas at the beginning of the unit students made observations of rocks more informally, now we had learned several important scientific processes that we could use to formalize the way we made observations. We placed the rocks we had collected around the room in "observation stations." With each rock, there was a jeweler's loupe, several items to test hardness, a cup of water, and a dichotomous key that we had 
received during our previous field trip to the volcanic national monument. Before we began working on identifying rocks, we reviewed behavior expectations and talked about how scientists use the provided tools. Additionally, I let students know that they would be able to work at their own pace and choose which rocks they wanted to identify as they moved from station to station. Students used the dichotomous key and their own designed float test to classify and identify the different rocks we had found. They recorded the information in a chart that we created together in their science notebooks. The chart included three columns, a number identifying the mystery rock, evidence the students observed, and what type of rock they thought it was. As students were working, I observed students were using the tools provided to make their observations. Many students recorded their observations in their notebooks and were successful in identifying the rocks that we had collected.

After students worked on classifying rocks for 30 minutes, we brought our science journals over to sharing circle. During this portion of the lesson, students shared their initial thoughts regarding our question about Moody Ridge. I prepared students by explaining that we were going to answer the question about Moody Ridge being volcanic by using evidence that we gathered as we observed the rocks that we had collected. I explained to students that we were going to share our claims about what rock we thought they were using an OREO sentence structure. The OREO structure is another example of a practice that is commonly used amongst teachers that does not have a clear origin. I heard about this structure from a $3^{\text {rd }}$ grade teacher at our school who felt our writing curriculum lacked enough explicit support for students in organizing their opinion writing. The $\mathrm{O}$ stands for state the opinion, $\mathrm{R}$ stands for reason, E stands for evidence 
and the final $\mathrm{O}$ stands for restating the opinion. Though a formulaic structure such as OREO takes away some of the cognitive demand, it seems to provide access to this type of explanation for many students. Furthermore, it was already an established routine from writing and therefore allowed students to focus on the content of the claims as opposed to learning a new routine. After several students shared their claims, I asked students to use the OREO sentence structure to write their own thinking about Moody Ridge being volcanic.

What did we learn? There is much discussion in the research literature as described in the STEM content and practices section of the literature review regarding the benefits of supporting student engagement through capturing their interest and letting their questions lead the learning. However, as a teacher, there are several barriers to accomplishing this vision. These barriers include the time required to adapt or design a curriculum, a need for teaching practices that support such curriculum design or adaption, and a school or professional climate that hesitates to leave behind professionally designed curriculum. However, data from this research study provides a description of how student interest and questions can be the driving force behind learning when the teacher has established teaching practices and a clear understanding of NGSS standards as well as the corresponding teaching practices, their students' funds of knowledge, and their local context.

Having a good understanding of students' funds of knowledge and our local context was essential in selecting a phenomenon that would connect with students' interest and give rise to meaningful questions that would lead to an authentic exploration of the NGSS standards for our grade level. Understanding students' funds of knowledge 
happened both informally and formally throughout the year. Informal observations happen on a daily basis as students share about their daily experiences, interact in the classroom, and through observation on the playground and during field trips. Formal ways to garner more information about students' funds of knowledge happened through parent and student questionnaires, writing and speaking prompts, and weekly community circles. Informal and formal observation of students' funds of knowledge indicated that many students participated in recreation activities in the natural areas around our region. Another important feature of their fund of knowledge was their innate interest in the activity of collecting rocks. Many days after recess students would bring in rocks to share with the class. Furthermore, many students participated in rock collecting with their family as this is a popular pastime in our region. Equally important to understanding students' funds of knowledge is being aware of how these funds of knowledge connect with NGSS content and local features that can become objects of study. In our region, we have a rich geologic history with countless volcanic features and a national volcanic monument. Using students' funds of knowledge and an understanding of the local context our grade level team decided to start this unit with the phenomena of collecting rocks and making observations of that rock.

In the unit described above, teaching routines were essential as we delved into the uncharted territory of exploring students' interests. The previously established teaching routines engaged students in NGSS science and engineering practices. Specific teaching routines corresponded to specific NGSS science and engineering practices. For example, the learning began in the same way that we had initiated all of our science units this year, with a carefully selected phenomenon. This was a phenomenon that students had some 
experience with their daily lives and would lead to questions related to corresponding NGSS standards for $2^{\text {nd }}$ grade. We explored this phenomenon using already established teaching practices such as the Observe, Wonder, Learn (OWL) chart. The OWL chart corresponds to the NGSS practices of asking questions, defining problems and planning and carrying out investigations. Because this routine and corresponding practices have been largely introduced in previous units or in previous school years, students could focus on deepening their learning as opposed to learning new routines. From the list of generated questions, the teacher had to select which questions students were most interested in would lead subsequently to further study of the subject. In this case, selecting the appropriate question required deviating from the planned experiences and responding to students' interest. However, such responsiveness may have deepened the learning experience for students because they were able to explore a question in which they were authentically interested. Once a question was selected, the teacher's role was to design learning experiences that would allow students to make sense of the question. The already established teaching practices were instrumental in providing the rungs of the ladder that supported students developing ideas and engagement in NGSS practices. During the course of the unit, students were engaged in NGSS practices including designing and carrying out their investigations, asking questions, clarifying further to define problems, developing and using models, engaging in argument from evidence, and constructing explanations. These practices were instrumental in providing scaffolding as I planned or adapted learning experiences. Rather than having to design from scratch, I was able to connect previously established routines and NGSS practices to the new content that students were interested in. 


\section{Engineering Design to Solve Relevant Problems}

In the following section of this chapter, I describe some of the wealth of knowledge and expertise that $2^{\text {nd }}$-grade students possess regarding building and designing items from everyday objects. Additionally, I describe how $2^{\text {nd }}$-grade students' desire to solve real-world problems can lead them to deeper engagement. Unfortunately, commercially available science curriculum and engineering kits are many times only loosely connected to this student interest, expertise, and sense of enterprise. Student expertise to solve locally relevant problems can be a productive inroad to science and engineering education for many students. Yet, there is still a need to explore how teachers and students can work as co-designers to create such locally relevant engineering projects. One significant theme that emerged during the course of this research project was that the teacher and students might take the lead at different times of a project to facilitate an engaging learning experience for all students.

Everyday engineers. During the course of the school year students, many times shared about building forts, building with Legos, or doing craft projects outside of school. During these everyday activities, students used many different types of materials including Legos, craft supplies, and natural materials found outside. One example of this happened earlier in the year when we went on a field trip to a local natural area to survey the Golden-Mantled Ground Squirrel (Callospermophilus lateralis ${ }^{2}$ ) population. This field trip was part of a larger project where students where making observations of

\footnotetext{
${ }^{2}$ https://en.wikipedia.org/wiki/Golden-mantled ground_squirrel
} 
different habitats and comparing their diversity. During lunch, several students worked together to gather small ponderosa twigs and pine needles to make a "ground squirrel house." This group of students used the twigs to build a dome-shaped frame. The students arranged the twigs in such a way that made a somewhat stable structure. During the course of the building, the house collapsed several times. Students would then rebuild the house slightly differently trying out different ways to arrange the structure to make a sturdy design. This process of planning, building, and rebuilding — creative problem solving - happened without prompting or support from adults and captivated their attention during the entire 15 -minute break.

Another time during the school year that I observed students design and build using everyday objects was during inside recess. When the weather is not conducive to playing outside students stay in the classroom. During this time, students play games, socialize, and work on craft projects. A handful of students always work on craft projects. Students gather supplies and tools and start designing and building their interesting creations. I would many times receive a smattering of "gifts" at the end of recess. I was always amazed at the different hinges and folds the students would use to make pop-up features on their cards. One example was a student who drew a volcano and then added pop-up trees to the volcano that would then fall over when the lava flow (a student's hand) came down the mountain. Both the outdoor and indoor building projects were student imagined and student created without any adult support. This illustrates that many students have expertise in building and can independently design and create objects that they imagine. 


\section{Curriculum from scratch: Designing snack containers. Each year Western}

Elementary organizes a week of STEM activities during their STEM week. On the year that data were being collected for the research project the theme was "reducing waste". We worked with a local nonprofit group, the Environmental Center, to put on an assembly that highlighted the issue of waste in our everyday lives. The town landfill is less than a mile away from our school and many students are familiar with its existence. During the assembly, the presenter showed how much waste is put in the landfill each year and in how many years the landfill would be full. Several different projects sprung up throughout that week in our school including a waste audit, many discussions about reducing waste from school lunches, and a collection of compostable food items that could be donated to a local pig farmer. As part of this school-wide effort, our class worked on an engineering design project that would limit the amount of waste our class produces. We chose to focus on designing a solution to our classroom waste so that students could see the impact their solution was having. In contrast, designing a solution to reduce the amount of waste in Oregon would lack the opportunity to see a measurable change from our intervention. The scale of the problem may be an important consideration and it seems that a smaller scale problem may be more suitable for $2^{\text {nd }}$ grade students because they can see a change from their efforts. An important consideration for this design focus was to give students important learning experiences connected to NGSS standards. In this engineering project, the context of reducing waste led the planning, and NGSS standards guided the way in which the students explored the context. 
Every day our class used one sheet of paper towel per student as part of our snack routine. This seemed like a waste of paper towels, which we could easily fix by substituting a reusable option. Based on this knowledge regarding the flow of waste in the classroom, I decided that we would design and build snack containers. When facilitating a design project with students it may be helpful for the teacher to have an end goal in mind and then present it to students in such a way that they take ownership. This may be important because it helps direct the learning to meet certain standards and scaffolds students' ability to plan and follow-through on a project. Students do have expertise in using everyday materials and can design and build objects on their own. However, teacher scaffolding and facilitation are a key component the help students learn from each other and follow through on design cycles to further improve their projects and help them meet design criteria. On Tuesday, we collected all the paper towels from snack and put them in a pile in the middle of our meeting rug. Students were asked to come over to the rug and to make some observations about the pile of paper towels. Given the large stack of towels, and Monday's school wide events pointing out the problem of waste at our landfill, it did not take long to realize that we had a problem on our hands. In this learning experience, the teacher's role was setting up a situation so that the problem naturally occurred to students. The schoolwide focus was instrumental because it highlighted the local problem to students. The teacher's role was to take this local problem and present it in a way to students so that they could see how they were part of this problem and could be part of the solution. A misconception that I had is that student-led engineering projects need to be entirely student led. An entirely student-led engineering project would be a valuable experience for students. However, facilitating 
such a project with a group of $2^{\text {nd }}$ graders would be logistically challenging and would run the risk over overwhelming both teachers and students. In this project, I presented a situation to students with an outcome in mind. Given a carefully orchestrated discussion, students were quick to realize the problem and seemed excited about designing a solution. I asked students to bring recycled materials from home that might be used in their design.

On Wednesday, many students arrived with recyclables, such as yogurt and cherry tomato containers, plastic water bottles, Legos, and cardboard. During our dedicated STEM learning time, I presented the design challenge to students. Students would need to work together to design a reusable snack container that would help limit the waste that our classroom produces. Students would make these snack containers from a collection of recycled items collected from home or school. Design constraints were that the container had to have a latch, be able to hold a handful of dry snacks and be washable. Students would first draw an individual design and then work with a group to come up with a collective consensus for a design. Students would be designing the container to meet the design constraints using the materials at hand. In doing so, the plan was that students would use their expertise in materials, containers (in terms of shape and size), and latches to come up with a design for their group. This connected to important NGSS learning standards in the Properties of Matter domain that involved observing, classifying, and testing materials (NGSS Lead States, 2013). Whereas, the launch was carefully orchestrated to give students the sense that they were coming up with their project plans, this phase of the learning experience was more teacher directed. This was done intentionally because it would provide necessary scaffolding to direct students in 
learning processes that would lead to successful engineering design. The shared constraints provided a layer of challenge where students would be able to see how other students or other groups addressed this challenge in different ways. This re-emphasized that there is more than one way to solve a problem effectively. The group learning process emphasized first coming up with an individual design and then combining the best ideas from other designs. This was a practiced routine in our class that helped students work together to come up with a design that was a part of strengthening the role of the collective. This previously practiced routine was critical because of the inherent challenge in combining ideas from different individuals. Again, this was planned intentionally so that students could access the important work related to NGSS standards of testing and using materials to solve a problem and not be limited by process-related challenges that may be difficult to navigate for $2^{\text {nd }}$ graders.

An outcome of the previously described learning processes was a great diversity of designs using many different recycled materials. One example of this was how students made latches. Students used different materials including Velcro, magnets, tape, Lego pieces, and pipe cleaners to serve as closures or latches for their containers. For example, the students attached the hook side of the Velcro to one side of the latch and the loop side to the other. When pressed together the hooks and loops stuck the lid to the container. Tape and pipe cleaners were used to create one large hook and loop system. In this system, the students used tape and pipe cleaners to create a loop on one side of the container and then a pipe cleaner was pushed through the loop to create a fastener system. Students glued the magnets to the lid and container. When the magnets came into contact, they would pull the lid to the container. The students used Legos as well. They 
attached one Lego to a lid and the other to the container body. When pressed together, the Legos stuck to each other. In each of these systems, students had to understand the properties of the materials and decide how to use them to come up with a design solution. This indicates that students were engaged in using their understanding of materials to repurpose for a specific goal. It is difficult to say if students would have the same level of engagement in designing a latch if there was no context. It was clear that the context provided an important backdrop for this challenge and motivated student to persevere when they faced difficulty with their design.
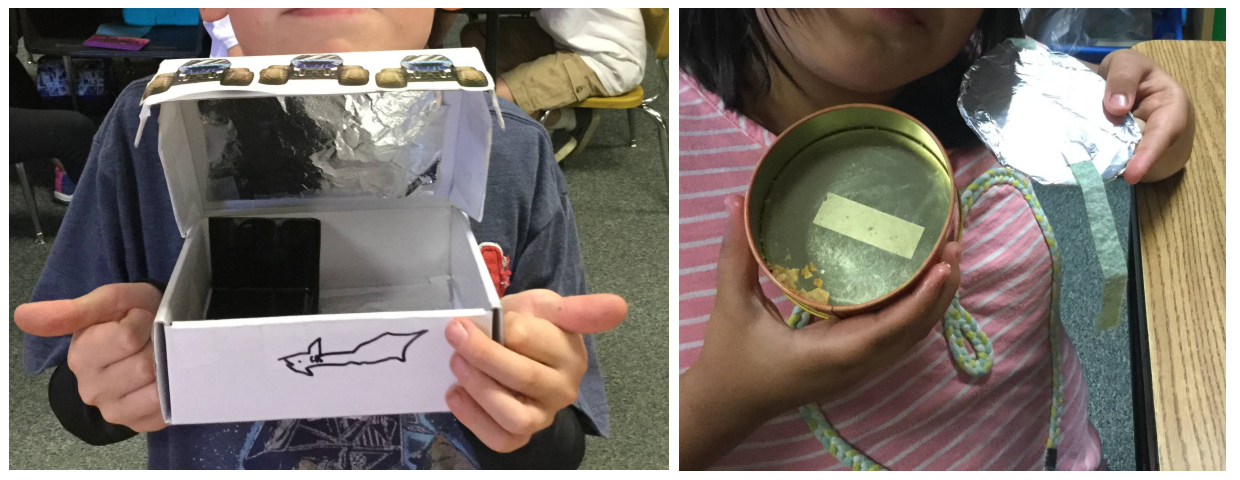

Figure 4.4 Students created their own designs at home and then used their snack containers on a daily basis to reduce the amount of waste our classroom produces.

An important point in the design process was when each group created a design that met the design criteria we had established (see figure 4.4). This was a significant accomplishment but it did not solve the problem of waste in our classroom. We had eight snack containers but needed one for each student. Before we could build the additional containers, unfortunately, we ran out of time and STEM week was drawing to a close. We need to address new curriculum and standards the following week. Though there is 
no one at our school who keeps track of which standards have been addressed, there is a commitment to give all students opportunities to participate in learning activities related to all NGSS standards. However, knowing that students were excited about this project and making the assumption that families would help at home, completing this project was assigned as a homework. As a result, we sent home the design specifications and a description of the project. It was exciting to see the projects start arriving the very next day. Within a week, most students had designed and built their own re-usable snack container and were using it or eating snack every day. The handful of students that were unable to build a snack container at home were allowed to build one during school.

Solving locally relevant problems is an equity-based STEM practice that research described in chapter 2 indicates may increase participation. Solving the problem of limiting our own waste as part of a larger effort to limit waste in the region appeared to be a motivating experience for students. I observed many students working collaboratively with others to design and build their group's re-usable snack container. Furthermore, when students were given the task to design and build their individual snack containers, most students completed this project and brought it back to school. The context of reducing waste was productive because it seemed relevant to students and lent itself to many different projects that could address the NGSS standards. In this project, the teacher's role was providing a framework by posing the problem and facilitating the learning processes. The students' role for this important work was to test materials and use the tested materials to meet the design constraints. As the learning experience progressed, they took greater and greater control until finally at the end of the project when they were designing their own project without any support from me. As I 
facilitated this project, I was amazed to see the degree of ownership the students had for their final designs. One example of this ownership is that every day for the remainder of the school year students used the snack containers and limited our classroom waste.

Adapting existing curriculum: hand pollinators. Whereas the previous design project was created without the use of a pre-existing curriculum, there are other times where it might be helpful to adapt an existing unit. Such was the case towards the end of the school year. We were using a purchased/adopted curriculum which asked students to design an object that would either disperse seeds or pollen (NGSS Lead States, 2013). This commercial curriculum included a context with a problem to be solved by using the engineering design process. The context provided was that several kids were planting a garden. The problem presented was that the children did not have a way to spread seeds around the garden. The task for students was to design an object that would help the kids disperse seeds throughout their garden. There are several problematic aspects with this learning experience. First, this is not actually a problem. Several students in the class have large gardens or live on farms where there is never an issue with spreading seeds because seed dispersal tools for large areas have already been designed. Moreover, most home garden plots are not large enough to require a commercially designed seed dispersal tool. Furthermore, based on previous experience with this task, designing an effective seed dispersal tool with the materials provided by the purchased curriculum led to student failure. Based on these considerations, I sought a different approach.

One pressing local and regional issue is the continued demise of pollinators in our area (Fagen, 2018). There is a regional focus on planting pollinator gardens to help sustain the local pollinator population and an interest in supporting a healthy bee 
population. This is especially important for dwindling wildflower natives in our area that rely on pollinators to reproduce and sustain. In contrast to the premise offered by the purchased curriculum, the demise of pollinators is a real problem that local groups are trying to solve. Within this context, the issue is plants not being pollinated due to a lack of pollinators. An available open source curriculum guides students through designing a hand pollinator that would work with wildflowers. Similar to designing a reusable snack container this context dealt with an actual local problem. Additionally, the design task connected to NGSS standards (NGSS Lead States, 2013) and could be successfully completed by students using available materials and processes with which they were familiar. Having already completed a design task designing a popsicle cooler successfully earlier during the course of this research project it seemed that this design task would help create richer data that supported earlier findings. Instead of changing the teaching processes established from earlier data, we combined the curriculum elements from the purchased curriculum, found curriculum, and previously successfully learning processes to create a learning plan that took the best from each and recombined them to create a unique learning experience for students.

We introduced the task to students with the help of a local biologist from the U. S. Forest Services who works with student groups. Without this important connection, this project would not have had the same depth. We went on a field trip to a natural area that we had studied in the fall when we were learning about species diversity in different habitats. On this field trip, the biologist led us through several learning activities that emphasized different ways that plants are pollinated and the symbiotic relationship between pollinators and flowers. One challenge during the field trip was staying focused 
on the learning — the students became too excited many times about their surroundings. Though students may not have learned all the content provided during the field trip, we referred back to this field trip many times during the following learning experiences. In this way, it was an important connection for students throughout our learning process. At the end of the field trip, the biologist explained that she and other biologists were concerned that if local pollinator populations died off there would be no pollinators to help the wildflowers reproduce. Though this problem was not an actual problem currently, it was plausible enough so that students were concerned enough to design solutions.

There are different ways to approach this problem including designing pollinator gardens and creating bee boxes. However, we needed a design activity that could be done in a classroom by a group of approximately $252^{\text {nd }}$ graders. We adapted a free preview from the Engineering is Elementary curriculum (Museum of Science, Boston, 2015) for our students. This curriculum provided an idea that we could fold into our context and already established learning routines. The following day, we began the engineering designing process. During a whole group discussion, we reminded students of the problem and began exploring different ways to solve it. Based on previous data gathered during the re-usable snack container design project, it would be important to create the conditions that would support students coming to a pre-determined idea while still keeping the discussion open to include many students' solutions. We created a list of possible solutions and then narrowed down the list based on what we could do in the classroom with the limited amount of time and materials. We decided on designing a tool that people could use to move pollen from one plant to another. 
The following day, we asked students to explore materials that students could use to pick up pollen. Materials included pipe cleaners, puffballs, feathers, tape, erasers, and popsicle sticks. The initial exploration was informal to give students a sense of the different materials. After that, groups of students picked three materials that they wanted to explore further. One factor that was different about this design project is that we would be evaluating the materials with an experiment. In the experiment, a model was set up to mimic the process of pollen moving from one flower to the next. We used baking soda in a cup to mimic pollen from one flower while black construction paper cut out in the shape of a flower would be the other flower. When students picked up pollen and moved it to the black flower, they could release pollen and visually see how much pollen landed on the black paper. Students quantified the amount of pollen carried and released by giving it a rating of a small, medium, or a large amount. They recorded this information in their science notebooks to use later during the design part of the project. Students found that cotton balls and feathers were the material that picked up the most pollen. Students shared results with each other using claim and evidence statements. Using claim and evidence statements was an established routine that students had experience with from previous science experiments and from discussing texts during reading.

During the rest of the design project, we closely followed the established routines from previous design projects. Earlier findings from this research project indicated that these routines helped students navigate the complex social and emotional terrain of collaborative group work. For this reason, we continued using the same routines. Students began designing by coming up with ideas independently through sketching. 
Then, groups were established based on the compatibility of ideas and students were given the task of combining different ideas to create a new idea. Once students had combined ideas, they began building the prototype of the idea. When built, they tested their idea and redesigned to help make it work correctly. The end result was that each group designed a unique hand pollinator that could be used to move pollen from one plant to another. In general, the hand pollinators had a handle made of straw and pipe cleaners and one of the tested materials affixed to the top of the handle. The materials, such has pom poms, or feathers, was then used to pick up and move pollen. In this case, we did not build pollinators at home. Rather, students did a gallery walk and voted on their top three favorite designs using stickers. The design that had the most votes was then mass-produced so that every student would have a pollinator to take home.

This final design project looked at whether a project that contained both local and relevant features may be a contributing factor to increasing student engagement. Student expertise from out-of-school experiences in addition to in-school experiences established throughout the year may be equally important to student engagement. Additionally, this final project indicated that the student expertise that comes from a classroom routines and then coming back to them throughout the year has a positive effect on student engagement. Looking at data from the beginning of the research project there is a sense that routines and ways of working together were still being established. Thoughtfully considering the SEL skills required and teaching and/or adapting routines helped students engage in the early design project. However, establishing these routines was even more powerful once students had developed proficiency with them. With the established 
routines and learning processes in place, students were more adept at working together to design solutions to locally relevant problems.

\section{Explanation of Discoveries}

During the course of this research project, I discovered much that is already known. In rediscovering the familiar, my beliefs and practices were affirmed, and my thinking became deeper and more nuanced. Similar to my students picking up a rock and looking at it in a new way, I expanded the way I think about the occurrences in my classroom on a daily basis. This research project helped me understand how the role of teacher and student influence each other in a dialogic process (Freire, 1970/1993) and how the practices that students engage in may be just as important as the content they learn. The practices students used while participating in learning activities will hopefully become adopted and adapted by students as they work towards becoming citizens that seek out knowledge of their world and are motivated to solve problems to make this world a better place. In the following section, I will summarize what I learned about each of the research questions that have guided this project. In the next chapter, I discuss the implications of this research and how it can inform the way that educational organizations support teachers and students in creating E-STEM learning environments.

Co-enacting equity-based STEM teaching practices. If I were to draw a picture of what I learned about co-enacting STEM teaching practices it would be a tree. The trunk and branches of the tree are the routines and learning structures that a teacher puts in place. They are fractal-like patterns that repeat on different scales in different ways and for different purposes. However, like the trunk and branches of a tree, their strength is in its flexibility. When a breeze blows, the branches do not break but rather 
bend with the wind. In teaching, this flexibility occurs when teachers are responsive to the needs and interests of the student. The needs and interests of the students influence how teaching practices are used and for what purpose. I found that balancing structure with flexibility supported my students flourishing in the classroom. Too often classrooms have become places where students are told to learn yet do not get to experience learning. In contrast, during the course of this research project, I asked students to engage in certain practices over and over in different types of situations. These practices allowed them to discover learning for themselves. For example, we wrote about observations, talked about observations with partners, and shared observations with the class. What we observed and how we observed changed based on what we were studying and what students found interesting. What we did with these observations also changed based on our purpose. The pattern of making observations occurred in many different contexts and for many different purposes. This pattern of structure and flexibility may have helped students deepen their understanding of observation and it may have helped transfer this skill of observing to their own lives. Table 4.4 shows several examples of STEM teaching practices, the structured part of these practices, and how it was adapted to incorporate student needs and in different situations. 
Table 4.4

Teaching Practices: Structure and Flexibility

\begin{tabular}{|c|c|c|}
\hline $\begin{array}{c}\text { Teaching } \\
\text { practice name }\end{array}$ & Underlying structure & Notion of flexibility \\
\hline Observation & $\begin{array}{l}\text { Students are asked to use their } \\
\text { senses to describe an object, } \\
\text { phenomenon, or what is being } \\
\text { said. } \\
\text {-What do you notice? }\end{array}$ & $\begin{array}{l}\text {-Students observe how someone } \\
\text { feels when problem-solving } \\
\text {-Students observe a phenomenon } \\
\text { and describe what they think is } \\
\text { making sense } \\
\text {-Students make observations that } \\
\text { change the direction of study on a } \\
\text { field trip } \\
\text {-students observe relevant } \\
\text { features during a design project } \\
\text { and change their design } \\
\text { accordingly }\end{array}$ \\
\hline $\begin{array}{l}\text { Asking } \\
\text { questions }\end{array}$ & $\begin{array}{l}\text { Students ask questions they have } \\
\text { regarding a topic, or a prompt } \\
\text { What do you wonder? }\end{array}$ & $\begin{array}{l}\text {-Asking questions regarding a } \\
\text { science topic which changes the } \\
\text { course of learning } \\
\text {-Asking questions about why a } \\
\text { design problem exists and how it } \\
\text { can be solved } \\
\text {-Asking questions about what } \\
\text { caused a disagreement }\end{array}$ \\
\hline $\begin{array}{l}\text { Explaining } \\
\text { thinking }\end{array}$ & $\begin{array}{l}\text { Students explain the reason } \\
\text { behind what they think } \\
\text { What do you think? }\end{array}$ & $\begin{array}{l}\text {-students develop their own } \\
\text { explanations for how they solved } \\
\text { a math problem } \\
\text {-students explain their thinking } \\
\text { about why or how a phenomenon } \\
\text { occurred } \\
\text {-student explain how they feel } \\
\text { about a pressing friendship } \\
\text { problem }\end{array}$ \\
\hline
\end{tabular}

Each of these examples has the components of both structure and flexibility. The structure is the aspect of the teaching practice that stays the same in different contexts and provides repeated experiences for students to practice a specific way of thinking. This practice, which is repeated, is an important component of providing students 
opportunities to learn. The repeated practice helps reduce the cognitive load on students so they can focus more attention on relevant aspects of learning that are being asked to do. The repeated structure is also very important and essential for reducing the cognitive load on teachers who are adapting the curriculum with limited time or resources available to them. The flexibility with the teaching practice encourages the teacher to respond to students' needs and interests. Flexibility supports integrating student input in the curriculum design process. Each time student input is recognized and incorporated students may be encouraged to make further contributions in the future.

\section{STEM teaching practices influence on student and teacher engagement.}

Implementing equity-based STEM teaching practices has an impact on both teacher and student engagement.

Reflecting on the ebb and flow of my engagement in teaching, I see a strong correlation between my level of engagement and times that I have responded to student input. For example, in all three sections of the analysis, there were incidents that I would describe as jumping off points where student interest or concern required that I adapt or redesign the teaching course that we had established. Examples include when students were not working well together in groups, when students became interested in crystal formation, and when students tackled the problem of school waste. Many times, this meant that I needed to research student questions or concerns, think about experiences that would allow them to learn more about these questions or concerns, and then try out these activities with students. I would argue that these activities are the heart of the teaching profession but much of these skills have been lost in my colleagues as they rely on adopted textbooks and curriculum to engage learners. It is true that such a 
personalized experience for students brings along with it inevitable successes and failures. However, more often than not students reciprocate the engagement I had shown by leaning in and learning with me. This type of reciprocity may be an element of the relationship that has not been part of traditional classroom spaces. I would argue that this type of reciprocity, when given in different contexts across a school year, broadens participation and creates a more equitable learning environment.

During the course of this research project, STEM teaching practices were important tools that supported equitable student engagement with the science and engineering practices outlined in the NGSS standards (NGSS Lead States, 2013). The teaching practices previously described gave students opportunities to participate in meaningful and authentic ways of doing science and engineering. In a class of 24 students, it is reasonable to expect that not all students thought all the learning experiences were meaningful and engaging. Students have different experiences and areas of interest so it is important to provide a broad array of experiences that tap into different students' areas of interest. For that reason, we kept coming back to the different science and engineering practices throughout the year with different content and in different ways. Having repeated exposure to these practices may have helped students adapt and adopt these practices into the ways they approach learning the answers to their questions and designing solutions to problems. This type of engagement and the changes in students' ways of thinking and their identities are difficult to describe fully. I discuss this limitation of the study further in a subsequent part of this chapter. However, this journey continues in my teaching. Now, having completed another two school years, I continue to see the fruits of this type of labor. At the end of the school year, we walked 
out to our local park to make observations about the problem of cheatgrass (Bromus tectorum $^{3}$ ), an invasive species in our region. As we walked back, one student brought me a flower and told me about her observation that the flower had two types of lobes and she wondered why that was. Another student asked about where all the frogs from the previous fall had gone. Yet, another student wanted to show me a pine cone and describe what he or shesaw. The observations, questions, and thinking were bubbling up spontaneously. These are the type of science and engineering practices we had worked on all year and that they were spontaneously being used by students can be seen as an indicator that the STEM teaching practices were effective. Nevertheless, the lingering question I have is where they effective for all and how can we know.

Given the difficulty of measuring and describing individual student engagement due to both IRB constraints and the constraints of occupying both roles of researcher and teacher, it is difficult to say objectively to what degree the projects engaged students. I discuss this issue further in the following section on the limitations of the study. This research project does provide numerous detailed descriptions of students engaged in ESTEM activities. In addition, it adds the unique perspective of teacher engagement while working at creating a more equitable learning experience for students. It is my hope that these observations will provide both researchers and practitioners with valuable insight in

\footnotetext{
${ }^{3}$ https://en.wikipedia.org/wiki/Bromus tectorum
} 
to the type of actions a teacher may take to create a more equitable learning experience for students.

\section{Limitations of the Study}

One main limitation of this study is that it does not try to provide a measurable level of student engagement. Such an accounting of student engagement would be helpful in making claims about what activities are most effective. Initially, this was one of the goals of the study. However, it became clear that to gather fine-grained and reliable data on student engagement there would need to be a greater level involvement of the researcher. It would require a significant amount of time observing student behavior while they are engaged in classroom activities and there would need to be a significant amount of time analyzing data with students to develop a clear picture of student engagement. There were three significant challenges with this level of involvement. First, the teacher/researcher would not be able to adequately perform the role of the teacher because he would be too occupied with gathering data. Second, the major focus on co-creation of learning experiences would at the very least be watered down if not be impossible. Third, the IRB process made the final problem clear. To gather and analyze this amount of data with student input would be disruptive to the normal course of a student's $2^{\text {nd }}$-grade learning experience and would risk harm to the teacher and student relationship. To show a more fine-grained analysis of how teachers and students cocreate engaging learning experiences, we would need additional research staff, funding, and methodologies such as participatory action research for gathering young students' perspectives on engagement without disrupting their school experience 
Another limitation of this study is that it does not provide information on how the study group's race, class, and gender intersect with engagement and equity-based STEM teaching practices. Additionally, this study does not address the question of how engagement in STEM learning during 2nd grade connects with future participation in advanced STEM coursework and STEM careers. These are critical questions to address because of the continuing lag in participation rates of underrepresented genders and minorities in STEM careers (Holdren, Marrett, \& Suresh, 2013). To address both of these questions a team of researchers and teachers would need to work together to create an optimal pathway for STEM learning from the beginning of a students' academic work in Kindergarten, through high school and possibly college, and then to their eventual career. The challenge of creating such an optimal pathway for learning brings up the unfortunate reality that current pathways for STEM achievement for underrepresented students are at best fragmented and at worst non-existent.

The study described in this project was of short duration and did not gather specific data regarding engagement and underrepresented students. It is debatable if student experience in this 2nd-grade class had a positive impact on their engagement in STEM learning. An important tenet of answering questions about race, class, and gender and engagement In STEM learning would be developing methodologies that provide data on participant perspectives without marginalizing the individuals that are participating in the study. Gathering such data was beyond the scope of this research project because of the risk associated with a teacher doing research on their own 2nd-grade students. 


\section{Chapter 5: Discussions}

This chapter begins with a story. As a teacher of young children, stories are what we weave with our students. These are stories of learning, stories of who we are as teachers and students, and where we are in relation to the world. Too often such stories are co-created between student and teacher in relation to place, have positioned students on the margins while a dominant worldview of competition and assimilation is reinforced. There have always been powerful counter currents in society that work towards inclusion and equity but educational institutions continue to be slow to change. Though new educational policies may strive for equity, they many times simultaneously limit the role of teachers and students in classrooms. For example, in our school district, it is common place to invest millions of dollars to purchase curriculum while investing almost nothing in professional development. This policy creates a situation where teachers do not have the tools to adapt and improvise in ways that would include student voice and choice, and often feel unprepared to teach the curriculum that has been placed in their classroom. In similar ways, diverse perspectives have been diminished as having value in research world and in research writing. For example, I should be describing the context of the research problem and summarizing the findings in this section of my paper. However, if we value that voice of teachers and students, we may want to expand our idea of what a research paper should be. Again, there are valuable examples of this happening in the educational research (Susinos \& Haya, 2014; Veale, 2005), but institutions are slow to change. Therefore, I begin with a story, and then I summarize the context of the research problem and findings. After a summary, I discuss each of the findings and connect them to that research data described in Chapter 4. 
Our classroom has one small window that looks out onto a concrete courtyard and a brick wall. Despite the size of this window, it has repeatedly surfaced as an important opportunity for engaging learning. If you stand off to the side of the window, and tilt your head just the right way, you can see the playground, the sky, and the beginning of the sagebrush steppe that extends for hundreds of miles to the east. One afternoon, we were working on an unremarkable academic task when a thunderstorm boomed overhead, and a deluge descended on our school. Second graders rushed to that small window and craned heads to see what was happening. Is this why they designed a school with one tiny window in each classroom? So, students could yearn for a direct experience. Maybe the small window was a metaphor for the way that our society has chosen to educate students. Learning happens between these four walls. We have assessments to measure the effectiveness of this learning, and if you are in need of further support, we have another smaller room with four walls where you can try to learn as well. In any case, we decided to step outside and experience the thunderstorm. As we came back into the classroom, someone exclaimed that you can tell how far away the thunderstorm is by counting the number of seconds between lightning and thunder. So began a lesson on why counting seconds between thunder and lightning tells you the distance the thunderstorm is away from you. In this case, the thunderstorm was an unexpected natural phenomenon that sparked student interest. According to the data from this research project, following such an interest is an important inroad to creating classrooms that are more equitable. Students and teachers can be more engaged by pursuing learning experiences connected to local and relevant phenomena. Furthermore, this initial spark could have led to further investigations that aligned with NGSS 
standards for our grade level. For example, we could have studied the erosion this deluge had created, and then we could have engineered solutions to limit such erosion. In the process, we most likely would have had cause to discuss SEL concepts as well. From this one event, experienced through a tiny window, we could have experienced what it means to engage in authentic learning with others.

Recent calls for equitable access to integrated STEM learning and NGSS standards have led some states, districts, and schools to focus on improving STEM learning experiences for all students. In the preceding example, and in many examples throughout this research project, integrated STEM learning and NGSS standards were a support for what were hopefully relevant and meaningful learning experiences for many students. However, these learning experiences did not arise from a blue sky no less than a thunderstorm occurs from thin air. Rather, equitable learning experiences arise in classrooms when certain conditions exist. In the preceding chapter, I described some of these conditions including the structure and flexibility afforded by equity-based STEM teaching practices, the importance of following student interests and concerns, as well as localizing curriculum. In this chapter, I address the implications and recommendations for creating E-STEM learning experiences based on the conditions that surfaced when researching the following research questions.

1. How do students and teachers negotiate equity-based STEM teaching practices?

2. How do different enactments of STEM teaching practices influence student and teacher engagement? 
Focusing on these questions brought up several important recommendations for creating equitable learning experiences for young children. My emergent recommendations are:

1. Teachers should be seen as professionals;

2. Curriculum design should be responsive to and sustain students' questions, interests, and concerns;

3. Teachers should be encouraged to know their students every day, all year long;

4. Teachers should be supported to use flexible curricular structures throughout;

5. Ongoing high-quality professional development should be provided to all teachers with the goal of creating equitable educational systems.

\section{Putting the Toothpaste Back in the Tube: Re-professionalize Teaching}

As previously discussed, West Elementary is a unique case because it developed a STEM mission that emerged out of a grassroots movement led by teachers to improve the educational experience of students. One precipitating factor that caused this grassroots movement was the global trend of education reform via top-down mandates. As I discussed in the literature review (Chapter 2, p. 28), these mandates have negatively affected many schools throughout the globe and eroded teacher autonomy. These topdown mandates include nationalized standards, mass-produced curriculum, and high stakes testing with accountability measures (Apple, 2001; Bailey, 2000; Kempf, 2016; Kohn, 2000; Valli \& Buese, 2007). Through the advocacy of teacher leaders, school administrators, and a shifting district wide culture led by a new superintendent, the teachers at West Elementary have invested in creating the space they need to reprofessionalize their practice. 
This extensive research project found three productive teaching practices to create E-STEM learning environments are (a) following students' interests and questions, (b) incorporating SEL learning, and (c) solving locally relevant problems. However, the current educational climate may not support teachers adopting these challenging practices. To shift the role of the teacher from that of curriculum delivery mechanism to one of curriculum designer, the following changes should be considered. Teachers require the (a) autonomy to adapt and/or create curriculum based on student input, (b) descriptive standards to support instruction, (c) time to work with teachers to plan learning experiences, and (d) time during the instructional day to teach STEM. Table 5.1 details when certain key resources were salient during this research project, how they were deployed, and why they were significant. 
Table 5.1

Resources to Re-professionalize Practice and Provide E-STEM Learning Experiences

\begin{tabular}{|c|c|c|c|}
\hline Resource & When & How & Why \\
\hline $\begin{array}{l}\text { Autonomy: Ability to } \\
\text { adapt and/or create }\end{array}$ & $\begin{array}{l}\text {-planning for } \\
\text { instruction } \\
\text {-during instruction in } \\
\text { response to students' } \\
\text { interests, questions and } \\
\text { concerns } \\
\text {-after instruction to } \\
\text { prepare for the } \\
\text { following year }\end{array}$ & $\begin{array}{l}\text {-planning with } \\
\text { colleagues following } \\
\text { National/state standards } \\
\text { as a framework } \\
\text {-listening to students } \\
\text {-adapting resources to } \\
\text { local contexts or } \\
\text { creating new resources } \\
\text { based on local context }\end{array}$ & $\begin{array}{l}\text { Teacher autonomy } \\
\text { supported place-based } \\
\text { emphasis, potentiated } \\
\text { efforts to localize } \\
\text { curriculum to } \\
\text { incorporate students' } \\
\text { interests, questions, and } \\
\text { concerns. }\end{array}$ \\
\hline $\begin{array}{l}\text { Descriptive standards } \\
\text { such as NGSS and } \\
\text { CCSS }\end{array}$ & $\begin{array}{l}\text {-when planning for } \\
\text { instruction }\end{array}$ & $\begin{array}{l}\text {-standards are used to } \\
\text { understand the content, } \\
\text { practices, and } \\
\text { connections that } \\
\text { students are able to } \\
\text { learn } \\
\text {-connecting standards to } \\
\text { local context }\end{array}$ & $\begin{array}{l}\text { The standards provided } \\
\text { a framework of } \\
\text { discipline specific } \\
\text { content, practices, and } \\
\text { connections that helped } \\
\text { us articulate and } \\
\text { prioritize what students } \\
\text { can be learning and } \\
\text { how they can learn it. }\end{array}$ \\
\hline $\begin{array}{l}\text { Time to work with } \\
\text { fellow teachers }\end{array}$ & $\begin{array}{l}\text {-when planning for } \\
\text { instruction } \\
\text {-when adapting } \\
\text { instructions based on } \\
\text { students' interests, } \\
\text { questions, and concerns } \\
\text {-when unexpected } \\
\text { events happen that } \\
\text { change the course of } \\
\text { curriculum }\end{array}$ & $\begin{array}{l}\text {-share promising } \\
\text { teaching practices } \\
\text {-design and/or adapt } \\
\text { curriculum to meet the } \\
\text { needs of students } \\
\text {-find ways to integrate } \\
\text { content and standards in } \\
\text { innovative ways }\end{array}$ & $\begin{array}{l}\text { Time to work with } \\
\text { teachers was important } \\
\text { because the sharing and } \\
\text { critiquing of ideals } \\
\text { supported that } \\
\text { adaptation and/or } \\
\text { design of curriculum to } \\
\text { meet the needs of } \\
\text { students and fit the } \\
\text { local context. }\end{array}$ \\
\hline $\begin{array}{l}\text { Allocated regular time } \\
\text { for STEM instruction }\end{array}$ & $\begin{array}{l}\text {-One hour a day was } \\
\text { dedicated to STEM } \\
\text { learning experiences } \\
\text {-autonomy was granted } \\
\text { to shift time from } \\
\text { different subject areas } \\
\text { if needed }\end{array}$ & $\begin{array}{l}\text {-administration allows } \\
\text { flexible use of } \\
\text { instructional time } \\
\text {-integrating content } \\
\text { when possible } \\
\text {-cutting core content } \\
\text { curriculum that was } \\
\text { redundant }\end{array}$ & $\begin{array}{l}\text { Students need time } \\
\text { every day throughout } \\
\text { the year to learn STEM } \\
\text { content, practices, and } \\
\text { connections in an } \\
\text { authentic way. }\end{array}$ \\
\hline
\end{tabular}

Though these resources provided some degree of support to improve teaching and learning, there are still unmet needs that limit the scope and reach of the work being done 
to re-professionalize teaching to improve E-STEM learning opportunities for all students. This is especially true for teachers that have been socialized in the culture of curriculum delivery and accountability, and who may feel uncomfortable designing and implementing STEM learning experiences. In a model that sees the teacher as delivering curriculum and being bound by accountability, there is no room for teaching based on the students' experiences. In such a model, curriculum cannot be adapted and student input falls flat on ears that may hear, but teaching that does not respond. Rather, teaching becomes a rote activity that moves students forward, towards pre-determined standards, but does not build the robust learning identities that all student deserve. To move beyond this still all too present model, teachers need support.

Based on this research project, I address the need for further professional development, and flexible curricular structures across content, in a later section of this chapter. However, states, districts, and schools that would like to enhance student participation in E-STEM learning experiences can strengthen their support for teachers in the strategic ways described in Table 5.1. Needless to point out, many of these supports for teachers are not dependent on fiscal investment but rather a reallocation of time and recommitment to establishing trusting professional relationships.

A key feature of re-professionalizing practice to create a sustainable equity-based STEM learning experience is a generative experience for teachers. Generative learning occurs when "the learner sees the need to integrate new knowledge with existing knowledge and continually reconsiders existing knowledge in the light of new knowledge" (Franke, Carpenter, Levi, \& Fennema, 2001, p. 656). 
During the course of this research project, my colleagues and I were able to use the resources described in Table 5.1 to support STEM learning experiences by focusing on social and emotional learning, incorporating student interest, questions, and concerns, and solving locally relevant problems. Examples of how we did this are documented in Chapter 4. In each of these cases, there was a risk associated with leaving the welltrodden path of curriculum delivery. However, the daily positive and negative feedback from listening to students, prompted us to reconsider the knowledge we had and further develop this knowledge in light of new information. Such a cycle of reflecting on pedagogy, and changing practices, is common for teachers but constrained by the current educational climate. In the current educational climate of following mandated textbooks as curriculum, teachers are told that they are successful when their students achieve benchmarks on standardized assessments. Rather than taking pedagogical risks and developing their knowledge, many teachers dutifully do what they are told and then can fall into the trap of blaming students and families for not achieving benchmarks. However, I would contend that a different system might be necessary if we are reaching towards equitable learning experiences. Rather than mandating curriculum and measuring arbitrary benchmarks, we could pay attention to students' love of learning. In the case of this research project, flexible teaching practices that adapted to students' needs were instrumental in shaping curriculum and subsequent learning experiences. This responsive stance, can position students as having agency and power in their own learning. Such an experience is in direct contrast to the failed institutional practices that perpetuate educational inequity in our nation's schools and leave many students disenfranchised from STEM disciplines. When students experience E-STEM learning 
throughout the school year, both informal and formal feedback from parents and students show that learners are more interested, engaged, and excited about learning. This feedback reinforces the risks we take, confirms the generative knowledge of teaching that we are constantly revising, and strengthens the resolve to continue the pedagogical work that we are developing.

One example of this feedback happened during the spring 2019 as I was writing the final chapters of this dissertation. The story begins one warm sunny afternoon as our class went outside for a break. As soon as we stepped outside, we noticed thousands of butterflies flying over our school. There was a palpable excitement as several students exclaimed, "Can we learn about that?" We embarked on a journey learning about the successive stages of the California Tortoiseshell ${ }^{4}$ butterfly migration that happens annually in our region. Through our research on this species, we learned that on some years these butterflies experience population booms and will migrate vast distances to find new ranges. We read that this year the California desert near Mexico had experienced an especially wet winter, which may have caused a population boom (Spillman, 2019). Then we hypothesized that they California tortoiseshell had flown from the California desert, north along the Eastern Sierra Mountains, and towards the Southern Cascades Mountains. Finally, the butterflies may have veered west and flown above our school. Then in the fall, within 5 months, we thought they might make a dash back south in one generation. Though we could not find much information on this

\footnotetext{
${ }^{4}$ See Lotts \& Naberhaus (2019) for a description of California Tortoiseshell migration.
} 
migration, we thought that they might follow a similar migratory pattern as Monarch Butterflies. Several weeks after school had let out for the summer, I was in the Cascades Mountains when I noticed tens of thousands of these butterflies. I imagined my students having the same experience this summer with their families and now understanding the remarkable journey successive generations of butterflies took to come here. I imagined my students feeling excited about understanding the story about how something came to be, just like I was experiencing in that moment. This feeling of knowing is at the root of learning and is quite different than traditional notions of achievement. One area that is needed for further research, is understanding these type of learning experiences, where the natural environment, learning, and a deeply felt experience combine to create knowledge that is heartfelt.

One promising area that I would like to learn more about is land-based education (Wildcat, McDonald, Irlbacher-Fox, \& Coulthard, 2014). Similar to place-based education (Smith, 2002), land-based education includes an emphasis on the local environment. However, land-based education is deeply rooted in an indigenous experience of land, traditional knowledge, and relationship with the land. Furthermore, land-based education focused on revitalizing indigenous knowledge system has been created since time immemorial. Currently, the focus of land-based education has been on educating indigenous students. However, as we continue to understand more about the negative effect of colonization on all people and our planet, highlighting different knowledge systems centered on relationship with the people, land, and learning will be important to consider. 


\section{Beyond Red, Yellow and Green: Knowing Students}

At a conference several years ago, I met a teacher who told me a story about how teaching had become more focused on knowing if your student was categorized as "red," "yellow," or "green" based on the most recent assessment data than knowing your student as a person. She emphasized this point by sharing that she did not know until the middle of the year that one of her students did not have a bed to sleep on at night, but she knew in the first week that this student was below grade level in reading. In the current educational climate, teachers feel the pressure to raise achievement scores but many times this pressure has made teachers forget who the students are that come to school every day. Ironically, raising student achievement score is advocated for as an equitable outcome widely, but focusing on narrow views of achievement may inadvertently drive teachers to neglect the social and emotional needs of students (Au, 2011; McNeil, 2002). Such pressures are sometimes explicit, as in some states where test scores are used to restructure schools (Ravitch, 2016). In other educational systems, this pressure is implicit but pervades everything school districts do-from buying curriculum resources to the focus of staff meetings and yearly evaluations. An increased focus on a broad view of equity, that includes social and emotional dimensions such as my students found relevant, can re-focus our efforts to see students as more than just achievement scores but as qualities of fellow humans with hopes, fears, interests, and aspirations. Such a multidimensional knowledge of students is at the root of a relationship of care and trust between students and teachers. This research project has helped me see that such a relationship is a significant cornerstone for educational equity. 
During the course of this research project in a classroom facing many of the same barriers and pressure as classrooms across our nation, there were many incidents where knowing students deeply changed the course of our curriculum. Examples from the research project include being responsive to students' intellectual curiosity as well as their social and emotional needs. Examples of being responsive to intellectual curiosity include the following; learning about crystal formation in rocks, and studying a local landform on a field trip to pick up trash. Just as importantly, there were times when responsive changes in curriculum were focused on social and emotional learning. For example, when students were designing their video with Scratch Jr. we spent a significant amount of allocated instructional time learning about the process of working as a team and establishing trusting relationships with each other as peers. A significant change in myself as a teacher due to this research project was understanding that students concerns about social and emotional learning can be on the same level as academic learning to create E-STEM learning experiences for all students.

However, the current educational climate with a concentrated focus on academic outcomes only, mass produced curriculum with an artificial fit to most contexts, and accountability to a standardized test, does little to encourage teachers to be responsive to their students. In her argument to educate the whole child, Nel Noddings (2005) wrote, "We can and should ask all teachers to stretch their subjects to meet the needs and interests of the whole child" (p. 8). Such a broad view of curriculum is critical for developing E-STEM learning experiences that can be "stretched" to include students" interests and needs. Given the constraints teachers face, we may need to work towards changing the educational climate to one that encourages teachers and students to establish 
trusting relationships that are at the core of creating such E-STEM learning experiences.

In Table 5.2, I illustrated in detail some of the barriers that classrooms face and recommendations based on my research project that may overcome those barriers.

Table 5.2

Knowledge of Students: Cornerstone to Creating E-STEM Learning Experiences

\begin{tabular}{|c|c|c|}
\hline Barrier & Recommendation & Explanation \\
\hline $\begin{array}{l}\text { Classroom diversity and } \\
\text { teaching responsibilities } \\
\text { can overwhelm a teacher's } \\
\text { ability to know each student }\end{array}$ & $\begin{array}{l}\text { Lower class sizes-around } \\
20\end{array}$ & $\begin{array}{l}\text { Lower class sizes give } \\
\text { teachers more time to } \\
\text { dedicate to each student and } \\
\text { teachers are able to respond } \\
\text { to students' interests, } \\
\text { concerns, and questions. }\end{array}$ \\
\hline $\begin{array}{l}\text { Teachers feel pressure to } \\
\text { increase test scores and } \\
\text { help students reach } \\
\text { standardized achievement } \\
\text { benchmarks. }\end{array}$ & $\begin{array}{l}\text { Educational leaders at all } \\
\text { levels can emphasize a } \\
\text { balance between academic } \\
\text { learning and social and } \\
\text { emotional learning. }\end{array}$ & $\begin{array}{l}\text { Educational leaders can } \\
\text { create an organizational } \\
\text { culture that supports } \\
\text { teachers knowing their } \\
\text { students and responding to } \\
\text { their students. }\end{array}$ \\
\hline $\begin{array}{l}\text { Teachers may have limited } \\
\text { experience adapting and } \\
\text { designing curriculum based } \\
\text { on their knowledge of } \\
\text { students. }\end{array}$ & $\begin{array}{l}\text { Increase support for } \\
\text { teachers through sustained } \\
\text { professional development } \\
\text { including instructional } \\
\text { coaches, professional } \\
\text { groups, and teacher led } \\
\text { research projects. }\end{array}$ & $\begin{array}{l}\text { Teachers that have } \\
\text { permission and support will } \\
\text { do amazing work with their } \\
\text { students. }\end{array}$ \\
\hline
\end{tabular}

Some of the barriers listed, such as reducing class sizes and providing high quality professional development, require a re-investment in education that must be supported by citizens. For this to happen teachers and educational leaders need to communicate with voters and tax payers the needs that currently exist in classrooms but also a vision for what can be possible given such a re-investment. However, some of the 
recommendations, like emphasizing academic, social, and emotional learning do not require a fiscal investment. Nevertheless, changing a culture requires a commitment to interrogate current practices and change practices based on an expanded vision for education. This research project has shown me that the reward of developing trusting relationships with students, and then trusting this relationship to influence curriculum, is worth the effort. Such efforts to create trusting relationships can have a profound impact on students' opportunity to engage in E-STEM learning experiences. However, if this is only localized in individual classrooms, equitable learning experiences for students will not have a lasting impact. Rather, entire schools and districts could be built around trusting relationships and care. Such a focus would allow teachers to develop their craft with their students and for students to experience equitable learning opportunities throughout their educational experience.

\section{Curricular Structures across Content: Decentralizing Curriculum}

Curricular structures that are flexible yet can be used across content and throughout the year may be an important support for teachers and students designing ESTEM experiences such as those described in Chapter 4. An unfortunate reality is that teachers' workload has become overwhelming in light of federal, state, and local policies as a consequence of NCLB (Valli \& Buese, 2007). Consequences of the ever-expanding NCLB mandates include the demise of teacher-student relationships and the whittling down of teachers' sense of efficacy (Valli \& Buese, 2007). This may be one unfortunate reason that advocating for E-STEM experiences does not gain much traction with elementary school educators. However, implementing curricular structures that can be used as a link across core content areas may provide an important scaffold for teachers 
and students when designing and implementing equity-based learning experiences. These curricular structures are associated with equity-based teaching practices but are more specific in how they connect with curricular goals and allow for student input and adaptation. For example, an equity-based teaching practice may be eliciting student thinking, whereas a curricular structure that elicits student thinking could be a morning meeting, a number talk, or a discussion using text evidence about a book. Following is an example of one such curricular structure and how it supports teacher and student engagement in designing E-STEM learning experiences.

One curricular structure that I used repeatedly during the course of this research project was the OWL chart. OWL stands for "observe, wonder, learn." It is an adaptation from the KWL chart, created by Donna Ogle in $1986^{5}$ is an acronym for "know, wonder, learn". Teachers commonly use the OWL chart in elementary school science classrooms. However, were the OWL chart was first used is unclear and not well documented. That the OWL chart is related to the KWL chart is significant because many elementary teachers and students would have familiarity with the KWL curricular structure and would then only need to understand the differences between the KWL and OWL. The OWL chart is a curricular strategy used to observe phenomena, pose wonderings, and chart their further learning. It was generally used at the beginning of a learning experience. It is related to the equity-based teaching practices of connecting to

\footnotetext{
${ }^{5}$ https://en.wikipedia.org/wiki/KWL_table
} 
students' background knowledge, eliciting student thinking, and letting students chart the course for their own learning. The curricular goal of using the OWL chart was to make observations, ask questions about those observations, and then imagine trajectories for learning about those questions. These goals correspond to the practice standards in NGSS as well as literacy and math standards. During the course of the research project we used the OWL chart to investigate several phenomena as discussed inChapter 4, including data about waste generated in the school, inability of different materials to pick up or collect pollen, features of rocks, and problems that occurred with group work.

The key features of the OWL chart, observe, wonder, and learn categories, stayed the same in each of the times it was used. This was important because students would know what type of thinking was be elicited by the curricular structure. Because students already knew the type of thinking that was being asked, they could focus their cognitive processes on coming up with ideas that would further their own learning and the learning of others. That key features of the curricular structure remain the same would be important for teachers because they would already have the experience to use the structure effectively and thus, they would be able to use it at impromptu times when a learning opportunity within the class occurred. During the research project such an impromptu occurrence happened when we found rocks at Moody Park (Chapter 4, p. 149) and students wanted to learn more about how the landforms at the park were created.

An additional benefit is the flexibility of the curricular structure; it can be used effectively with many different contexts. However, more importantly, it is flexible because student input decides which direction it goes. What students observe and their 
questions become the basis for further learning. For example, when we were observing rocks (Chapter 4, p. 137) students noticed small crystals in the rock. Though this was not part of the planned learning experience, this became a part of the plan because the students were interested in it. To deviate from curricular plans, teachers need to know that they have curricular structures that can be used to support the developing learning trajectory. In the case of investigating the rocks we found, I was able to extend student learning using the pre-established curricular structures of reading and discussing a text, designing an experiment, and using a model to explain how the phenomenon occurred.

The true benefit of using curricular structures that promote equity-based STEM experiences will be realized when educational organizations build these into their support structure for students and teachers. If a school collected a series of curricular structures, students would experience these same structures across content areas and throughout several grades. The inherent flexibility of such structures would allow the structure to grow with students, while still being familiar enough to encourage creativity in thinking and risk taking. Such a series of curricular structures would benefit teachers because they could work with colleagues to continue to innovate such structures, and teachers could use them with their students in different ways. Teachers could develop collective efficacy and would be emboldened to take on the challenge of providing all students with equity-based STEM learning experiences.

\section{Professional Development}

This research project does not provide evidence for the efficacy of high-quality professional development in creating E-STEM learning experiences for students. Highquality professional development has been found to be span several years, include 
collective participation, and contain the core features of content, active learning, and coherence (Garet, Porter, Desimone, Birman, \& Yoon, 2001; Lee \& Buxton, 2010; Lee et al., 2004). At West Elementary, there has not been this kind of high-quality professional development in recent history. Our school district allocates one day a week were students are released one and a half hours early for teacher development/improvement. District and school administration schedules professional development experiences for teachers that include whole school meetings, grade level collaboration, and district wide professional learning activities. Though it seems that this would provide teachers many opportunities to enhance professionally, several key features are lacking. Most notably, the professional learning activities lack collective participation and/or duration. For example, in the last four years West Elementary has had five one-hour professional learning experiences focused on NGSS that all teachers at the school have participated in. It would be hard to argue that a yearly average of less than an hour of professional development on a topic would provide adequate learning experiences to support teacher development. Furthermore, during that same time, $56 \%$ of the staff has turned over. This would mean that even though the entire teaching staff working at the school was involved in each professional development activity, four years later, only $44 \%$ of staff had participated in all sessions. Though teachers have largely been supportive of the STEM focus at West Elementary, there is a growing realization at our school that teachers need sustainable high-quality professional development or teacher attrition will continue. Furthermore, without support, teachers that endure at West elementary will struggle to change teaching practices to provide equitable learning experiences for all students. This trend is mirrored across the nation as teachers largely in favor of higher standards, but 
without adequate professional development, struggle to help students develop the necessary depth in learning or leave the profession at alarming rates (Darling-Hammond, 2003; Garet et al, 2001).

Based on the findings of this research project, I recommend two key goals for professional development that would qualitatively enhance students' access to E-STEM learning activities: (a) increasing teacher flexibility through understanding of subject matter, and (b) increasing teachers' ability to effectively use curricular structures. These two features of teacher practice would allow teachers to incorporate student thinking and student questions in productive ways that align with discipline specific practices. Increasing subject matter knowledge was important during this research project because it allowed our class to explore areas of a topic that fascinated students. One example of this was when we studied the crystals in volcanic rock. Though this was different that the planned learning experience, having knowledge of the subject matter allowed me to connect back to NGSS expectations while honoring student interest in this aspect of the topic. In contrast, lacking an understanding of content can limit a teacher's ability to improvise curriculum. For example, one of our $2^{\text {nd }}$ grade NGSS standards is focused on biodiversity across different ecosystems. In a recent conversation, a fellow teacher asked "what is biodiversity?" That an experienced educator working at a STEM school does not know what biodiversity is points to the failure of our educational system from Kindergarten all the way to teacher education programs and teacher professional learning. We cannot expect teachers to follow student interests and questions if they have not had the necessary support to understand the subject they are being asked to teach. 
The other goal of professional development could be to help teachers understand enduring curricular structures that are flexible and promote equity-based teaching practices. Teachers understanding of such structures would support their ability to change their own teaching practices, as they improvise content, to meet the interests and questions of their students. On one hand, STEM education is still too often characterized by telling students information and then having students re-produce that information on an assignment. On the other hand, it can be too little structure, as in doing "fun" engineering projects that have little to do with using scientific knowledge. Flexible curricular structures, as described in this research project, would be an important scaffold for teachers and students to delve into authentic learning experiences support student engagement in E-STEM practices.

High quality professional development did not have a large impact on this research project because it was practically non-existent. The lack of professional development may have created a situation at West Elementary where students experience dramatically different pedagogy depending on who their teacher is. For all teachers at schools to be able to develop engaging STEM learning experiences with their students they will need to have the necessary professional experiences that give them the confidence and skills to embark on such exciting learning journeys.

\section{Future Directions}

In a Framework for K-12 Science Education, the authors argued that all students should receive learning experiences that will prepare them to "see how science and engineering are instrumental in addressing major challenges that confront society today, such as generating sufficient sustainable energy, preventing and treating diseases, 
maintaining supplies of clean water and food, and solving the problems of global environmental change" (National Research Council, 2012). Furthermore, the framework for K-12 Science Education, and the subsequent NGSS standards that were written using this framework, have specific recommendations for addressing issues of equity for diverse students. However, as Rodriguez (2015) pointed out, such lofty goals are far from being realized in most elementary schools where science instruction is seen as a nice extra-curricular activity that can be squeezed into some extra time after the No Child Left Behind high-demand subjects such as math and reading have been addressed. Even at a school such as West Elementary, where STEM learning experiences are a stated objective, administrators and teachers struggle to find the resources to make the goal of STEM learning experiences a reality. Rodriguez (2015) argued that new standards would not achieve new results unless there is a clear understanding of why science instruction has been waylaid in elementary schools for so long. There is a dearth of research exploring the lack of E-STEM instruction in elementary schools, with emphasis on specific barriers to such instruction, and possible ways to move forward.

This participatory action research project provides valuable insights in the struggles and opportunities that exist in one classroom. Just as importantly, this research project improved the learning experience of myself, the teacher, and students involved. However, this participatory action research project had several constraints that may have limited the opportunities for both learning and action. As discussed in the methodology section of this dissertation, the constraints posed by the IRB, and the constraints of doing research while teaching $2^{\text {nd }}$ graders, limited the ways in which the teacher/researcher and students were able to participate. One challenge encountered during this research project 
was how to gather data on student perspectives while teaching, without taking away time from student's educational experience. This challenge points out a need for further work on developing creative methodologies engaging young students in knowledge production through participatory action research (Veale, 2005). Another challenge was the constraints imposed by the IRB committee. Although they were put in place to safeguard the rights of students, these constraints may have unintentionally limited student participation. I would recommend that IRB committees, education researchers, and potential teacher/researchers work together more extensively to develop a shared understanding of the unique nature of participatory action research methodologies, and how to safeguard students while still giving students authentic ways to participate in knowledge production activities. A final recommendation for making participatory actions research a possibility for teacher/researchers and their students is increasing the level of support for this research from a better partnership between public schools and the universities. In retrospect, it would have been very helpful to have a research assistant, flexible teaching responsibilities, or an online cohort doing similar projects. Such supports would have allowed us to develop an understanding of the student perspective on equity-based teaching practices. Though this participatory action research project was in many ways a success, having adequate support would have further strengthened the work.

Another limitation of this research project is that it did not delve into the important aspects of how students' race, class, gender, interests, and ability influence their engagement with equity-based STEM teaching practices. Historically, students who differ from the norm have been marginalized in education settings. Learning more about 
the unique way individual students interact with E-STEM teaching practices would allow for valuable insights into how these practices may be fine-tuned at the micro-level. An additional limitation of this study is that it only followed students for one year. As I write this, the group of students that participated in this research project are in the $5^{\text {th }}$ grade. They have a mixed experience since then. Some students had experiences in more traditional classroom setting while others had educational experiences more in line with what we were trying to establish in $2^{\text {nd }}$ grade. I am curious as to how all these different experiences have affected their learning and their developing identities. The current participation gaps that still exist in STEM learning opportunities and STEM careers indicate an urgent need to develop a fine-grained understanding of the unique experiences of individual students and how their histories and identities influence their engagement in STEM learning opportunities across time. Follow-up research is required on a larger scale and with a more fine-gained lens to see if the findings of this research project are similar across classrooms and if my recommendations regarding re-professionalizing teaching, knowing all students, curricular structures across content and professional development have an impact on the experience of students and teachers.

On a final note, I leave you with the question. If we could increase E-STEM learning experiences for all elementary school age students, would we? To that question, I would answer, not yet. During this research project I had the opportunity to read an extensive literature base and explore what it takes to create E-STEM learning experiences in my classroom with my students. Though there are still gaps in the research base, there is enough to point educators in a direction that would improve outcomes for many students. However, currently political will to marshal resources for all students does not 
exist. Both students and teachers do not have the support they need to create E-STEM learning environments in elementary school classrooms. The conundrum of working at Western Elementary STEM School is we are given the permission to teach STEM, but without adequate resources, this is both a blessing and a curse. It is a blessing because we can be innovative, try new approaches, and engage students in authentic learning experiences. It is curse, because having permission without the resources leads to fatigue, exhaustion, and eventual burnout. In the last five years, $56 \%$ of our teachers have left our school. Some have left the profession all together. This research project has shown me the power of teachers and students working together to creating E-STEM learning environments. The next step is to begin the critical political work of advocating for the resources teachers and students need to spread E-STEM learning environments for young children throughout our schools, districts, and state. One key avenue towards this goal is helping teachers engage in participatory projects with their young students to create E-STEM learning environments. Doing so, would change the power dynamic in many classrooms and give more young students opportunities to influence how and what they learn in STEM. This research indicates that such participatory opportunities generate new knowledge for teaching and learning and improve the classroom experience for both teachers and students. As students have such learning experiences, it is my hope that they would then grow up and become adults who value equitable learning opportunities. Then, we could revisit the question, if we could increase E-STEM learning experiences for all elementary school age students, would we? The answer would be a resounding YES! 


\section{References}

Aguirre, J., Mayfied-Ingram, K. J., \& Martin, B. D. (2013). The impact of identity in K-8 mathematics: Rethinking equity-based practice. Reston, VA: National Council of Teacher of Mathematics.

Aguirre, J., \& del Rosario Zavala, M. (2013). Making culturally responsive mathematics teaching explicit: A lesson analysis tool. Pedagogies: An International Journal, $8(2), 163-190$.

Anderson, R. D. (2002). Reforming science teaching: What research says about inquiry. Journal of Science Teacher Education, 13(1), 1-12.

Archer, L., Dewitt, J., \& Osborne, J. (2015). Is science for us? Black students' and parents' views of science and science careers. Science Education, 99(2), 199-237.

Atwater, M. M. (1996). Social constructivism: Infusion into the multicultural science education research agenda. Journal of Research in Science Teaching, 33(8), 821837.

Au, W. (2011). Teaching under the new Taylorism: High-stakes testing and the standardization of the 21st century curriculum. Journal of Curriculum Studies, 43(1), 25-45.

$\mathrm{Au}, \mathrm{W}$. (2016). Social justice and resisting neoliberal education reform in the USA. FORUM, 58(3), 315-324.

Apple, M. W. (2001). Comparing neo-liberal projects and inequality in education Comparative Education, 37(4), 409-423. 
Bailey, B. (2000). The impact of mandated change on teachers. In N. Bascia \& A. Hargreaves (Eds.), The sharp edge of educational change (pp. 112-128). New York, NY: Routledge-Falmer.

Bannister, V. P., Bartell, G. B., Battey, D., Hand, V. M., \& Spencer, J. (2007). Culture, race, power, and mathematics education. In F. K. Lester (Ed.), Second handbook of research on mathematics teaching and learning (pp. 405-433). Reston, VA: National Council of Teachers of Mathematics.

Barton, A. C. (1998). Reframing" science for all" through the politics of poverty. Educational Policy, 12(5), 525-541.

Barton, A. C., \& Tan, E. (2009). Funds of knowledge and discourses and hybrid space. Journal of Research in Science Teaching, 46(1), 50-73.

Barton, A. C., \& Tan, E. (2010). We be burnin'! Agency, identity, and science learning. The Journal of the Learning Sciences, 19(2), 187-229.

Blank, R. K. (2013), Science instructional rime is declining in elementary schools: What are the implications for student achievement and closing the gap? Science Education, 97, 830-847.

Bay-Williams, J. M., \& Livers, S. (2009). Supporting math vocabulary acquisition. Teaching Children Mathematics, 16(4), 238-245.

Boaler, J. (2008). Promoting 'relational equity' and high mathematics achievement through an innovative mixed-ability approach. British Educational Research Journal, 34(2), 167-194. 
Boaler, J., \& Staples, M. (2008). Creating mathematical futures through an equitable teaching approach: The case of Railside School. The Teachers College Record, 110(3), 608-645.

Brown, B. A. (2006). "It isn't no slang that can be said about this stuff": Language, identity, and appropriating science discourse. Journal of Research in Science Teaching, 43(1), 96-126.

Brown, B. A., \& Spang, E. (2008). Double talk: Synthesizing everyday and science language in the classroom. Science Education, 92(4), 708-732.

Brown, B. A., \& Ryoo, K. (2008). Teaching science as a language: A “content-first" approach to science teaching. Journal of Research in Science Teaching, 45(5), 529-553.

Brown-Jeffy, S., \& Cooper, J. E. (2011). Toward a conceptual framework of culturally relevant pedagogy: An overview of the conceptual and theoretical literature. Teacher Education Quarterly, 38(1), 65-84.

Buxton, C. A. (2006). Creating contextually authentic science in a "low-performing" urban elementary school. Journal of Research in Science Teaching, 43(7), 695721.

Cadwell, R. J., Fiedler, F., Haynie, K., Kern, L. A., Laumatia, L., Meyer, C., \& NavickisBrasch, A. S. (2014, June). Restoring water, culture, and relationship: Using a community based participatory research methodology for engineering education. Paper presented at the American Society for Engineering Education, Indianapolis, IN. 
Camarata, S. (2017). The intuitive parent: Why the best thing for your child is you. New York, NY: Penguin.

Cazden, C. B. (1988). Classroom discourse: The language of teaching and learning. Portsmouth, NH. Heinneman.

Celedón-Pattichis, S., \& Ramirez, N. G. (Eds.). (2012). Beyond good teaching: Advancing mathematics education for ELLs. Reston, VA: National Council of Teachers of Mathematics.

Chapin, S. H., \& O’Connor, C. (2007). Academically productive talk: Supporting students' learning in mathematics. For the Learning of Mathematics, +, 113-128.

Civil, M. (2007). Building on community knowledge: An avenue to equity in mathematics education. In N. S. Nasir \& P. Cobb (Eds.), Improving access to mathematics: Diversity and equity in the classroom (pp. 105-117). New York, NY: Teachers College Press.

Civil, M., \& Planas, N. (2004). Participation in the mathematics classroom: does every student have a voice? For the Learning of Mathematics, 7-12.

Clandinin, D. J., \& Connelly, F. M. (1992). Teacher as curriculum maker. In P. W. Jackson (Ed.), Handbook of research on curriculum (pp.363-401). New York. NY: Macmillan.

Cobb, P., Confrey, J., Lehrer, R., \& Schauble, L. (2003). Design experiments in educational research. Educational Researcher, 32(1), 9-13.

Cobb, P., \& Hodge, L. L. (2002). A relational perspective on issues of cultural diversity and equity as they play out in the mathematics classroom. Mathematical Thinking and Learning, 4(2-3), 249-284. 
Coghlan, D., \& Brydon-Miller, M. (Eds.). (2014). The SAGE encyclopedia of action research. Thousand Oaks, CA: SAGE.

Cohen, E. G., \& Lotan, R. A. (1995). Producing equal-status interaction in the heterogeneous classroom. American educational research journal, 32(1), 99-120.

Common Core State Standards for Mathematics. (2010). Common core state standards for mathematics. Washington, DC: National Governors Association Center for Best Practices and the Council of Chief State School Officers.

Cook-Sather, A. (2006). Sound, presence, and power: "Student voice" in educational research and reform. Curriculum Inquiry, 36(4), 359-390.

Craig, C. J. (2012). "Butterfly under a pin": An emergent teacher image amid mandated curriculum reform. The Journal of Educational Research, 105(2), 90-101.

Creswell, J. W. (2013). Qualitative inquiry and research design: Choosing among five approaches. Thousand Oaks, CA: SAGE

Czerniak, C. M., \& Johnson, C. C. (2007). Interdisciplinary science teaching. In S. K. Abell \& N. G. Lederman (Eds.), Handbook of research on science education. (pp. 537-559). London: Routledge.

Darling-Hammond, L. (2003). Keeping good teachers: Why it matters, what leaders can do. Educational Leadership, 60(8), 6-13.

Darling-Hammond, L., Burns, D., Campbell, C., Goodwin, A. L., Hammerness, K., Low, E-L., McIntyre, A., Sato, M, \&. Zeichner, K (2017). Empowered educators: How high-performing systems shape teaching quality around the world. San Francisco, CA: John Wiley \& Sons. 
DeFur, S. H., \& Korinek, L. (2010). Listening to student voices. The Clearing House: A Journal of Educational Strategies, Issues and Ideas, 83(1), 15-19.

Delpit, L.D. (1988). The silenced dialogue: Power and pedagogy in educating other people's children. Harvard Educational Review, 58(3), 280-299.

Delpit, L. D. (2006). Other people's children: Cultural conflict in the classroom. New York, NY: The New Press.

Dewey, J. (1938). Democracy and education in the world of today. New York, NY: Society for Ethical Culture and the Ethical Culture Schools.

Diaz-Strong, D., Luna-Duarte, M., Gómez, C., \& Meiners, E.R. (2014). Too close to the work/there is nothing right now. In D. Paris, \& M.T. Winn (Eds.), Humanizing research: Decolonizing qualitative inquiry with youth and communities (pp.3-19). Thousand Oaks, CA: SAGE.

Durlak, J. A. (Ed.). (2015). Handbook of social and emotional learning: Research and practice. Guilford Publications.

Durlak, J. A., Weissberg, R. P., Dymnicki, A. B., Taylor, R. D., \& Schellinger, K. B. (2011). The impact of enhancing students' social and emotional learning: A metaanalysis of school-based universal interventions. Child Development, 82(1), 405432.

Eisenhart, M., Finkel, E., \& Marion, S. F. (1996). Creating the conditions for scientific literacy: A re-examination. American Educational Research Journal, 33(2), 261295. 
Emdin, C. (2010a). Affiliation and alienation: hip-hop, rap, and urban science education. Journal of Curriculum Studies, 42(1), 1-25.

Emdin, C. (2010b). Urban science education for the hip-hop generation. Rotterdam: Sense.

Fagen, D. (2018, May 3). In praise of pollinators: Bees and other insects play an important role in agricultural production. The Bulletin. Retrieved from https://www.bendbulletin.com/sp/5091575-151/in-praise-of-pollinators

Father Luke, the KKK, and the Doctrine of Americanism in Bend. (2017). The Homesteader,43(5), 1, 3-4, 6-8. Retrieved from https://www.deschuteshistory.org/wp-content/uploads/2014/07/2017-MayHomesteader.pdf

Featherstone, H., Crespo, S., Jilk, L., Oslund, J., Parks, A. \& Wood, M. (2011). Smarter together! Collaboration and equity in the elementary math classroom. Reston, VA: National Council of Teachers of Mathematics.

Felitti, V. J., Anda, R. F., Nordenberg, D., Williamson, D. F., Spitz, A. M., Edwards, V., \& Marks, J. S. (2019). Relationship of childhood abuse and household dysfunction to many of the leading causes of death in adults: The Adverse Childhood Experiences (ACE) Study. American Journal of Preventive Medicine, 56(6), 774-786.

Flores, A. (2007). Examining disparities in mathematics education: Achievement gap or opportunity gap? The High School Journal, 91(1), 29-42. 
Fradd, S. H., \& Lee, O. (1999). Teachers' roles in promoting science inquiry with students from diverse language backgrounds. Educational Researcher, 28(6), 1442.

Franke, M. L., Carpenter, T. P., Levi, L., \& Fennema, E. (2001). Capturing teachers’ generative change: A follow-up study of professional development in mathematics. American Educational Research Journal, 38(3), 653-689.

Frankenstein, M. (1990). Incorporating race, gender, and class issues into a critical mathematical literacy curriculum. The Journal of Negro Education, 59(3), 336347.

Freire, P. (1970/1993). Pedagogy of the oppressed (New rev. 20 $0^{\text {th }}$ Anniversary ed.). New York: Continuum

Frey, N., Fisher, D., \& Smith, D. (2019). All Learning is Social and Emotional: Helping Students Develop Essential Skills for the Classroom and Beyond. ASCD.

Frykholm, J., \& Glasson, G. (2005). Connecting science and mathematics instruction: Pedagogical context knowledge for teachers. School Science and Mathematics, 105(3), 127-141.

Fortus, D., Dershimer, R. C., Krajcik, J., Marx, R. W., \& Mamlok-Naaman, R. (2004). Design-based science and student learning. Journal of Research in Science Teaching, 41(10), 1081-1110.

Fusco, D., \& Barton, A. C. (2001). Representing student achievements in science. Journal of Research in Science Teaching, 38(3), 337-354. 
Garet, M. S., Porter, A. C., Desimone, L., Birman, B. F., \& Yoon, K. S. (2001). What makes professional development effective? Results from a national sample of teachers. American Educational Research Journal, 38(4), 915-945.

Gay, G. (2010). Culturally responsive teaching: Theory, research, and practice. New York, NY: Teachers College Press.

Gee, J. P. (2000). Identity as an analytic lens for research in education. Review of Research in Education, 25(1), 99-125.

Geier, R., Blumenfeld, P. C., Marx, R. W., Krajcik, J. S., Fishman, B., Soloway, E., \& Clay-Chambers, J. (2008). Standardized test outcomes for students engaged in inquiry-based science curricula in the context of urban reform. Journal of Research in Science Teaching, 45(8), 922-939.

González, N., Moll L., \& Amanti C. (Eds.) (2006). Funds of knowledge: Theorizing practices in households, communities, and classrooms. Mahwah, NJ: Erlbaum.

González, N., Andrade, R., Civil, M., \& Moll, L. (2001). Bridging funds of distributed knowledge: Creating zones of practices in mathematics. Journal of Education for Students Placed at Risk, 6(1-2), 115-132.

Gopnik, A., Meltzoff, A. N., \& Kuhl, P. K. (1999). The scientist in the crib: Minds, brains, and how children learn. Farfield, NJ: William Morrow \& Co.

Greer, B., Mukhopadhyay, S., Powell, A. B., \& Nelson-Barber, S. (Eds.). (2009). Culturally responsive mathematics education. New York: Routledge.

Guba, E. G., \& Lincoln, Y. S. (1989). Fourth generation evaluation. Newbury Park, CA: SAGE. 
Gutiérrez, R. (2002). Enabling the practice of mathematics teachers in context: Toward a new equity research agenda. Mathematical Thinking and Learning,4(2-3), 145187.

Gutiérrez, R. (2008). A “gap-gazing” fetish in mathematics education? Problematizing research on the achievement gap. Journal for Research in Mathematics Education, (29), 357-364.

Gutiérrez, R. (2013). The sociopolitical turn in mathematics education. Journal for Research in Mathematics Education, 44(1), 37-68.

Gutiérrez, K. D., \& Rogoff, B. (2003). Cultural ways of learning: Individual traits or repertoires of practice. Educational researcher, 32(5), 19-25.

Gutstein, E. (2003). Teaching and learning mathematics for social justice in an urban, Latino school. Journal for Research in Mathematics Education, 34(1), 37-73.

Gutstein, E. (2006). Reading and writing the world with mathematics: Toward a pedagogy for social justice. New York, NY: Routledge.

Gutstein, E., \& Peterson, B. (Eds.). (2005). Rethinking mathematics: Teaching social justice by the numbers. Milwaukee, WI: Rethinking Schools.

Hand, V. (2003). Reframing participation: Meaningful mathematical activity in diverse classrooms. Unpublished dissertation, Stanford University, Stanford, CA.

Hargreaves, A., \& Fullan, M. (1998). What's worth fighting for out there?. New York, NY: Teachers College Press

Hartman, S. L., Hines-Bergmeier, J., \& Klein, R. (2017). Informal STEM learning: The state of research, access, and equity in rural early childhood settings. Journal of Science Education and Civic Engagement, 9, 32-39. 
Henningsen, M., \& Stein, M. K. (1997). Mathematical tasks and student cognition: Classroom-based factors that support and inhibit high-level mathematical thinking and reasoning. Journal for Research in Mathematics Education, 524-549.

Heron, J., \& Reason, P. (1997). A participatory inquiry paradigm. Qualitative inquiry, 3(3), 274-294.

Herschbach, D. R. (2011). The STEM initiative: Constraints and challenges. Journal of STEM Teacher Education, 14(1), 96-122.

Hiebert, J. (1997). Making sense: Teaching and learning mathematics with understanding. Portsmouth, NH: Heinemann.

Holland, D., Lachicotte, W., Skinner, D., \& Cain, C. (1998.) Identity and agency in cultural worlds. Cambridge, MA: Harvard University Press.

Holdren, J. P., Marrett, C., \& Suresh, S. (2013). Federal science, technology, engineering, and mathematics (STEM) education 5-year strategic plan: A report from the Committee on STEM Education National Science and Technology Council. Washington, DC: Executive Office of the President National Science and Technology Council..

Howard, T. (2012). Culturally responsive pedagogy. In J.A Banks (Ed.), Encyclopedia of Diversity in Education (pp. 1-7). Thousand Oaks, CA: SAGE.

Hudicourt-Barnes, J. (2003). The use of argumentation in Haitian Creole science classrooms. Harvard Educational Review, 73(1), 73-93.

Hufferd-Ackles, K., Fuson, K. C., \& Sherin, M. G. (2004). Describing levels and components of a math-talk learning community. Journal for Research in Mathematics Education, 35(2), 81-116. 
Hursh, D. (2007). Assessing No Child Left Behind and the rise of neoliberal education policies. American Educational Research Journal, 44(3), 493-518.

Jenkins, D. L., Davis, L. G., Stafford Jr, T. W., Campos, P. F., Connolly, T. J., Cummings, L. S., ... \& O’Grady, P. W. (2013). Geochronology, archaeological context, and DNA at the Paisley Caves. Paleoamerican Odyssey, 32, 485-510.

Johnson, C. C. (2011). The road to culturally relevant science: Exploring how teachers navigate change in pedagogy. Journal of Research in Science Teaching, 48(2), 170-198.

Jones, S. M., Bouffard, S. M., \& Weissbourd, R. (2013). Educators' social and emotional skills vital to learning. Phi Delta Kappan, 94(8), 62-65.

Kazemi, E., \& Stipek, D. (2001). Promoting conceptual thinking in four upperelementary mathematics classrooms. The Elementary School Journal, 102(1) 5980.

Kemmis, S., \& McTaggart, R. (1988). The action research reader. Geelong, Victoria: Deakin University Press.

Kemmis, S., McTaggart, R., \& Nixon, R. (2013). The action research planner: Doing critical participatory action research. New York, NY: Springer.

Kempf, A. (2016). The pedagogy of standardized testing: The radical impacts of educational standardization in the US and Canada. New York, NY: Springer.

Kohn, A. (2000). Standardized testing and its victims. Education Week, 20(4), 46-47.

Krathwohl, D. R. (2009). Methods of educational and social science research: The logic of methods. Long Grove, IL: Waveland Press.

Ladson-Billings, G. (1995). Toward a theory of culturally relevant pedagogy. American 
Educational Research Journal, 32, 465-491.

Lather, P. (1992). Critical frames in educational research: Feminist and post-structural perspectives. Theory Into Practice, 31(2), 87-99.

Lee, O. (2003). Equity for culturally and linguistically diverse students in science education: Recommendations for a research agenda. The Teachers College Record, 105(3), 465-489.

Lee, O. (2004). Teacher change in beliefs and practices in science and literacy instruction with English language learners. Journal of Research in Science Teaching, 41(1), $65-93$.

Lee, O., \& Buxton, C. A. (2010). Diversity and equity in science education: Research, policy, and practice. New York, NY: Teachers College Press.

Lee, O., Fradd, S. H., \& Sutman, F. X. (1995). Science knowledge and cognitive strategy use among culturally and linguistically diverse students. Journal of Research in Science teaching, 32(8), 797-816.

Lee, O., Hart, J. E., Cuevas, P., \& Enders, C. (2004). Professional development in inquiry-based science for elementary teachers of diverse student groups. Journal of Research in Science Teaching, 41(10), 1021-1043.

Lee, O., \& Luykx, A. (2006). Science education and student diversity: Synthesis and research agenda. Cambridge, MA: Cambridge University Press.

Lotts, K. \& Naberhaus, T. (2019). California Tortoiseshell. Retrieved from https://www.butterfliesandmoths.org/species/Nymphalis-californica 
Martin, D. B. (2009). Liberating the production of knowledge about African American children mathematics. In D. B. Martin (Ed.), Mathematics teaching, learning, liberation in the lives of black children (pp. 3-36). New York, NY: Routledge.

Maxwell, J. A. (2013). Qualitative research design: An interactive approach. Thousand Oaks, CA: SAGE.

McNeil, L. (2002). Contradictions of school reform: Educational costs of standardized testing. New York, NY: Routledge.

McNeill, K. L., Katsh-Singer, R., \& Pelletier, P. (2015). Assessing science practices: Moving your class along a continuum. Science Scope, 39(4), 21.

Mitra, D. L. (2004). The significance of students: can increasing" student voice" in schools lead to gains in youth development?. Teachers College Record, 106, 651688.

Morgan, P. L., Farkas, G., Hillemeier, M. M., \& Maczuga, S. (2016). Science achievement gaps begin very early, persist, and are largely explained by modifiable factors. Educational Researcher, 45(1), 18-35.

Moschkovich, J. (1999). Supporting the participation of English language learners in mathematical discussions. For the Learning of Mathematics, 19(1), 11-19.

Moschkovich, J. (2007). Examining mathematical discourse practices. For the Learning of Mathematics, 27(1), 24-30.

Mukhopadhyay, S. (2009). The decorative impulse: ethnomathematics and Tlingit basketry. ZDM, 41(1-2), 117-130.

Nasir, N. I. S. (2004). " Halal-ing" the child: Reframing identities of resistance in an urban Muslim school. Harvard Educational Review, 74(2), 153-174. 
National Academy of Education. (1999). Recommendations regarding research priorities: An advisory report to the National Educational Research Policy and Priorities Board. New York, NY: Author.

National Research Council. (2011). Successful K-12 STEM education: Identifying effective approaches in science, technology, engineering, and mathematics. Washington, DC: National Academies Press.

National Research Council. (2012). A framework for K-12 science education: Practices, crosscutting concepts, and core ideas. Washington, DC: National Academies Press.

NGSS Lead States. (2013). Next generation science standards: For states, by states. Washington, DC: The National Academy Press.

Noddings, N. (2005). What does it mean to educate the whole child? Educational leadership, 63(1), 8 .

Oregon Department of Education. (2019). Assessment results. Retrieved from http://www.ode.state.or.us/search/page/?id=1302

Paris, D., \& Winn, M. T. (Eds.). (2014). Humanizing research: Decolonizing qualitative inquiry with youth and communities. Thousand Oaks, CA: SAGE.

Parsons, E. C., Travis, C., \& Simpson, J. S. (2005). The Black cultural ethos, students' instructional context preferences, and student achievement: An examination of culturally congruent science instruction in the eighth grade classes of one African American and one Euro-American teacher. Negro Educational Review, 56(2/3), 183. 
Penuel, W. R., Lee, T., \& Bevan, B. (2014). Designing and building infrastructures to support equitable STEM learning across settings. San Francisco, CA: Research+ Practice Collaboratory.

Perry, T., Steele, C., \& Hilliard, A. (2003). Young, gifted, and Black. Promoting high achievement among African-American students. Boston, MA: Beacon.

Plano-Clark, V. L., \& Creswell, J. W. (2010). Understanding research: A consumer's guide. Boston, MA: Pearson.

Rahm, J., \& Moore, J. C. (2016). A case study of long-term engagement and identity-inpractice: Insights into the STEM pathways of four underrepresented youths. Journal of Research in Science Teaching, 53(5), 768-801

Ravitch, D. (2016). The death and life of the great American school system: How testing and choice are undermining education. New York, NY: Basic Books.

Rodriguez, A. J. (1998). Strategies for counterresistance: Toward sociotransformative constructivism and learning to teach science for diversity and for understanding. Journal of Research in Science Teaching, 35(6), 589-622.

Rodriguez, A. J. (2015). What about a dimension of engagement, equity, and diversity practices? A critique of the next generation science standards. Journal of Research in Science Teaching, 52(7), 1031-1051.

Roehrig, G. H., Moore, T. J., Wang, H. H., \& Park, M. S. (2012). Is adding the E enough? Investigating the impact of $\mathrm{K}^{-12}$ engineering standards on the implementation of STEM integration. School Science and Mathematics, 112(1), $31-44$. 
Roemeling, A. (2018, November 17). Violent student behavior on the rise officials say. Retrieved from https:/www.registerguard.com/news/20181117/violent-studentbehaviors-on-rise-officials-say

Rosebery, A., Warren, B., Ballenger, C., \& Ogonowski, M. (2005). The generative potential of students' everyday knowledge in learning science. In T. Romberg, T. Carpenter, \& F. Dremock (Eds.). Understanding matters: Improving student learning in mathematics and science (pp. 55-80). Mahwah, NJ: Erlbaum. .

Roth, W. M., \& Barton, A. C. (2004). Rethinking scientific literacy. New York, NY: Routledge.

Roth, W. M., \& Désautels, J. (2002). Science education as/for sociopolitical action. counterpoints: Studies in the postmodern theory of education. New York, NY: Peter Lang..

Roth, W. M., \& Lee, S. (2004). Science education as/for participation in the community. Science Education, 88(2), 263-291.

Ruby, R. H., Brown, J. A., \& Collins, C. C. (2013). A guide to the Indian tribes of the Pacific Northwest ( $3^{\text {rd }}$ ed.). Norman, OK: University of Oklahoma Press

Sandoval-Taylor, P. (2006). Home is where the heart is: A funds of knowledge-based curriculum module. In N. Gonzalez, L. C. Moll, \& C. Amanti (Eds.), Funds of knowledge: Theorizing practices in households, communities, and classrooms (pp. 165-178). New York, NY: Routledge.

Sarama, J., Clements, D., Nielsen, N., Blanton, M., Romance, N., Hoover, M., Staudt, C., Baroody, A., McWayne, C., and McCulloch, C., (2018). Considerations for STEM education from PreK through grade 3. Waltham, MA: Education 
Development Center. Retrieved from http://cadrek12.org/resources/considerationsstem-education-prek-through-grade3.

Saxton, E., Burns, R., Holveck, S., Kelley, S., Prince, D., Rigelman, N., \& Skinner, E. A. (2014). A Common Measurement System for K-12 STEM education: Adopting an educational evaluation methodology that elevates theoretical foundations and systems thinking. Studies in Educational Evaluation, 40, 18-35.

Schoenfeld, A. H. (1992). Learning to think mathematically: Problem solving, metacognition, and sense making in mathematics. In D. A. Grouws (Ed.), Handbook of research on mathematics teaching and learning (pp. 334-370). New York, NY: Macmillan.

Seiler, G. (2001). Reversing the "standard" direction: Science emerging from the lives of African American students. Journal of Research in Science Teaching, 38(9), 1000-1014.

Seiler, G., \& Elmesky, R. (2007). The role of communal practices in the generation of capital and emotional energy among urban African American students in science classrooms. The Teachers College Record, 109(2), 391-419.

Shulman, L. S. (1987). Knowledge and teaching: Foundations of the new reform. Harvard Educational Review, 57(1), 1-23.

Skovsmose, O. (1990). Mathematical education and democracy. Educational Studies in Mathematics, 21(2), 109-128. 
Skovsmose, O., \& Borba, M. (2004). Research methodology and critical mathematics education. In P. Valero \& R. Zevenbergen (Eds.), Researching the socio-political dimensions of mathematics education (pp. 207-226). New York, NY: Springer.

Skovsmose, O., \& Greer, B. (2012). Opening the cage: Critique and politics of mathematics education. New York, NY: Springer.

Slattery, P. (2006). Curriculum development in the postmodern era: Teaching and learning in an age of accountability. New York, NY: Routledge.

Smith, G. A. (2002). Place-based education: Learning to be where we are. Phi Delta Kkappan, 83(8), 584-594.

Smith, L. T. (1999). Decolonizing methodologies: Research and indigenous peoples. London: Zed Books.

Smyth, J. (2006). Educational leadership that fosters 'student voice.' International Journal of Leadership in Education, 9(4), 279-284.

Spillman, B. (April, 2019). Migrating California butterflies descend on the Lake Tahoe Basin high Country. Retrieved from https://www.rgj.com/story/news/2019/08/07/lake-tahoe-basin-high-countrylivened-up- migrating-butterflies/1949151001/

Stein, M. K., Engle, R. A., Smith, M. S., \& Hughes, E. K. (2008). Orchestrating productive mathematical discussions: Five practices for helping teachers move beyond show and tell. Mathematical Thinking and Learning, 10(4), 313-340.

Strauss, A., \& Corbin, J. M. (1990). Basics of qualitative research: Grounded theory procedures and techniques. Thousand Oaks, CA: SAGE. 
Sullivan, A. (2001). Cultural capital and educational attainment. Sociology, 35(4), 893912.

Susinos, T., \& Haya, I. (2014). Developing student voice and participatory pedagogy: a case study in a Spanish primary school. Cambridge Journal of Education, 44(3), 385-399.

Suskind, D.. (January 26, 2016). Teacher as researcher: The ultimate professional development. Retrieved from https://www.edutopia.org/blog/reacher-researcherultimate-professional-development-dorothy-suskind

Tan, E., Barton, A. C., Turner, E., \& Gutiérrez, M. V. (2012). Empowering science and mathematics education in urban schools. Chicago. IL: University of Chicago Press.

Taylor, M. W. (2013). Replacing the 'teacher-proof'curriculum with the 'curriculumproof' teacher: Toward more effective interactions with mathematics textbooks. Journal of Curriculum Studies, 45(3), 295-321.

Taylor, Q. (1982). Slaves and free men: Blacks in the Oregon Country, 18401860. Oregon Historical Quarterly, 83(2), 153-170.

Tobin, K. G., Elmesky, R., \& Seiler, G. (Eds.). (2005). Improving urban science education: New roles for teachers, students, and researchers. Lanham, MD: Rowman \& Littlefield.

Turner, E. E., Drake, C., McDuffie, A. R., Aguirre, J., Bartell, T. G., \& Foote, M. Q. (2012). Promoting equity in mathematics teacher preparation: A framework for advancing teacher learning of children's multiple mathematics knowledge bases. Journal of Mathematics Teacher Education, 15(1), 67-82. 
Turner, E., \& Varley, M. (2007, March). Fostering critical mathematics agency among upper elementary Latino/a youth. Paper presented at the annual meeting of the American Educational Research Association, New York, NY.

Valli, L., \& Buese, D. (2007). The changing roles of teachers in an era of high-stakes accountability. American Educational Research Journal, 44(3), 519-558.

Varelas, M., Becker, J., Luster, B., \& Wenzel, S. (2002). When genres meet: Inquiry into a sixth grade urban science class. Journal of Research in Science Teaching, 39(7), $579-605$.

Vasquez, J. A., Sneider, C., \& Comer, M. (2013). STEM lesson essentials: Integrating science, technology, engineering, and mathematics. Portsmouth, NH: Heinemann.

Veale, A. (2005). Creative methodologies in participatory research with children. In S. Greene \& D. Hogan (Eds.), Researching children's experience: Approaches and methods (pp. 253-272). Thousand Oaks, CA: SAGE.

Voegelin, E. W. (1955). The Northern Paiute of Central Oregon: A chapter in treatymaking part 1. Ethnohistory, 2(2), 95-132.

Vogt, W. P., Gardner, D. C., \& Haeffele, L. M. (2012). When to use what research design. New York, NY: Guilford Press.

Wager, A. A., \& Stinson, D. W. (Eds.). (2012). Teaching mathematics for social justice: Conversations with educators. Reston, VA: National Council of Teachers of Mathematics. 
Warren, B., Ballenger, C., Ogonowski, M., Rosebery, A. S., \& Hudicourt-Barnes, J. (2001). Rethinking diversity in learning science: The logic of everyday sensemaking. Journal of research in science teaching, 38(5), 529-552.

Waters, E., \& Sroufe, L. A. (1983). Social competence as a developmental construct. Developmental Review, 3(1), 79-97.

Weber, E., Fox, S., Levings, S. B., \& Bouwma-Gearhart, J. (2013). Teachers' Conceptualizations of Integrated STEM. Academic Exchange Quarterly, 17(3).

Wertsch, J. V. (1991). A sociocultural approach to socially shared cognition. Perspectives on socially shared cognition. Washington, DC,: American Psychological Association. (85-100).

Willox, L., Collaborative Action Research Endeavor (CARE) for Quality, (retrieved from https://careforquality.weebly.com/background.html)

White, R. E. (2012). The power of play: A research summary on play and learning. St. Paul, MN: Minnesota Children's Museum.

Wildcat, M., McDonald, M., Irlbacher-Fox, S., \& Coulthard, G. (2014). Learning from the land: Indigenous land based pedagogy and decolonization. Decolonization: Indigeneity, Education \& Society, 3(3), 1-15.

Wikipedia contributors. (2019, September 15). Central Oregon. In Wikipedia, The Free Encyclopedia. Retrieved from https://en.wikipedia.org/w/index.php?title=Central_Oregon\&oldid=9158982 49 
Wood, C. (2007). Yardsticks: Children in the classroom, ages 4-14. Turners Falls, MA: Northeast Foundation for Children.

Yackel, E. \& Cobb, P. (1996). Sociomathematical norms, argumentation, and autonomy in mathematics, Journal for Research in Mathematics Education, 27(4), 258-477.

Zimmerman, B. J. (2000). Self-efficacy: An essential motive to learn. Contemporary educational psychology, 25(1), 82-91.

Zins, J. E., Bloodworth, M. R., Weissberg, R. P., \& Walberg, H. J. (2007). The scientific base linking social and emotional learning to school success. Journal of Educational and Psychological Consultation, 17(2-3), 191-210. 


\section{Appendix A-Informed Consent Form for Parents}

\section{Improving STEM Teaching and Learning through Teacher Research}

Your child is invited to take part in a study. This study is part of a doctoral research project from the Graduate School of Education, Portland State University. The researcher, Frank Heimerdinger, how is also your child's teacher, hopes to learn how teachers and $2^{\text {nd }}$ grade students can work together to improve Science, Technology, Engineering and Math (STEM) classroom participation. Your child is invited because they have important ideas about this topic.

If you let your child take part in the study he/she will participate in regular classroom experiences. In addition to the regular classroom experiences, your child's STEM schoolwork will be collected and used to answer research questions regarding participation and improving teaching and learning. This student work will not be analyzed for the research project till after your child has received end of year grades.

Additionally, the teacher-researcher will not know who is participating till after the end of the school year. This is done to make sure that you and your child feel comfortable not participating in the study.

While joining this study your child may experience some emotional stress. We will remind students that they can speak with the school counselor or another adult to solve any problems that arise. Your child does not have to take part in this study. It won't affect his/her grade or relationship with the teacher. You may take away your permission for your child to join this study at any time. Also, your child may take away his/her permission at any time.

Your child may not receive any direct benefit from taking part in this study. However, your child may experience an improved teaching and learning environment and may develop a better understanding of what type of teaching helps them learn best.

Your child's identity will be protected. All information gathered will be kept private. Your child will be given a fake name in written documents. Files will be in a locked file cabinet and in a password protected computer.

It is the investigator's legal obligation to report child abuse, child neglect, elder abuse, harm to self or others or any life-threatening situation to the appropriate authorities, and; therefore, your confidentiality will not be maintained.

If you have questions or concerns about your child joining this study, contact Frank Heimerdinger at frank.heimerdinger@bend.k12.or.us or 503-969-7032.

If you have concerns about your child's rights as a research subject, please contact: PSU office of Research Integrity, $1600 \mathrm{SW} 4^{\text {th }}$ Ave., Market Center Building, Ste. 620, Portland, Or, 97201; phone (503) 725-2227 or 1(877)480-4400.

Your signature means that you have read and understand the above information. You agree to let your child take part in this study. The researcher will give you a copy of this form.

$\overline{\text { Signature }} \quad$ Date

Print name

Name of the student 


\section{Appendix B-Child Assent Form \\ Improving STEM Teaching and Learning through Teacher Research}

\section{Child's name}

My name is Frank Heimerdinger and I am a doctoral student at Portland State University. Your parents (or guardian) have said that it is okay for you to take part in a research study on how to make Science, Technology, Engineering and Math teaching better. If you choose to do it, you will be asked to do the following between January 15, 2017 and June 1 ${ }^{\text {st }}, 2017$ :

- Participate in regular classroom activities

- Allow your work to be included in the research after the end of the school year

Your privacy is very important to us. We have done many things to protect you:

- We won't tell anyone if you take part in this study or not.

- Your teacher will not know if you are participating till after the end of the school year

- Your name and what you tell us will be kept confidential as much as allowed by law. (By "kept confidential" we mean that the names of people who take part in the study will not be given to anyone else. During the study, if you say that you are thinking about harming yourself or others we need to let your parents and the principal know. Also, if you say that you are being abused by an adult I would need to report that to the adults at our school in charge of keeping students safe.

- Your name and other personal information, which we need in order to keep track of your work, will be kept in a locked file cabinet or in a locked file on the computer so that no one other than the research staff will be able to see it. For example, this form (which has your name on it) will be kept in a locked file cabinet.

- When we write or talk about what we learned in this study, we will leave things out so no one will be able to tell whom we are talking about.

If you have questions or concerns about joining this study, contact Frank Heimerdinger at frank.heimerdinger@bend.k12.or.us or 503-969-7032.

If you have concerns about your rights as a research subject, please contact: PSU office of Research Integrity, $1600 \mathrm{SW} 4^{\text {th }}$ Ave., Market Center Building, Ste. 620, Portland, Or, 97201; phone (503) 725-2227 or $1(877) 480-4400$.

If you do want to try it, please sign your name on the line below. Remember-you can stop to take a break at any time, and if you decide not to take part anymore, let me know.

Child's Signature

Investigator's Signature
Date

Date
Child's Printed Name

Investigator's Printed Name 
Appendix C-Lesson Plan and Notes Form

\begin{tabular}{|c|c|}
\hline Date: & \\
\hline Plans & Observation notes \\
\hline
\end{tabular}


Appendix D-Data Analysis Form

\begin{tabular}{|c|c|c|}
\hline Date: & & \\
\hline What happened? & $\begin{array}{l}\text { What do you Notice about } \\
\text { what happened? }\end{array}$ & $\begin{array}{l}\text { Trends, Patterns, or } \\
\text { Questions }\end{array}$ \\
\hline & & \\
\hline & & \\
\hline & & \\
\hline & & \\
\hline & & \\
\hline & & \\
\hline & & \\
\hline & & \\
\hline & & \\
\hline & & \\
\hline & & \\
\hline & & \\
\hline & & \\
\hline & & \\
\hline & & \\
\hline & & \\
\hline & & \\
\hline & & \\
\hline & & \\
\hline & & \\
\hline & & \\
\hline
\end{tabular}

